
Digitized by the Internet Archive in 2008 with funding from Microsoft Corporation 
FROM MATTER TO MAN 



\section{FROM ....}

MATTER TO MAN

\section{A NEW THEORY OF THE UNIVERSE}

BY

A. REDCOTE DEWAR

\section{LONDON}

CHAPMAN \& HALL, LIMITED 



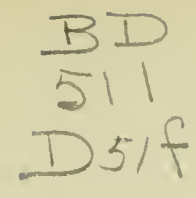

\section{CONTENTS.}

CHAPTER I.

THE ORIGIN OF ExisteNCE, . . . . . . I

CHAPTER II.

First Causes, . . . . .

Sect. I. First Causes generally,--2. The Unknowable.3. The Infinite and Supernatural.-4. Deity.-5.Orthodox and Heterodox First Causes identical.

\section{CHAPTER III.}

The Constitution of the Universe; Or Space, Eternity, Matter, Energy, and Cause, . . . . 32

CHAPTER IV.

The Coxstitution of Matter,

Sect. I. The Elements.-2. Atoms.-3. The Classification of the Elements.-4. The Combining WVeights of the Elements. 


\section{CHAPTEK V.}

The Constitution of LNergy,

Sect. I. Fundamental Energies. -2. Secondary Energies. 3. The Conservation of Energy.-4. The Correlation of Physical Forces. -5. Energy as Automatic. -6. The Duality of Energy.-7. Magnetism.

\section{CHAPTEK VI.}

The Primary LaW's of Energy,

Sect. I. Like-Material-Attraction. - 2. Sexual-MaterialSelection. -3. Polarity.-4. Like-Central-Repulsion.5. Magnetic Induction.

\section{CHAPTER VII.}

The Secondary Laws of Energy, .

Sect. I. Gravitation, -2. Cohesion.-3. Chemical Attraction.

CHAPTER VIII.

The Evolution of Gases and Liquids, . . . $\mathrm{jo}_{3}$

CHAPTER IX.

The Evolution of Minerals, . . . . . 106

Sect. 1. Geometrical Minerals.-2. Snow Flakes. -3. Arborescent Minerals.

\section{CHAPTER X.}

Tile Causes of Mineral Evolution,

Sect. I. Substance.-2. Structure. -3. Energy.-4. Form.5. Design. -6. Life.-7. Intelligence. 
CHAPTER XI.

The Erolution of Vegetals,

Fungi, Algæ, Cryptogams. Mechanism. Nerrous Systems. Parasitical Plants, Insectivorous Plants, Protophyta, Functions of Plants.

\section{CHAPTER XII.}

The Causes of Tegetal Erolution,

Sect. I. Vegetal Substance.-2. Cells.-3. Structure.4. Energy. -5. Form.-6. Sex.--7. Species.-8. Life.9. Intelligence.-IO. The Aim and Purpose of Vegetal Evolution.

\section{CHAPTER XIII.}

The Evolution of Aximals, $1 S_{1}$

Protozoa, Molluscs, Corals, Plant-Iike Animals, Electric Animals, Animals as Machines.

\section{CHAPTER XIV.}

Causes of Animal Evolution,

I. Animal Substance.-2. Cells and Unicellular AnimaIs. -3. Structure.-4. Mechanism.-5. Reproduction.6. Form.-7. Energy and Life.-8. Inter-relation of Life and Death.-9. Intelligence.

\section{CHAPTER XV.}

The Evolution of Man,

I. Man's Substance.-2. Origin.-3. The Human Ovule. -4. Subjection of Organisms to their Environments. -5. Metamorphosis. -6. Genital Centres and Causes of Variation,-7. Man's Embryological Development. -S. Summary of Man's Materialistic Evolution. 


\section{CIIAPTER XVI.}

Tite Evolution of Mini, . . . 250

Sect. I. The Human Mind,-2. The Evolution of Human Consciousness. - 3. The Will or Reflex Action. -4. The Mind as a Five-Sense Organ, - 5. Mind and Mechanism. -6. Electric Action in Mental Phenomena. -7. Man's Automatic Mental Apparatus. - $\$$. Summary.

\section{CHAPTER XVII.}

The Evolution of Worlds, . . . . . 274

\section{CHAPTER XVIII.}

Man's Place in Nature, $2 \mathrm{SO}$

CHAPTER XIX.

Tire Purpose of the Universe, . . . . $2 S_{7}$ 


\section{FROM MATTER TO MAN.}

\section{CHAPTER I.}

Tine Origin of Existence.

TIIE preliminary problem in all human speculation has ever been, the origin of existence, and it still frets the natural philosopher; but the solution is partly determined by the definition of the problem, and its accuracy for to-day depends almost wholly upon the meaning which present intelligence attaches to the term origin.

Every origin in the universe necessarily includes both the thing made and that out of which it is made. For as nothing begets nothing, so something must be begotten of something. As no definition of origin, therefore, however orthodox, can be accurate which assumes a creation of something from nothing, origin in so far as it refers to the universe is meaningless. Hence, origin is only a term which describes a particular transition stage of existence between 
present states of being and preceding states of being, no matter how far our steps may be retraced. This, however, is not the common belief.

A well-known scientist, more noted for his orthodoxy than his accuracy, recently said, "Creation, strictly speaking, is inconceivable to us, yet it is a fact. The system of visible things in which we live was certainly not the author of itself."*

Now, "creation" was a word invented by the most learned men of a byegone age, to express the notion that something may be created out of nothing. This was a simple matter to them, for the ignorant man's imagination is illimitable, and vacuities naturally beget vacuities. As this miracle however is, from the indestructibility of matter, impossible, creation is a fallacious and ignorant hypothesis, yet we are assured it is a "fact." A "fact" again is a word denoting something demonstrable; but as creation is not demonstrable, our mentor's vocabulary again requires revision.

Further, although it may be quite true that the system of visible things in which we live is no more the author of itself than any man is the author of himself, yet it is equally certain that as day but succeeds day, and peer succeeds peer, so existence is but an endless succession of "living pictures," a panorama having no author, because requiring none, other than that each picture had a picture preceding

* The Duke of Argyle on "Prof. Huxley on the War-path," Nineteculh Century", January 1891. 
it. The system of visible things to-day thus virtually has its authorship in the system of visible things yesterday, and to-morrow that again of to-day, and so on interminably, either backwards or forwards. For the present is always both the end of, and the beginning to, existence: an eternal hub of being, whether earth or men existed or not.

Again, the application of the restricted term author -a term derived from the puny operations of men on this planet-to universal operations, is another instance of erroneous teaching, for we are comparing what cannot be compared. Tracing the origin of things to their furthest ken on orthodox lines, we arrive, it is alleged, at an author who did the impossible and inconceivable thing of creating the present system of visible things from nothing. But, unfortunately for this deduction, it also warrants us, who see further than our fathers, to ask the equally legitimate and more pertinent question, "Who amid the eternal sequences was the author of this author?" and the mere fact that we can ask such a startling genealogical question and get no inteligible answer, disposes of the supposition in its entirety. Problems of this nature are not quite so "easy, nor are they in quite the same category as tracing the pedigree of a peer.

A common question is: Was the beginning a chaos? -a time when there were no planets, stars or solar systems, when all was a crude, unformed, inert mass of matter waiting a Creator? But the answer 
again would be, "If so, from whence came the Creator?"

Kant's nebular theory of creation, clever though it be, does not solve the ultimate origin of the universe, for the origin of his basis "nebulous matter" would itself require to be explained, as well as the cause of "the centre of attraction" set up, which started the universe in motion.

From an abstract point of view, the universe is a virtual chaos just now. The orthodox, indeed, style the earth the perfection of creation, an exemplary model of order, method and peace, fit work of an omniscient, methodical and all-wise Creator. But this conception was cradled in ignorance, was nursed by credulity and sustained by fear. It was the necessary consequence of believing the earth to be not only the centre but the sum of the universe. As a matter of fact, earthquakes, volcanic eruptions, tidal waves, earth-subsidences, cataclysms, tornadoes, thunders and lightnings, disturb and devastate our globe unceasingly. It revolves on its axis every twenty-four hours; it whirls round the sun at sixty times the velocity of a cannon ball; it doubles that tremendous pace in its circumnutation, along with the rest of the solar system, towards Hercules; it is subject to endless perturbations by Jupiter, Venus, and other planetary bodies; hence, disorder and hurly-burly are more the rule than the exception.

Similarly with all the heavenly bodies, "general incoherence is the rule of the universe. The stars are 
as specks of dust dancing in a sunbeam. The centre is everywhere, the circumference nowhere."*

If then our investigations involve the principle of universal disorderliness now, no necessity calls for our postulating the universe either more or less disorderly at any antecedent time; consequently, there is only one intelligible escape from the dilemma (if dilemma there be, seeing it is of man's own making), and that is to predicate, on the orthodox and only possible mode of reasoning at the present time-an uncaused basis of things. We differ, however, from the orthodox as to the basis. Thus, we enunciate as indisputable that the universe as a whole, and not as an incomplete or incomprehensible part, is uncaused; that it never had or could have had a Creator, that it never had a beginning, even as it never can have an end; hence, that it never was and never can be more chaotic, disorganised, and unformed than it is now. True it is that progress and improvement may occasionally be registered on one or other of the myriads of worlds, but this is counterbalanced by equal rack and ruin in others; hence, from the very conditions of eternal existence by which opposites are irrevocably locked together-as growth and decay, aggregation and disintegration, cause and effect, life and death-the universe as a whole, ever has been, now is, and ever shall be, as it is.

This assumption of a perpetual universe in perpetual motion, and that motion a perpetual * "Philosophy" (Trans.), p. 460 . André Lefèvre. 
average uniformity, may be simply illustrated. When water is boiling and bubbling in a pot its action seems chaotic: order is apparently absent and disorder rampant. Yet closer scrutiny reveals more or less rhythm in the seething froth, a sequence even in the blowing and bursting of the water bells, as well as a cycle in the rotation of the chemical changes. Hence, if even we can see an order reigning in this chaos, what would there not be to a "conscious atom"--dancing through a life-time in the hundredth part of a second-in this terrible topsyturvy?

Similarly, are we not such conscious atoms at home in our planetary hurly-burly? May not all this seeming astral and mundane order be but the illusions of ignorance, the mirage of nonentity, the kaleidoscopings of insignificance; even as our sensations of sabbath quiet and midnight stillness are utterly irreconcileable with the earth's frantic "corkscrew" through space. May not the order of the stars be but the halo of distance and our dreams of perfection the perspective of prejudice? We mundane midgets impose our time, our sequence, our orderliness, our interpretations, and our Deities on the universe, as inalienable privileges and divinely begotten rights, as if we were ourselves lords of space, the acmè of creation; instead of being mere accretions of atomic dust, accidents of a moment, and parasites of a planet which is itself but a mote in the sunbeam of eternity. 
Moreover, the universe cannot be measured by planetary rules or weighed by planetary scales, for Eternity has no stages to limit its duration, Existence no clock to regulate its epochs, and the Everlasting no map to define its areas. To a Sphinx, calm, impassive, colossal, sitting upright in space, with head in the stars and feet in the deeps-a being to whom time was unknown, days and nights incomprehensible, age a mystery, and planets as pearls-all the order we prate about would be inappreciable to him. The flight of even suns and stars in their courses would seem but as a mesh of fire-flies on a summer's night, and as devoid of order and sequence as the bubbling of boiling water-bells to us.

A water-bubble blows on the kettle's surface for a second and disappears, falling but to reform the domes of others incessantly. Similarly, by universal reckoning, what are planets in their cyclic revolution, the things they produce, and the time they last before dispersing again into their constituent nebulous elements, but similar ephemera. We, true enough, parcel out time into past, present, and future; but this feat is the measure of our own littleness; for what are ten thousand mundane years to an universal day? Lastly, the earth has endured and apparently improved and progressed for thousands of years; hence, it may last, improve, and progress for thousands of years more; but this apparent permanency cannot save it from the dissolution inseparable of necessity from the haphazard conditions of its ephemeral 
constitution, or accord even probability to man's peevish whine for immortality. What then, by universal time-dials, shall the duration of our earth's life history be, in its transition from chaos to chaos, but as the blowing and bursting of a planetary bubble in the cauldron of eternity?

As non-existence, non-manifested existence, motion without matter and matter without motion, are all contrary to reality, as well as impossible in fact and inconceivable in imagination, as beginnings to existence, no absolute origin of, or beginning to, existence is or was possible. All is a vast, impersonal, yet pregnant now, beginning and ending momently. The eternal is begotten matutinally in every sunrise, and buried nightly in every sunset: its midwife and undertaker itself. 


\section{CHAPTER II.}

\section{First Causes.}

Section I. First Causes generally :-

Twin problem to the Origin of Existence is that of the First Cause of the universe. Our duty is again definitive, viz., to determine the meaning of the terms cause and first cause.

A cause, pure and simple, is either the agent of or the antecedent to, any effect.

A first cause, on the other hand, is a cause which preceded the first condition of things; a something which existed in nothing; which evolved itself out of nothing; and which created the present existence out of nothing.

Although the problem of a first cause is thus an obviously absurd one, we may, owing to the widespread belief in it, profitably discuss it at greater length. Investigators generally confound the creation of the earth with the creation of the universe. Philosophical confusion not infrequently begins with a similar lack of discrimination; for there is no great 
gulf fixed between fools and philosophers. The creation of the earth compared to the creation of the universe is as a child's problem to a paradox. For the present constituents of the earth existed before the earth's actual creation, in other forms as nebulae, cosmic dust, meteors, or other planetary and astral material. The earth, in fact, in creation, or more correctly in evolution, could only be a re-formation of other earths, or a re-arrangement of the constituents of other astral bodies which had already existed. The creation of the universe, on the other hand, is assuming an impossibility. For, as the sum of all those things which exist, the universe neither has nor could have a beginning; antecedents to it are impossible. Blot out existence and non-existence is assumed, the absence of causes as well as of causal material; consequently, the assumed creation of the universe could not be a re-formation of other universes, but would be a distinct creation of something from nothing, by a something, say a Deity, who was Himself nothing, which is a reductio ad absurdum.

To render the argument clearer, let us take a simple illustration. When a cart wheel revolves we do not seek a cause for the revolution of each spoke in the wheel, but a cause for the revolution of the wheel as a whole. Yet the one involves the other, for the motor power for both is the same. Nature, similarly, resembles a vast revolving wheel, whose motions include an infinite number of sub-motions, each again sub-divided, classified, and apportioned 
under different heads as natural forces. These submotions, consequently, if accurately read, should solve also the rotation or motion of the universe as a whole; but confusion instead of comprehension here supervenes. Something anterior to and transcending everything known or conceivable is sought for, eren by physicists, as a cosmical first cause; hence the great ultimate question is still fretfully said to be, What is the first cause of nature's rotation? As if a beginning could be attached to the motion of indestructible matter in motion. In other words a beginning is sought to the beginningless.

This demand for a First Cause doubtless dazed ignorant dunces in the past, and still puzzles immature logicians in the present, because the aforementioned cart-wheel has been seen both at rest and in motion. But they orerlook the fact of the wheel's externals. That the wheel-wright, for instance, who turns the wheel, is external to it; while nature through the indestructibility of its constituents (matter in motion) has neither externals nor antecedents; everything is internal. Consequently, when such a supererogatory power as a First Cause to nature's rotation is invented, an external to nature itself is not only implied, but, as with man and the wheel, a Something in that external, more omnipotent, intelligent, and eternal than anything internal ; transcending even nature itself. The squirrel is not only inside the cage but outside of it as well. The universe is postulated to have an outside. It is curious how man 
cannot rid himself of himself in his philosophy. If he disclaims making the universe, he at least foists it upon his deities. But if men fashion their own deities - their invariable practice to-day as hitherto-it follows that they also construct their own universes. For, translating their philosophy into intelligible language, the universe is to them exactly what they understand and state it to be, and it cannot to man at any time ever be anything else.

The myth of a First Cause obviously originated in that confusion of ideas, common to past ignorance and perpetuated by present pedantry, which confounds the philosophical first cause with the scientific or cosmical first causes; the linear hypotheses of beginnings and ends with the true cyclic facts of unending evolution and devolution. "What man is really anxious to ascertain is, not who the Causer of the laws of the universe is, for the Causer would have to explain his own origin and existonce, but what the laws themselves are.

Finally, as a check to much scientific, theologic, and metaphysical nonsense, it should be distinctly understood in both science and philosophy that to seek for the origin of ultimates is as unscientific and unphilosophical as in religion it is blasphemous.

Section 2. The Unknowable as a First Cause:(The doctrine of the Unknowable is of modern origin, the product of agnosticism, its inventor $\mathrm{Mr}$ Herbert Spencer. ) It comprises three phases:-(I) 
The Unknown Unknowable. (2) The Cosmic Unknowable or "the force under phenomena." (3) The Unknowable as an Infinite Energy.

I. The Unknown Unknowable.-In Mr Spencer's formula of an Unknowable, a First Cause, or an Energy, is foisted upon the universe in such a way that its very existence, as well as its nature, eludes our comprehension. It is absolutely unintelligible, and interminably unknowable. By this positive assertion of the existence of an Unknowable, along with ordinary human unknowability of it, the doctrine virtually involves the hypothesis of an Unknowable, unknown to the ignorant mass of mankind generally, but familiar in some incomprehensible fashion to the superior intellectual perceptions of its inventor.

The elements of this supercilious doctrine have obviously been borrowed from Kant. That great but misguided thinker declared that a Supreme Creator was not an object to be known or proved, in the strict sense of the term. He would "even fear to know anything of his duties, his God and his soul, convinced that if they were objects of his knowledge, they must be in themselves illusions, phenomena purely human" "how could they be anything else?) "of his mode of seeing and conceiving."

The chief stumblingblock to intelligent men with these paradoxes is, How are we to know if we don't know? Is it because we don't know that we know? Or, How are we as men to know, not as men, but as 
phantoms? It really does not seem possible to handle such hypotheses seriously. They rather provoke, and should obtain, as Dr Thomas Brown said, "ridicule," for ridicule is always the strongest argument against nonsense.

By the standards of to-day intelligence, moreover, if an assertion is nonsensical to us, governed as we of course must be by the highest to-day knowledge (which decides what is sense and what is nonsense), it should be treated as nonsensical by us, in order to protect our own sanity. If we are not to stop at the doorway of the comprehensible and draw our orvn distinctions between sense and nonsense on the very threshold of knowledge, there is an end to all comprehension, sense, and intelligence. Permit the unintelligible in one form, it is permissible in all. Far better were it to revert to our nursery rhymes, and at least not pretend to an intelligence which we cannot sustain. Nothing in philosophy is truly more pitiable than to witness how great intellects, after breaking loose from their moorings of scientific reason and practical demonstration, plunge under the wing of some unintelligible hypothesis into a tempest of their own verbosity, where, borne aioft on an inflation solely of words, and floundering hopelessly in the bathos of a "peradventure," they fondly imagine themselves cleaving the empyrean of "pure intelligence."

Words undoubtedly are words, but they are meaningless save when expressing intelligible ideas, or 
symbolising objects. An agnostic or a metaphysician is quite at liberty to style his uncouth terms, pedantic phrases, and interminable sentences, his thoughts or his reason ; but, fundamentally, they are only words, undemonstrable to intelligent men as aught save conjoined letters of a humanly concocted alphabet.

Fortunately for humanity in the mass, its sanity is protected from and convoyed safely through all epidemics of philosophical incoherences by that ne plus ultra of existence-man must be sensible in order to live. Even a Pyrrho had sometimes to punish his cook for spoiling his dinner.

In this connection an American writer tersely says, "A reason which will not accept its own paper is hopelessly bankrupt." On the same lines, it may further be added that a humanity which will not accept its own science, uphold its own knowledge, trust to its own inferences, believe in its own creeds, and abide by the consequences of its own observations, experiences and experiments, in preference to the science, knowledge, logic, beliefs, observations, experiences and experiments of any past age whatsoever, is hopelessly imbecile.

As all agnostic and metaphysical speculations must, equally with present intelligible knowledge, be tried by the present standard of intelligence (scientific logic and verified fact), we see no evidence either of a known or of an unknown Unknowable. Indeed, this image which $\mathrm{Mr}$ Spencer, like a modern Nebuchadnezzar, has enthroned, but typifies in a 
more civilised fashion that unreasoning fear and consequent abject devotion ever shown by ignorant humanity towards all strange, startling and inexplicable natural phenomena. The legitimate successors of the vulgar superstitions of the past are thus the intellectual intuitions of the present. After the medicine-man the priest, after the priest the metaphysician, after the metaphysician the agnostic, after the agnostic the theosophist, after the theosophist the pantaloon.

II. The Cosmic Unknown, or the Force under Phenomena:-The assumption by Mr Spencer of the Unknowable as a First Cause has undoubtedly arisen from a confusion of ideas. A first cause in non-existence has been confounded with ordinary every-day causes in existence, through logical inability to comprehend the full meaning of that great natural fact, the indestructibility of the constituents of existence.

By describing the Unknowable as a "force under phenomena causing phenomena," Mr Spencer has laid a mine to his own foundations, for the cause of a phenomenon, according to all evidence, must necessarily be the phenomenon's own antecedents in other phenomenal forms. "The fallacy of the hypothesis, as well as the unwisdom of Mr Spencer's mode of philosophising, may be illustrated in several ways:-

I. Mr Spencer or any thinker may, if he choose, descant upon what he thinks unknowable, but he 
has no right to assume equal obtuseness in other people.

2. Mr Spencer should be loyal to his Unknowable, and not falsify his argument by endeavouring to describe either what it is or is not; for by so doing he obviously renders the conception not only knowable, but partially at least, known. Thus when he even finds in this Unknowable something to fear or reverence he commits himself. He lacks both policy and loyalty to his own conception.

3. If a force under, or a first cause to phenomena exists, exerts influence over us, and, as the Creator to the created, the producer to the product, holds some affinity to us as a universal phenomenon, we cannot logically or intelligibly concede that because this "force" is unknowable to Mr Spencer, it shall be so eternally to humanity. We would require some other authority than Mr Spencer as an ultimate and infallible philosophical oracle. Besides, a time must in the inevitable evolution of things-if they have unfolded themselves aright in the past-arise in the future, when men shall enjoy a closer communion with, and a clearer conception and knowledge of, any alleged but as yet unknowable or unknown natural power or law.

4. $\mathrm{Mr}$ Spencer, through a similar obliquity of intellect to metaphysicians, confounds the perceived force under phenomena (motion as manifested in phenomena, or the phenomenal antecedents as causes, to phenomenal consequents) with some fancied force 
preceding phenomena, a force preceding even the force or energy in noumena; in other words, a force preceding existence. Consequently, while he bases his criticism on, acquires his notion of, and deduces his principle or hypothesis of an "Unknowable" from the energy resident in the knowable, he applies his theory to both non-existence and existence indiscriminately, as if both were alike. In other words, he confounds nothing with something, the impossible with the possible, the inconceivable with the conceivable, and does not know it.

5. No particular exigency demands the translation of a mere law, or force, or energy, or phenomenal cause, or any mere man-made natural mystery, into a deity; yet, as a consequence of his confusion, and to the confusion of his whole philosophy, Mr Spencer confesses to the existence of a something corresponding to a God. Even an agnostic cannot thus exist without his fetich.

III. The Unknown as an Infinite Energy.-Mr Spencer's latest definition of the Unknowable is to the effect that "at the bottom of all argument we at last come to the one absolute certainty, the presence of an infinite and eternal Energy from which all things proceed." * But, as definition implies knowledge, this categorical enumeration virtually states what is alleged to be unstateable. For what is defined cannot be unknown, far less unknowable; hence much has been conveyed as actually known 
in these few lines of Mr Spencer's. For instance :-

(I) A knowledge of it to the extent given is absolutely certain.

(2) It is present.

(3) It is $a n$ infinite Energy.

(4) It is infinite and eternal, not finite and ephemeral.

(5) It is energy, not matter.

(6) All things proceed from it, including, we suppose, even indestructible matter.

The most striking objections to this agnostic paradox are as follows:-

(I) Is the knowledge absolutely certain only to $\mathrm{Mr}$ Spencer, or is it so absolutely certain to everybody that all eternity shall think as Mr Spencer in his wisdom or ignorance now does?

(2) If it be present, why cannot we test the Energy through the things in which it is present or which it influences?

(3) If the Energy has personality, it has constituents: what are they?

(4) By what evidence does Mr Spencer determine the Unknowable to be solely an infinite Energy and not a finite material property as well, when any conceivable infinite involves only an extension of the known finite?

(5) If all things proceed from Energy, how does Mr Spencer account for its twin-eternal and twinindestructible potency, matter? How is it possible 
to prove the generation of matter from energy, when all evidence demonstrates energy to be only a property or condition of matter? Moreover, energy absolutely requires matter for its manifestation, hence without matter could practically never exist, and certainly without it could not possibly be known to or seen by men. All evidence confirms the supposition that existence is a duality, not a unity; wedlock, not celibacy. It takes two potencies, matter and energy, to produce visible phenomena, and no natural product, mineral, vegetable, or animal, is exempt from this dual law.

In an incisive exposure of Mr Spencer's formula, a caustic critic advised the author to "stick to his evidence and nothing more;" but the censor, in a weak moment, ventured the following rash improvement:- "All observation and meditation, science and philosophy, bring us to the practical belief that man is ever in the presence of some energy or energies of which he knows nothing, and to which, therefore, he would be wise to assign no limits, conditions, or functions." *

But the merest tyro would reply that if there be any energy in nature of which man at present knows nothing, it would be infinitely wiser to determine whether it is or is not related to the energy of which he knows something, than to write himself down a Dogberry. Man would be reflecting on his own intelligence if in this scientific age he could not at * Mr F. Harrison, Nineteenth Century, February i\$85. 
least assign some limits, conditions and functions, to that which he at least knows to exist, or to be, or which is, or whatever terms are applicable to the identification of the thing. It is solely by this mode of arguing from the known to the unknown that all our progress in true science and philosophy hitherto has been accomplished; that ignorance and superstition have been dispelled; that the great modern doctrine of natural evolution has been discovered; and that everything worth knowing has been learnt. Hence, to forsake this tried and trusted intellectual highway for any retrograde mode of thought would be a base capitulation of hard-won triumphs and a backward step on the world's royal road. Confessions of ignorance are only temporary; man recognises no ultimate goal to his knowledge.

Mr Spencer's attempt to degrade the orthodox First Cause, and to erect in its place an Unknowable understood only by himself, and of which he is the self-elected Melchizedek, may thus be regarded as a failure. Instead of establishing a Supreme Unknowable in the universe, he has only invented a fetich, manipulated by himself, the essence of whose attributes curiously resembles the precocious child's definition of a snake, "Nothing with a tail to it."

After all, there is no great distinction between $\mathrm{Mr}$ Spencer and a Japanese carver of Buddhas or an Italian painter of Madonnas. The Eastern custom has ever been to materialise their deities, the Western 
to idealise them; the habit in both cases purely constitutional.

Section 3. The Infinite and the Supernatural as a First Cause:-

"He who proclaims the existence of the infiniteand no man can escape it-comprehends in that assertion more of the supernatural than there is in all the miracles of all the religions, for the conception of the infinite has the twofold character that is irresistible and incomprehensible." *

These sententious words by a gifted Frenchman obviously imply an argument for a supernatural Being, or a metaphysical First Cause. But the fallacy of the conception arises from the erroneous definition of the word infinite. Thus the infinite neither is nor can be supernatural, but only an extension of the natural, hence is part of the natural. There is, in fact, no supernatural. Supernatural implies supernature, or something above, outside of, or beyond nature. But as nature is only a synonym for existence (which, as present existence indefinitely extended, is necessarily infinite in extension), supernatural actually implies a. super-existence: hence, this in turn involves something still more nonsensical -a super-infinite.

Again, the infinite is not incomprehensible, for, as cyclic or working in cycles, it is comprehensible tc any intelligent mind. The infinite could not be * Pasteur on his election to the French Academy, IS82. 
infinite were it linear or drawn out to an end-an end that could be understood-for the characteristic quality of an end is its juxta-position to the beginning of something else. Infinite, therefore, must be, as an absolute, cyclic, or in a cycle: that is, from infinity to infinity. In other words, infinity is a circle, a mere whirl of evolutions whose ends are but other beginnings, and whose beginnings are but other ends; thus practically containing neither beginnings nor ends. Any other definition of infinite would be finity.

In infinity looms a world of shadow called the unknown, the unread, or the unlearned, an incognita daily vanishing as its wrung-out secrets are added to our stores of knowledge. In this unknown, as Pasteur and the orthodox confidently assert, dwells a First Cause; but it is there, like a hidden fetich, only to the ignorant and the credulous. All the wonders, productions, forces, and so-called inexplicable phenomena in nature attributed to supernatural causes are, as overwhelming evidence demonstrates, merely the ever-cycling effects of eternal natural laws, working through ceaseless motions inherent in the very constitution of existence itself-indestructible matter-inmotion.

Assuming the infinite to be, as we allege, only an extension of the finite, if we worship the infinite or anything in it, we practically worship the finite. But, what section of the finite would it be most reasonable to worship-the known or the unknown? "The un- 
known," answer the orthodox. But why should we glorify the unknown rather than the known? If it be merely on account of its mystery, as Pasteur implies, then the worship of the infinite becomes the worship of nescience, the adoration of stupidity, the deification of ignorance.

The mystery of the infinite is a necessary condition of our intelligence, for as something can only know (through motion or touch) of something, we as something can never understand nothing as anything else than a symbolical term denoting the antithesis to something. But an antithesis is not an entity. Further, there are doubtless things in infinity at present mysterious to us because beyond our sensuous touch, but their incomprehensibility does not thereby constitute them worthy objects of worship. The world is already overstocked with deities. Lastly, infinite, correctly defined, is only a term invented by humanity to express either a subjective condition of our present ignorance or the boundaries of our present intelligence; hence, as it contains no objective reality in itself, its apotheosis is as absurd as the deification of any other verbal expression similarly begotten-such as past, present, and future. More absurd, in fact, than to worship any animal, for all animals possess at least some demonstrable infinities in them through their indestructible substance in its endless re-creations.

The loftiest conception of infinite is thus not as a cause, not even as an antccedent or a consequent, 
but as an everlasting present, a never-ending day. Stationing ourselves aloft in space, watching from the eyrie of the universe the myriad worlds as they circle on in their endless way, that which we know as yesterday, to-day, and to-morrow is virtually one, for no sun ever sinks beneath the horizon of the infinite. The earth and planets in their torch-light procession round our glorious sun may point out the passing hours to other revolving spheres; but existence in its essence is only one rotation, one vast now, one eternal present; for time is not where there is neither beginning nor end, and First Causes are superfluous in perpetual motion.

\section{Section 4. The First Cause as a Deity :-_*}

Perhaps no subject better illustrates the progress of the human intellect than the history of the evolution of the Protestant Nineteenth Century Deity. When men first began to discuss First Causes, the Deity and a First Cause were synonymous; and this Deity, when not an idol, was a Spirit and a personal Being like unto a man. Instead of man being thus made in the image of God, God was made in the image of man. This conception still holds good with the middle and lower intelligences of the race. The highest intelligences, however, realise its absurdity. For it is preposterous that the inhabitants of such an

* Mr Edward Clodd in his Pioneers of Evolution has ably shown how religion has been a barrier to progress in knowledge and intelligence, but he ought to have bracketed metaphysics with it. 
insignificant planet as the Earth should arrogate to themselves the right to furnish a design for the Deity of the universe. A Deity, moreover, who is never the same for two consecutive centuries, nor alike in any two nations or tribes on the face of the earth. In this country and century the highest intellects have gradually etherealised their God, until now, as an "Energy" He has neither substance nor form.

But when the Deity is thus eviscerated, we fail to see why this "Energy" should not equally be the God of a comprehensible materialism as the God of an incomprehensible spiritualism.

It further never seems to strike theologians and metaphysicians how absurd it is for them to be for ever trying to prove the existence of a Deity by longwinded and hair-splitting arguments; for if He were as omniscient, omnipotent, and omnipresent as $\mathrm{He}$ is said to be, the terror of the universe, there would be no necessity for such proof; He would be superabundantly obvious. Consequently, when such extraordinary and strained arguments are required for proof, it is the strongest possible argument against the hypothesis. We are reminded of that ingenuous Edinburgh professor whose students never doubted of the existence of a God until he endeavoured to prove it.

Section 5. Orthodox and Heterodox First Causes Identical:-

Fundamentally, the hypothesis of a first cause 
enunciated by theists, agnostics or materialists is in its essence identical. Thus, the orthodox usually postulate a spirit as the origin of all things; but, by constituting it originless, they are merely clothing a phantom of their own imagination with eternal properties, and asserting the existence of an unmakeable something which ever existed. Agnostics, similarly, style their word-begotten Deity-" the Unknowable Energy"-an unmakeable something which ever existed, and "from which everything proceeds." Finally, materialists also postulate their first cause-matter-in-motion-an unmakeable something which ever existed. Hence, all three hypotheses are equally valid as assertions or assumptions. But the materialist claims this striking advantage over his opponents, he demonstrates by actual experiment what that elementary matter is, and what its forces are, which form the constituents of his eternal something; while the orthodox and the agnostic detail nothing and prove nothing, but begin their systems with assumption, expound them by aberration, and ratify them by reiteration.

The absurdity of the orthodox position attains its climax when its advocates reduce the origin of existence to an originator, creator, or spirit who transcends all existence and intelligence; who thus to man neither exists nor is intelligible; who as beyond human thought is unthinkable, and as beyond human knowledge is unknowable. Yet we, finite beings, are to fathom not only the infinite but the ultra-infinite, 
for we are to conceive what is inconceivable and to know what is unknowable. Postulated beyond the laws of thought, the laws of thought are yet to make a First Cause thinkable: postulated beyond the laws of knowing, the laws of knowing are yet to make a First Cause knowable; and postulated beyond the laws of existence, the laws of existence are yet to make a First Cause existable. Hence, if the acceptance by man of what is utterly inconceivable depends upon his conception of that negation as something necessarily conceivable, we harbour a logic fit only for lunatics, teach a philosophy fit only for fools, and live a life fit only for phantoms.

Brushing aside all unverifiable assumptions, two alternative hypotheses of a first cause and a first origin to existence remain :-

Firstly: That existence originated itself.

Since scientists demonstrated the impossibility of anything external to existence creating existence as a whole, seeing that existence has no externals, the orthodox naively imagine that the only alternative involves self-creation, or the contradictory hypothesis of an existence which created itself. Facetious theologians thus make merry over this crude deduction from their own ignorance, and jubilantly announce as evolution's last answer to the problem of creation the whimsical reply of Topsy, when interviewed on her origin, "'Spects I growed." But, unfortunately for the merrymakers, the retort is fatal where they least expect it; for, if we questioned their own Deity, or 
the First Causes of all religions, including even the "Energy" of the agnostics, as to their origin, what else could they answer but Topsy's "'Spects we growed."

If this be so, if First Causes grew spontaneously from nothing, what should hinder man or his matter from being similarly begotten? If assumption can be legitimised or materialised in any form, why scruple to manufacture omnipotences ad libitum? The most stupendous miracle and most improbable fiction may be equally god-fathered by assumption. But under this asinine interregnum science and philosophy would be crochets, culture and learning fads, truth and falsehood twin virtues, and fools and sages twin brothers.

The hypothesis of self-origination with respect to the universe as a whole is consequently untenable, hence the only impregnable position is :-

Secondly: That cxistence, as an ultimate, never had an origin outside of itself, for its component constituents or substratum merely eternally exist.

Invulnerable from every assailable vantage ground of science, reason, criticism, observation, experience and experiment, this last hypothesis is the only defensible stronghold for the intellect of to-day, because it contains three irrefragable propositions:-

(I) "Nothing from nothing comes, nothing to nothing returns."

(2) Something from something comes, something to something returns. 
(3) All origins and beginnings to either First Causes, Deities or phenomena, in whatsoever science, religion, mythology, or philosophy framed, involve an uncaused, uncreatable, and indestructible basis; an alplac and omega of being, out of which, of which, and in which, all existences, First Causes, Energies, and phenomena have ever been and must necessarily ever be eternally fashioned.) Hence, all origins or evolutions must be secondary to the eternal basis.) As the only basis we can accurately postulate is thus an eternal material one, a condition amply fulfilled by the indestructible, ever moving and ever lawgoverned substance of the universe; so the only ultimate origin can be but a transformation of this material basis, a kaleidoscopic change of state from one natural phenomenon to another eternally.

In conclusion, an ultimate origin to things is impossible, because what is ever is. The what is never can be the wohat is'nt. The eternal must be the eternal. Not the eternity of the neo-Berkeleyan, who pictures it as "time becoming lost in the unimaginable infinite of endlessness," but the ceaseless or cyclic eternity of to-day, which unrolls the present as a painted panorama, either back to the infinite past or forward to the infinite future. For the yesterday, to-day and to-morrow of earth are but one to the universe as a whole. Man as a planetary ephemeron may consistently enough speak of a yesterday, a to-day, and a to-morrow, for these are 
the natural conditions of his being; but existence to existence is an eternal to-day. The curtain of night never falls on the universe; it knows no new birth of sunrise or season, while death has no power over the only immortal. 


\section{CHAPTER III.}

Tine Constitution of the Universe: or Space, Eternity, Matter, Energy, and Cause.

Section I. Space, or the Habitat of the Things of Existence:-

The most intelligible definition of space is a void, or room for phenomena to display themselves. In a sense we are followers of Democritus, whose first principle was, "The only existing things are atoms and empty space." But it would be more correct to say, "The only existing things are atoms in emptiness," for the absence of everything cannot be denominated a thing objectively. "Nature abhors a vacuum" is an old saw; but, practically, the universe is a vacuum with the worlds inhabiting it. Philosophers say we cannot conceive of a limitless emptiness. Doubtless, because our functions of conception, brain motions, are themselves motions of something, not motions of nothing. But the idea is more conceivable than that of a limited emptiness, because if it be limited, something must define the limitations. Hence, 
with a choice of two paradoxical hypotheses, both seemingly incomprehensible in their entirety to man at present, it seems most reasonable to adopt the most intelligible.

Professor Tait says, the fact of displacement and the compressibility of all known bodies "involve the condition of space or intervals between atoms."**

Space, again, may be defined as nothing transformed into something, or an equivalent to something, through its enclosure by substance; and on these lines some notion of its infinity and boundlessness comes as near demonstration as seems possible to man. In a curious way, too, it indicates the undoubted relationship existing between something and nothing, showing how even creation may be daily occurring and yet no thing be actually made. Thus a builder, in taking possession of part of the sky by erecting a tower into the air, practically creates a number of rooms, for the spaces are virtually nothing, although we call them rooms. The exercise of his skill results in merely enclosing the nothing (emptiness) with something (matter), which then, for human purposes, becomes a something, a room or rooms, through this enclosure; yet the only real something about them is their externals, the walls, floors, and ceilings, those things bounding the nothing. The utility of the rooms, moreover, as rooms consists in their being, or remaining nothing or empty space.

* Properties or NHatter, p. I8. 
Even where space is occupied by a gas, as in the atmosphere, the area is not absolutely filled with the gaseous particles. According to the molecular theory of gases, space separates the particles, which space is emptiness.

Both scientifically and philosophically, therefore, the most accurate explanation of space is, the void between material objects.

Scction 2. Eternity including Time, or the Duration of the Things of Existence:

The idea of eternity is a necessary condition of our finite existence and limited five-sense thinking power, and only in so far as it is related to time can it be understood. Both time and eternity are fundamentally but measurements of the motion of the things of existence. Time is definite measurement of definite material motion, and is gauged from the annual revolution of our planet. Eternity is an indefinite measurement of universal motions, and is indefinite to us because, as finite beings tied to a finite planet, the universe is immeasurable by us.

Still, even as the infinite is only an extension of the finite, either back into the forgotten past or forward into the unknown future, so eternity is only an extension of present time either backwards or forwards, with endlessness each way. The grandeur of eternity is thus but in keeping with the immensity of the universe. 
Section 3. Matter, or the Substance of the Things of Existence:

Universally and for ages the fundamental substratum of existence has been called matter. The name is unimportant so long as it has a name. Through habit and use the term matter is intelligible to man, for it expresses better than any other we could invent all that we wish to convey or imply by it, hence there is no need to substitute one less familiar.

No definition of matter has ever given entire satisfaction to scientists and philosophers, and never shall until an authoritative vocabulary of scientific and philosophic terms is published and agreed to by the world at large; a hopeless consummation, for it would involve an agreement among all men to think alike. Still, as each age must have an intelligible definition of matter, as of other things, for itself, a definition for ourselves to-day is imperatively demanded and is all that we actually require.

Mr Herbert Spencer pronounces matter to be "unintelligible and incomprehensible,"* but he should have added, to himself, for much depends upon the nature of the inquiry as well as on the quality of the intellect which inquires. The verdict of human experience hitherto affirms that on all subjects of knowledge, those who ask unintelligible questions necessarily receive only unintelligible answers. Stones will not yield bread nor serpents fish, though men are ever trying the experiment.

* First Principles. Appendix, p. 578 . 
Some scientists also endeavour to discover what matter is from the point of view of a matterless being, even as metaphysicians endeavour to discover what mind is from the point of view of an eviscerated brain. Both of them are but speculations for bedlam. Thus Professor Tait alleges that "a knowledge of what matter is in itself is probably unattainable by man." * It is not probably but utterly unattainable by man, for the very meaning of human knowledge is the relation of things to man or to other things known to man.

A knowledge of what matter is in itself, would involve a knowledge of what matter is to itself or to something not matter. Equally absurd questions would be, What is sight to itself, hearing to itself, or taste to itself?

What man actually requires is a knowledge of what matter is to him. What its relations, properties and conditions are, and wherein any condition of it is distinguishable from any other condition. On this subject he can speak with authority, for he, as matter, is matter's own spokesman. As to the extent of his knowledge, nature ever teaches him that which he is fit to understand; but the wise man of to-day is ever the fool of to-morrow. What matter is to us will be given in due sequence.

It is said to-day that "the most daring conception of the structure of the universe that has entered into

* Properties of Matter, p. I8. Also Clerk Maxwell in Appendix to same, p. 304 . 
the mind of man " is that of Lord Kelvin. He suggests that vortices in the "ether," like whorls shown in the air by puffs of smoke, are the beginnings of matter; so that force and matter are inconvertible. But the vortices cannot be matter, for these could not exist without a medium to form them. Further, if matter be made out of the medium, then the medium must itself be matter, or else we must frame a different definition of matter from the usual. In other words, if matter be something, as contra-distinguished from nothing, then "ether" or any other postulated existence must be matter. Consequently, to say that force and matter are inconvertible is to assert that something and nothing are inconvertible. This may be metaphysics, but it is not science. The most accurate definition of matter is probably that enunciated by Professor Flint as the ordinary chemical one, viz, "All material substances are divisible into elementary substances, which are sub-divisible into molecules, and ultimately into atoms possessed of distinctive qualitative as well as quantitative differences."

As regards the origin of matter it is, through its indestructibility, originless.

Section 4. Energy, or the Motion of the Things of Existence:

Energy is necessarily, from its constitution, co-equal with matter, each being indispensable to the other. Thus matter is never at rest. It is inseparable from its motion, for it possesses all its qualities in virtue of 
its motion. Separate matter from motion and you divorce matter from itself. It could not even exist in this malformed condition. It would, further, be indescribable, for its indestructibility, hardness, size, shape, etc., all involve conditions which are the result of change of place induced by its motion. Scientists, accordingly, have framed the molecular theory, which enunciates that matter, even in solids, is perpetually moving, one common illustration being the continual contraction and expansion of such a seemingly rigid substance as iron.

Although matter and motion are thus inseparable in practice, yet in theory each has its own laws. Hence the duty of the scientist is to discover what these laws are. For which see anon.

Section 5. Cause, or the Creator of the Things of Existence:

Cause in natural operations has been usually held to imply intentional cause, hence the conception of a personal Creator. But a more accurate investigation into the transformations of the universal kaleidoscope reveals two distinct kinds of causes.

(a) Cause by intention through law.-An occurrence actually happening by automatic laws, but brought about by design or intention in an organism which overrules these laws, i.e., when a man breeds a new variety of cat or dog.

(b) Cause by accident through law-An occurrence happening by automatic laws acting fortuitously, or 
without conscious combined intention or governance by an intelligence toward an end; as when a stray bullet kills a man on the battle-field. It has been asserted that "the elimination of chance is the great triumph of modern science." Huxley also, in one of his epigrammatical sentences said, "Chance and accident are only the aliases of ignorance."* But both writers ignore the fact that chance, like cause, has two distinct meanings, $\uparrow$ correlated to two distinct kinds of causes, viz., without assignable cause, and without assignable intention in the cause; or an unknown cause and a known but unintentional cause. Every occurrence necessarily results from a cause, but it may either be a chance cause or an intentional cause; it may happen by accident or it may be determined upon by design. For example, a blind beggar wishes to cross the street, but in doing so he is run over by a cab and killed. Was he, we ask, killed intentionally or by chance? We do not say was he killed without cause, for the fact of the cab-wheel dislocating his neck was sufficient cause to kill him. But if we can prove the absence of intention on the man's part to be killed, and no design on the part of the cabman, the horse, cab, wheel, or paving-stones, to kill him, then the only accurate verdict is, the beggar was killed by chance or sheer accident.

The presence or absence of intention in natural

\section{* Introductory Science Primer, p. II.}

+ Chance has two distinct meanings : the first, the absence of assignable cause ; and the second, the absence of design. Roget's Thesaurus. 
causes, far from being insignificant, is thus of profound importance in man's reading of the phenomenal record; for it involves all the difference between truth and falsehood, intelligence and superstition, science and metaphysics. Hence, instead of characterising this elimination of chance as a triumph, it may be stigmatised as one of the greatest banes in present science and philosophy.

In any case, its absence constitutes no vital principle in a thorough theory of evolution. Even Darwin fully established the importance of chance by demonstrating that natural selection was not an intentional selection on the part of nature or any of her agents, but a mere chance or accidental survival of the fittest. In other words, natural development happens solely by accidental organisms fitting themselves accidentally to accidental changes in the accidental conditions of a perpetually automatic and accidental existence.

True, Darwin is himself confused on the point, for he warns his readers that chance, as used by him, is "a wholly incorrect expression, and merely denotes our ignorance of the canse of each particular variation." ${ }^{*}$ But even if we knew the cause of the variation, provided the cause itself be accidental and not intentional-that is, happening without the intervention of a causer-the variation would still be chance, because the result of chance intention. In other words, the interaction of natural laws in matter is bound to produce something; but what that some- 
thing shall be neither the laws of nature nor the imagination of man can foretell. Whether a fond father shall have a son or a daughter is solely a matter of chance. This absence of causal intention in natural fundamentals is the position which the New Materialism assumes and maintains; while it practically constitutes the chief bone of contention between past and present philosophy and science. Thus the orthodox, on the one hand, strive to show by mere assumption, that the universe has been made and sustained in its transformations by a Creator; while the evolutionist affirms from evidence-the only truth-finder-that the eternally transitional condition of things is solely owing to the accidental working of fixed laws in eternally moving substance. The lives of conscious and intelligent organisms are indeed permeated by intentional as well as by accidental incidents; but the eternal duration of an eternal existence represents in its daily fruition only the chance outcome of unguided (yet not erratic) automatic laws. Whether arguments resting on assumption or on evidence shall ultimately prevail in this enlightened age is not open to question.

The preliminary principles of natural causation are thus as follows :-

(I) Nothing happens without a physical cause, though not necessarily an intentional cause.

(2) Every occurrence or consequent is preceded by a physical cause or antecedent condition and occurrence, or series of conditions and occurrences, from 
which it (the effect) follows by dire necessity. The cause of any particular condition, motion, or occurrence is thus solely the condition, motion, occurrence, or series of conditions and occurrences immediately preceding it.

All that man can determine as causes in natural operations, apart from his own endeavours, are thus solely those conditions known to him as the antecedents of certain effects. Hence, the notion of intentional natural causation may, as already observed, be banished from human speculation, for under the relentless accidental conditions of a ceaseless transformation of substance, antecedents and consequents inevitably tail to one another irrevocably, endlessly, and incontinently.

Cause, finally, is the automatic operation of matter in certain conditions and positions whereby certain effects are produced. Change the conditions or positions, and automatically or kaleidoscopically, the effect varies. Cause, therefore, resolves itself into the automatic working of the natural laws of matter and energy as presently to be enunciated. 


\section{CHAPTER IV.}

The Constitution of Matter.

Section I. The Material Elements:

The task of reducing matter to its ultimate constituents or tabling the scientists' material alphabet is an exercise of old standing, incomplete even now. Thales reduced the elements to water; Empedocles to fire, air, earth and water; Leucippus, Democritus, Epicurus and Lucretius to atoms. But it is only from the beginning of the seventeenth century that the chemical elements as we now know them began to be tabulated.

Although the elements are thus indestructible ultimates, the next things to nothing, and beyond which it is impossible for us as something to think, scientists even now fail to comprehend what these ultimate elements mean. Thus Lord Salisbury, in his Presidential Address to the British Association at Oxford (I 894), described the elements as a "mystery or enigma," because we did not know their "origin." This announcement from the virtual head-quarters of 
science shows that the highest intellects have not yet realised the fallacy of asking questions beyond the limits of intelligent reply, or the senselessness of seeking, by man's limited five senses, for the origin of ultimates. As in tracing an earl's pedigree we only need evidence of the existence of the founder of the family, and do not consider the present descendants "mysteries or enigmas" because the founder's own origin is obscure, so in natural ultimates all that philosophers require to know is proof of the existence of the ultimate. Consequently, when the orthodox assert that scientists ought to know the origin of their ultimate "matter," theologians in like manner ought to know the origin of their ultimate "God." A retort which shows that such super-sensuous puzzles are for fools and metaphysicians, not scientists and sensible men.

The list of the chemical elements up to date numbers seventy or more, and as a material alphabet, even should it be materially reduced, is ample enough for nature's utmost requirements, since its capacities for inter-combination are infinite.

The absurdity of the old alchemists' efforts to transmute dross into gold is thus thoroughly realised, for the quantity of gold in the universe, as of any element, is fixed beyond the power of any potency in existence either to add to or subtract from it; hence, it could no more be transmuted than created or destroyed.

Regarding the quantity or proportions of each element in the universe, no ruling principle seems to 
prevail. On earth those elements most needed for maintaining the present conditions and manifestations of earthly existence predominate; but whether the actual distribution of material and existing evolution of mundane conditions have been specially brought about by an Intelligent World-maker solely for the present manifestations of mundane existence and $\mathrm{His}$ own glory, or all earthly phenomena and organisms are merely the chance products of the chance conditions of a chance planet, are problems plainly unfolded in the sequel.

\section{Section 2. Atoms and their Properties:}

The notion that matter is composed of and may be reduced to atoms dates from the infancy of philosophical speculation. Proved true by scientific experiment to-day, it was equally so when, by guesswork, Leucippus and Democritus broached their atomic theories; and yet, until our own day no school of philosophy has sensibly extended the farsighted conceptions of those ancient Grecians.

At present scientists wrangle over the two hypotheses of discontinuous and continuous matter, or the hard atoms of Lucretius and the vortex atoms of Helmholtz and Lord Kelvin already mentioned. The latter theory is in its infancy, and so far as it is explicable (we do not say intelligible) is as follows:"The substance of existence is a primitive fluid, part of which is inert and part rotates. The inert part is everlastingly inert, and the rotating part ever- 
lastingly rotates. Only the rotating part constitutes phenomenal existence. This rotating part consists of vortex atoms, vortex filaments, vortex tubes or vortex rings."

How these vortex atoms constitute phenomena has not yet been ascertained, nor is ever likely to be; for the demonstration can only be accomplished by mathematical analysis, a task which Professor Tait says, "would tax to the utmost the powers of the greatest mathematicians for generations to come." Obviously, life is too short and intelligence too impatient to accommodate such a visionary theory. Besides, this conjectural manner of casting the horoscope of existence is too suggestive of the haphazard prognostications of gipsy fortune-tellers to merit the serious attention of practical scientists.

A further objection is that in order to explain the existence of one thing, matter, it has been found necessary to postulate the previous existence of two things, vortex atoms and an inert fluid. True, the vortex atoms alone are alleged to be matter, but if the fluid be not also matter, then, as Professor Tait aptly says, "it explains matter only by the help of something else which, though it is not what we call matter, must possess what we consider to be one of the most distinctive properties of matter.* This complacent method of explaining the origin of one thing by postulating the previous existence of two things is common enough in metaphysics, but its 
introduction into science is to be deprecated.* Without waiting, therefore, for the doomsday demonstration of the truth or untruth of this vexed theory of vortex atoms, we shall content ourselves with one more meet for man's present knowledge, intelligence, requirements, and average length of days, viz., that of the "Lucretian hard atoms," which appear to chemists and all trustworthy physicists amply sufficient to unravel the utmost intricacies of universal phenomena.

The inherent properties and qualities of atoms are briefly as follows :-

(I) Indestructibility.-Modern science has indisputably established the indestructibility of atoms. An atom of oxygen, for instance, is always an atom of cxygen. It manifests the same indestructibility of substance, perpetuity in energy, and unchangeability in property, either singly or as part of the thousand and one compound substances-mineral, vegetal and animal-with which it ceaselessly assimilates itself. It is impossible either to change or annihilate it. Similarly with all the atoms of all the elements. The elements in the material alphabet and letters in the linguistic are thus alike in function. For instance, $a$ possesses a signification distinct from $b, c, d$, or any other letter, but prefix it to nt as ant, and its passive classification as a vowel merges into its active vocation as a word-maker. Still, if separated, the letter loses nothing by its temporary alliance with others;

* It is a favourite pastime, however, with Lord Kelvin, for he also employed it in his humorous theory of "Seed-Bearing Meteors." 
in marriage or divorce it is ever the same. In a sense, it is indestructible, for $a$ is always $a$.

Vital as indestructibility thus is as a scientific premiss, it falls far short of its significance as a philosophical principle, for its bearing on the philosophy of evolution, the problem of existence and the science of life, is unparalleled. For example:-

(a) Through the eternal existence of the noumenon, or the substratum of phenomena, it involves the eternal existence, hence uncreatability of the constituents of the universe; hence also the absence of an origin to the universe, as already affirmed.

(b) It dispenses with a First Cause, or agent of creation outside of or independent of matter, for otherwise, as already shown, we would only be shifting the origin of matter to a cause whose origin was equally inexplicable with that of the thing caused; to a Creator more enigmatical than the eternal functions of the thing created; hence, only solving a minor mystery by concocting a greater. Indestructibility thus constitutes matter to be itself the only first cause of the universe. In other words, matter is not only the maker of the universe, but is alone the universe. Matter obeys the voices of nature because it also commands them; it executes because it also determines.

(c) Indestructibility prescribes a limit to both science and philosophy by defining the boundaries of the knowable in the cosmos, thus limiting the generation of nonsense, metaphysical or otherwise, by precluding 
men from theorising on causes or potencies beyond the objects of human sense.

(d) Indestructibility is a prime factor in production, for it ensures the ceaseless evolution of new phenomena. We can practically create new compound substances by merely varying the proportions of the old component constituents of things; for the contents of thousands of objects, unlike in secondary appearance and properties, consist of the same primary elements mixed only in different atomic proportions. Hence, as the variety of atomic proportions is through the magnitude of the material alphabet exhaustless, the evolution of new material combinations and productions is equally inexhaustible.

An ever-increasing complexity is thus the rule in the universe, whether in minerals, vegetals, animals, planets, suns or solar systems.

(e) Indestructibility endows matter with a charmed life, for, as Clerk Maxwell says, "It is independent of the dangers arising from the struggle for existence common to other known existences." In otherwords, matter as noumena is free from the infirmities imposed by it on its own offspring, phenomena. Hence, while phenomena change ceaselessly, while planets and suns melt away in fervent heat, and gods change from wood and stone idols into conditionless Spirits and agnostic Unknowables, matter in its adamantine atoms remains unchangeable and eternal.

(2) Eternality and Uncreatability.-That atoms are eternal, uncaused, and uncreatable follows of necessity 
from the preceding premiss of indestructibility. They further involve fixity in the quantity or number of atoms in the universe; for were it otherwise, were even one atom creatable, something and nothing would be convertible terms, the order of nature impossible, and chaos inevitable.

(3) Indivisibility.-Some define an atom, from its etymology, to be "a particle of matter which cannot be divided." It is thus assumed to be indivisible. Professor Clifford, however, asserts as the literal rendering "that which is not divided;" for we know nothing of possibilities and impossibilities, but only about what has and has not taken place. This is the true scientific attitude. At the same time, for the practical purposes of our to-day knowledge and the ends of materialism, we can assume an atom to be indivisible.

(4) Size. - With characteristic boldness, present physicists have calculated the size of an atom, and the effort is at least ingenious. Thus, says Lord Kelvin, "If a drop of water be magnified to the size of the earth, the atoms will average something between cricket balls and small shot." (Professor Tait suggests plums.) But this illustration, though lucid enough in its way, is not realisable; it however endorses the principle of atomic size. In our view, an atom would be better understood by predicating it the next thing to nothing. In the light of investigations to follow, it will thus be useful to remember that millions of atoms might dance on the point of a needle. 
(5) Shape. - Size in an atom involves shape. Hitherto this shape for all atoms has been postulated spherical; atoms being little spheres, and molecules groups of spheres. But, if atoms are of seventy or more different kinds, this assumption is contrary to evidence, for different substances naturally exhibit different specific structural forms; effects which could only be produced from a specific difference in the fundamental or atomic sub-structure of the substance. For example, rock salt crystallises as a cube. If this cube be split up until it can be split no longer, the residuum is always a cube; hence, reasoning from the visible to the invisible, a molecule of salt is also a cube. But a molecule of salt contains both sodium and chlorine, consequently, while the atoms of sodium and chlorine may not be cubical, by producing the cube form through their combination they must be not spherical but polygonal. Similarly with the atoms of all elements, they are probably polygons of various shapes. (See Mineral Evolution.)

(6) Weight.- "The atoms of the same element weigh alike, but the atoms of different elements have different weights." This quality of weight is a fact, but its cause is alleged unknown." (See Gravitation.)

(7) Kinds of Atoms.-Although the variety of substances on the earth is infinite, the fundamental bases are comparatively few, certainly not more than the number of the elements.

This number (seventy odd) is sufficient for all the needs of the universe, for not only may all known 
substances be resolved into them, but untold millions of new and undreamt of substances may be evolved from them.

It might be urged that the postulation of a universe comprising untold myriads of atoms, possessing in combination properties capable of infinite possibilities, is a very complex beginning. But, on the other hand, to commence with a "Creator" who called into being from nothing all these atoms with their infinite properties, is surely an infinitely more complex hypothesis, besides being absolutely unintelligible and inexplicable.

(8) Energy.-It is assumed from evidence that each ultimate atom or molecule in any substance is in intense motion ; molecules of diamonds even "quivering with shocks received from other molecules millions of times in a second." But unless this fundamental motion was subservient to orderly laws, order in the combination of bodies, or even in the universe, could never arise. What this energy is is revealed anon.

Equally important with all the above mentioned properties of the atoms are three now given for the first time:

(a) That Atoms are Magnets:

(b) That Atoms are dual or sexual in kind.

(c) As a consequence of the first, that the energy of the atoms singly or collectively as minerals, plants or animals is Mranetism.

The proofs of these fundamental facts are given in their due place. 
Section 3. The Classification of the Elements or the Sexuality of the Atoms:

In inquiring into the bottom combinations of matter, obvious questions seem to be:-Do all the seventy odd elements reciprocate and unite indiscriminately or discriminately? Are all combinations of atoms equally fit and equally fertile ; or are some elements repellant and sterile among theniselves as well as with others of a like class, and attractive and fruitful only with those of a dissimilar class? Are there not in the material alphabet, as in the linguistic, dual differences and dual preferences, arranged as distinct classes of constituents (similar to consonants and vowels), each with different functions and affinities, so arranged that their combined co-operation is absolutely essential to production? These points seem at one time to have been thought of, for we find in many chemical text-books a dual classification of the elements into Metallics and Non-Metallics as follows :-

Non-Metallics ( 15 ).-Oxygen (hydrogen), nitrogen, carbon, boron, silicon, sulphur, selenium, tellurium, phosphorus, arsenic, fluorine, chlorine, bromine, iodine.

Metallic (53).-Cæsium, rubidium, sodium, lithium, potassium, barium, strontium, calcium, magnesium, aluminium, gallium, zirconium, thorium, yttrium, erbium, ytterbium, cerium, lanthanum, didymium, niobium, zinc, nickel, cobalt, manganese, chromium, iron, cadmium, uranium, indium, copper, bismuth, lead, thallium, tin, titanium, tantalum, molybdenum, 
tungsten, vanadium, antimony, mercury, silver, gold, platinum, palladium, rhodium, ruthenium, osmium, iridium, beryllium, germanium, samarium, scandium.

But, curiously enough, this classification is alleged to be of no importance, a mere perfunctory arrangement, a concession to method and order yielded to merely "for the sake of simplicity." Other classifications were consequently sought for.

Thus Berzelius originated a dualistic theory which classed compounds in paired constituents or groups of constituents ; but, as a classification of compounds could not be a fundamental distinction in matter, his theory collapsed.

The need of a dual classification of substance continuing to be felt, chemists substituted and still endorse one equally incompetent; for they profess to find deep import in those superficial distinctions which are inevitable between constituents and a combination-between letters and language, for instance, or sugar and confectionery, viz., "Chemists have found that all substances they meet with may be divided into two great classes:-

“(1) Simple Bodies or Elements.-Substances out of which nothing different.can be got.

"(2) Compound Bodies. - Substances out of which two or more different things can be got. $\nmid$ "

This classification assuredly exists, is unquestionably correct, and may possibly be of service; but it is a

\footnotetext{
* Science Primer, Chemistry, P'rof. Roscoe, p. 60.

+ Chemistry Primer, p. 58; Prof. Roscoe.
} 
parody on human intelligence to designate it great. Truly enough, it contains facts, accurate as facts, and of value as describing a condition of things in the universe; but it is also devoid of any point which might suggest a vital principle in the combination of matter or afford any clue to material reciprocation and production. A similar classification of mankind might be facetiously advanced as follows :-

(1) Simple Bodies, Single Men or Bachelors.Substances or subjects out of whom nothing can be got.

(2) Compound Bodies, or Married Couples.-Substances or subjects out of whom two or more things can be got.

This classification is equally true, equally profound, equally scientific and equally philosophic with the other; but we should scarcely dignify it as great. The really great classification of mankind is as dual or sexual, male and female, the most essential antecedent to human reproduction. The question thus comes with added momentum, Would not a similar duality in elementary substance be productive of equally important issues in elementary reciprocation? From unlimited corroborative "evidence we belicve this to be the case, hence we enunciate as one of the fundamentals of the new Materialism that the normal chemical division of the elements into Metallics and Non-Metallics is the bottom classification of matter, the only one with confidence to be designated great.

The next query is, Is the above classification 
accurate? For when we note how thoughtlessly it has been instituted, how unquestioningly adopted, how mechanically copied, how apathetically maintained and how singularly misjudged, it would not be surprising were its flaws most glaring. But, contrary to expectation, it seems to contain only one doubtful element, hydrogen. This element has been invariably enrolled among the non-metallics, although many chemists surmised it might prove to be a metal, but taking into consideration all the evidence on the point we shall class it as metallic.*

With this alteration, are we warranted in ascribing to this dual classification of substance that importance, both scientifically and philosophically, which we assign it? The evidence is overwhelmingly affirmative, for no known natural product exists which does not contain both classes of these elements in combination. Matter itself must thus be sexual.

It will not for one moment be understood that we imply atoms to be male and female in the same sense as organisms. It is immaterial which class of atoms -metallic or non-metallic-we denominate male or female, for the sexual union or reciprocal combination of one metallic atom with a non-metallic atom would not generate other metallic or non-metallic atoms as children; because, on the basis of the atomic philosophy-the indestructibility and uncreatability

* The recent liquifaction of hydrogen by my namesake, Prof. Dewar, seems to show that hydrogen is a non-metallic, but we shall wait for further proof. 
of atoms-this procreation of atoms is impossible. What is implied by material sexuality is solely a reciprocal duality in fundamentals, which produces disparity in compounds.

All that follows shall further tend to show that this duality of the atoms is a fundamental principle which embodies one of the most salient truths in the science of the century.

Section 4. The Combining Weights of the Elements: In arithmetic each change of numerals in a sum involves, through the variation of the symbols, a difference in the value expressed; hence, in chemistry we might also infer that a mere variation in the quantity of a substance's constituent elements would produce a corresponding variety in the nature of the material product. But it is not so. The elements, indeed, hereby justify their postulation as an alphabet, for the laws of their combination in effecting production resemble those governing letters in language. For example, neither consonants nor vowels alone form a word,-both are required. Again, an indiscriminate mixture of consonants and vorrels does not produce a word but a medley. Further, a transposition of the letters of even a good English word into different combinations does not necessarily constitute other words with different meanings, but, in all probability, gibberish. Hence, words must be coined according to well-defined rules, from which little or no variation is permissible. 
In like manner with natural productions. Dalton discovered that in order to form a distinct compound each element would only combine with others in certain definite proportions. In order to establish the ratios of each, hydrogen, as the lightest element, was fixed upon as the standard, and its weight adopted as the unit of measurement. The combining weight of oxygen was thus ascertained to be 16, carbon 12, nitrogen 14, gold 196, etc. For example, I6 parts of oxygen and 2 parts of hydrogen form 18 parts of water. Half of those proportions, 8 and I form 9 parts of water. Any multiple of those quantities, such as 24 and 3,32 and 4,40 and 5 , form respectively 27,36 , and 45 parts of water. But if 20 parts of oxygen be mixed with 6 of hydrogen, only I6 parts of oxygen and 2 of hydrogen unite, 8 parts remain uncombined.

A law of definite proportion also governs the volume as well as the weight of combining elements, but the numerical relation differs. Thus two volumes of hydrogen unite with one of oxygen to form water.

The principle of equivalence among the elements is also interesting as confirming the deductions of science regarding the universal subjection of matter to inviolable law; but, as the atomic weight of each element occupies a simple arithmetical relation to its equivalents, the former (the law of combining weights) is the primary law in chemistry, and, coupled with the principle of the duality of the elements in class, it should without question be the dominating one. 
The consequences of the limitations involved by these automatic laws, as well as their necessity, are obvious. Without a fixed proportional combination of elements, chaos would be the normal condition of things and order the exception; hence in the very nature of being, in the fact of existence at all, and in the constitution of the atoms as elements, system in natural production, as in human language, is absolutely essential to the prevention of universal babel.

The law of the combining weights is also a rudimentary factor in the great evolutionary law of natural selection. Innumerable elements, for instance, may often meet in suitable conditions for combination, but, if unsuitable in proportion, no selection ensues, consequently there is no production; creation is virtually dead. In this restriction lurks not only a barrier to chaos, but a check to the indiscriminate and ceaseless germination of monstrosities. Further, we obtain a deeper insight into the great fact of material genesis-viz., that the universe is composed of atoms, omnipotent automata, built together of laws, self-going machines, infallible, indestructible and eternal; while the combinations of these atoms are not ephemeral lumps of clay, cut here and there and fashioned indiscriminately at the caprice of a Supernatural Potter, but similar automata, chance born and chance sustained, here to-day and gone tomorrow.

These two facts-the dual classification of the 
atoms and their combining weights-constitute two great complemental potencies, each necessary to the other's usefulness; and both resulting in a combined dual table with dual values, practically completing the science of chemistry. Although the discovery of the atomic weights was a red-letter day in chemistry, a law productive of wonderful results since, yet its development was hampered by ignorance of the true reciprocal elements. It was a cypher lacking part of its key; but with the establishment of the "material alphabet," this reproach can no longer be levelled at it.

In conclusion, necessary as the preceding laws are to nature, their comprehension by man is of still vaster import to humanity at large. Nature, as the original chemist, has ever been evolving new substances whenever and wherever the necessary conditions were available; but the human chemist, as the more intelligent of the two (if we can separate man from his compost, for man is only nature personified), should, in his more efficient laboratories, and by the aid of his superior apparatus, manufacture new substances ad libitum with the prescience of an oracle.

This finishes our review of matter in its material as distinct from its energial aspect.

Our material knowledge of matter may thus be assumed complete philosophically, at least for today, for it is cyclic; though probably incomplete scientifically or in details. Commencing with 
indestructible atoms as the substratum of the universe and the foundation of all things, mineral, vegetal, and animal, we infer, and shall eventually prove, that from them and them alone all products in existence, from the least to the greatest, from a molecule to a man, and from a grain of sand to a planet, are formed and composed; while, in their eventual disintegration every combination inevitably returns to the same primal atomic source from which it dates its birth, from thence to cycle on through other orbits of universal metamorphoses eternally. 


\section{CHAPTER V.}

\section{The Constitution of Energy.}

\section{(I) Fundamental Energies:}

The "Indestructibility of Matter" has been called the first great principle of science, and the "Indestructibility of Energy" the second. The basis of universal existence is consequently not millions upon millions of atoms merely existing, but all these atoms in incessant motion. This atomic energy may be divided into two kinds: (a) The fundamental energy of the atoms as units or individuals. (b) The fundamental energy of the atoms as groups of individuals. That is, while each atom has an inherent energy, this energy is not alike for all atoms. Each elementary group has a characteristic energy of its own. Thus, as there are seventy elements, there are at least seventy fundamental kinds of energies. This difference is a necessity in such a kaleidoscopic universe as ours. For in either a universal similarity or a universal diversity, chaos would have been interminable. Some play as well as some restriction was inevitable. 
(2) Secondary Energies:

Given seventy fundamental energies, it is obvious that with the mixture or combination of these seventy groups with one another the field for the evolution of secondary energies is illimitable. The energy necessary to evolve and maintain an infinity of substances and organisms thus keeps pace with the infinite inter-combinations of matter.

(3) The Conservation of Energy:

This is one of the general laws of energy based on energy's fundamental indestructibility. No energy is created. All energy in all bodies is but a transference of force or motion. Each energy in any substance dates its energy from some previous energy in another substance. No energy is thus lost, but only transferred into some different phase of energy in a different condition of matter.

(4) The Correlation of Physical Forces:

This principle, by being stated separately from the last, means that all known physical forces are correlated or inter-convertible one with the other. Thus magnetism, electricity, heat, and light are all inter-convertible with each other; a fact the full significance of which is hardly yet realised: for two other "forces" heretofore characterised as mysterious may have to be associated with them. We refer to Life and Mind.

\section{(5) Energy as Automatic:}

If an atom, as postulated, be an automaton, its energy must also be automatic. Hence, as all 
fundamental properties are indestructible, we reach the startling conclusion, that all energy, in all bodies, at all times, is automatic. This does not leave room for a Creator. Whaterer energy exists in any body capable of performing a certain action, we can also rely upon it being inviolably performed.

Automatism, moreover, is an absolute necessity in physical operations, for in no other way could the dance of millions of atoms on the point of a needle be regulated.

(6) The Duality of Energy:

From the fact that matter is dual and that reciprocity between the metallic and non-metallic elements is essential both to production and reproduction, this reciprocity is virtually a Dual or Sexual law of energy. The importance of such a law in such a fertile world as ours may be imagined.

While the above are the general principles of energy in the world, if not in the universe, there are also, what is more important to scientists, the definite laws of energy for producing definite effects and controlling definite phenomena. Some of these laws are new and some old, but the old ones are placed by us on a higher pedestal than they have hitherto occupied.

(7) The chief of these is:-Magnetism:

The longest known, most familiar, and least understood of all natural forces is magnetism or electricity, for both forces are practically identical. Ever since Jupiter hurled thunderbolts out of Olympus, the 
mysterious properties of the loadstone have been the wonder and awe of mankind. To these forces men have at different times accorded divine homage and ascribed universal sway; but it is only in recent years that their deep import has been surmised. Many scientists and sages, from Bacon onwards, including Newton, Gilbert, and Schelling, founded great expectations on the infinite possibilities obviously contained in magnetism, and laboured zealously to exalt it to the highest pinnacle of science; but the necessary evidence has been so long in accumulating that its unparalleled importance, in virtually underlying all other natural laws, is only becoming apparent to-day.

Gilbert and Schelling indeed audaciously announced that "Yolarity" was the universal law of nature; but they were preaching ahead of their times. That they failed to graft their views on the science of the age, was due to no flaw in their principles and no unsoundness in their reasoning, but chiefly to an insufficiency of evidence, coupled with the general incompetence, prejudice, and timidity of mankind. So far as their own crude knowledge buoyed them on, they doubtless saw the road clear to their own mind's eye, but they lacked the data wherewith to sweep the cobwebs of hoarded beliefs from the optics of their contemporaries. Truth truly is ever victorious, but only when equipped with the sword of victoryknowledge-and this they had not. They were too advanced in thought for the physical knowledge of 
their own times to establish a universal law of magnetism then, and too ignorant of to-day data to frame a universal law of magnetism acceptable now. Yet their speculations, like those of all earnest thinkers, were straws showing the current of human intelligence, indicating the poles of contemporary human thought, and clearly pointing out to their successors the path where the pioneers of progress ought to labour. But, as at many another crisis in human intelligence, when the lamps went out, men only lapsed deeper into darkness instead of soaring into light.

The claim of magnetism to be the chief force of nature or the dominating constituent of energy is thus of no mushroom growth. The contention has been simmering in the minds of able observers for centuries; it appears, in a more or less vague form in all the writings and speculations of present day scientists, and was even openly advocated by a French philosopher over twenty years ago.* Hence if truth lurks in it at all, the probability of its satisfying human aspirations now for a universal law is greater than ever beforc. Still, notwithstanding the great importance of magnetism, we cannot assert its absolute pre-eminence, for the other modes and constituents of energy are so interchangeable with it and with each other (as the law of the Correlation of Physical Forces affirms), that all must be included in nature's energial sovereignty.

* M. Lefèvre's Philosophy, Eng. Trans., p. 453. 
In order, however, to prove the fundamental nature of magnetism we start with the postulation of a fact affirmed by every physicist to-day and established in science beyond a doubt, viz., all iron is magnetic. As a consequence the constituents of iron bodies, the atoms of iron, inherently possess both attractive and repulsive energy. The proof has often been given as follows:-Every piece of iron is a natural magnet. Every iron magnet contains two poles, called positive and negative. If the magnet be broken in two, each piece becomes a smaller magnet endowed with two poles. This process is continued indefinitely, but the result is ever the same; each remnant is a complete magnet with two poles. The intellect then prolongs the operation mentally, when the body fails to perform it physically, until indisputable reasoning ultimately resolves all the fundamental atoms of the iron magnet into magnets with two poles.

The question then naturally suggests itself-Is iron the only element endowed with magnetic or attractive and repulsive forces? Are its atoms the sole monopolists of poles and polarity? Or, does iron not only exhibit more intensely what all atoms reveal more or less imperceptibly? Is iron not merely the spokesman or index of the energial constitution of all the elements, even betraying in a conspicuous manner the nature and source of universal energy.

Further investigation seems to endorse these inferences. Nature, from what we know of her, is not a likely subject to have fifth wheels to her coaches. 
If a dual law of magnetism with other co-ordinate forces proves sufficient for the cyclic or complete energy of one element, it is likely to prove equally efficacious for all. The deduction is at least logical, and appeals to to-day knowledge and research. It is extremely unlikely, as it would also be supremely ridiculous and supererogatory-from a human standpoint, because alien to all man's own mechanical expedients-to endow the different elements of matter with two principles when one would suffice. Further, as we are ignorant of any motion in nature so fundamental as the reciprocal attraction and repulsion of like and unlike matter, coupled with the opposite attraction and repulsion of unlike and like poles, we know of no rival force to magnetism so worthy of being installed as a universal natural law.

Another important point is the magnetism of the earth. That the earth is a magnet has long been an established scientific fact, but while potentially fruitful to a degree, the deduction has been almost ignored by both science and philosophy. A vital question, for instance, would be-What constitutes the earth's magnetism, or from what or whence does it derive its magnetic force? Obviously, the earth is not a magnet because it is wholly composed of iron, for that metal forms only an infinitesimal fraction of its substance; hence, the other elements, by occupying the same relation to the earth as iron should also be magnetic. But it is alleged we have next to no evidence of this, while what magnetic force they do 
exhibit is infinitesimal. This latter point, however, is immaterial so long as they furnish any evidence at all of magnetic control; it would obviously be extremely inconvenient for all bodies to be equally magnetic with iron; besides, it would involve a virtual surrender of each element's distinctive energy to that of iron. Each element is master in its own domain and governs with its own individual energy.

We are now brought face to face with the following facts:-All bodies belonging to the earth (including meteorites) are amenable to the magnetism or attraction of the earth by falling to it. The property of a magnet involves the manifestation of force more intensely at its poles than at its equator or centre. Thus, in sprinkling filings over a bar-magnet, the particles adhere tenaciously to the poles, but weakly at the equator or centre. Science reveals similar discrimination by the earth, for it attracts all bodies with greater intensity at the poles than at the equator; or, as Clerk Maxwell says, "The force of gravity at the level of the sea increases from the equator to the poles.* This fact demonstrates not only the magnetism of the earth, but the magnetic subjection of all mundane bodies and constituents. For as all substances and all elements sink their individual energial differences into the attractive and repulsive forces of the earth, the constituent particles or atoms of all these substances, by exerting the same force must also be magnets. In other words, all the atoms

$$
\text { * Theory of Heat, p. } \text { S4. }_{4}
$$


of all the elements in the earth are equally with iron, magnets with poles and polarity. This is a sweeping conclusion, but inevitable. What is true of a small magnet is in principle true also of a large one; hence, if the earth bc a magnet, its reduction to atoms should yield the result already authorised in the reduction of a small iron magnet. Thus, if we broke the earth in two, we should not have two earths with only one pole each, but two earths with two poles each. If these halves in turn be broken, the quartcrs shall also be magnets with two poles each. Thus we continue as in the former illustration, until by imagination we reach the smallest particle or ultimate atom of the carth, when the inevitable deduction must also be conceded, that erery particle of erery substance and every atom of every elcment in the earth is, equally with the earth itself, a magnet with poles and polarity. This is a most potent fact for materialistic evolution, as we shall see anon.

Again, if instead of brcaking a magnet, we welded a number of small iron magnets into one monster bar, the product would be, not numerous magnets with numerous poles, but one magnct with two poles. Similarly with the earth. . Its every constituent magnetic atom does not retain (absolutely) its individual energy, but merges it (partially; at least) into the earth's combined energy; consequently the atoms do not evolve a planet bristling with innumerable poles, but the earth careering through space as one huge magnet with two poles. 
The final question now is-From whence does the earth derive its magnetism? To this there are two answers. The first is, Its constituent atoms. The earth in substance is but the temporary aggregation of eternal atoms; hence, for the time being, it only manifests the energy of the sum of its constituents. As its every atom is a magnet with two poles, so the earth as a combined atom, so to speak, is also but a magnet with two poles. This is proved by dissipating the earth into its clements again, when each individual atom as an indestructible unit would resume its magnetism. The whole would but merge into the parts. In other words, only the atoms and their inherent energies are old and unchangeable; the forms into which they unceasingly aggregate, whatever they may be, are ever new and ephemeral. The earth and solar system might melt and pass away as in a vision, but the atoms with their everlasting polarities would still remain to create and recreate worlds unendingly, and people and repeople them with beings confronted ever with the same doubts and difficulties, and burdened ever with the same dread enigma of their existence.

The second answer to the question, From whence does the earth derive its magnetism? is, Its battery.

The earth is not a solid magnet like a bar of iron, for we are assured the interior is in a molten state. If this be so, this molten interior is virtually its magnetic battery, in which materials of all kinds are constantly dissolving, producing heat, and generating 
vast energies which make their influence felt in various ways:-Firstly, as magnetism at the poles. Secondly, as gravitation, or the magnetic attraction of all external or isolated bodies to the earth's surface. Thirdly, as gases, water, and molten material ejected to the surface through volcanoes, geysers, and burning and boiling springs of all kinds.

These energies, however, are more or less ephemeral, for unless these vast subterranean fires be kept supplied with new fuel, they will gradually die out, and the earth losing much of its present energy, shall retire to an even more insignificant position than it presently occupies in the universe.

Alive, therefore, as scientists now are to these stupendous subterranean forces and the energies which the law of the Correlation of Physical Forces involves, the next great feat of our inventors shall probably be to tap the earth's great store of electricity, and from thence draw energy enough to supply all the manufactories of the world.

We have now furnished the requisite proof that every atom is a magnet, and that its fundamental energy is magnetism. The inference from this basis is astounding, for not only does it involve the magnetism of the earth as well as the magnetism of all the constituents of the earth, but it establishes beyond a doubt the magnetism of all the products of the earth-mineral, vegetal, and animal. Every crystal, plant, animal, and man is thus a magnet, whose every energy-muscular, nervous, vital, or 
mental-resolves itself into the familiar operations of magnetism.

Still further, as all the planets and heavenly bodies are alike in nature, so far as we can judge from analogy, so must they be governed by similar energy to the earth. Hence we reach the final conclusion, that the bottom cnergy of the universe is also magnetism. 


\section{CIAPTER VI.}

\section{The Primary Laws of Energy.}

The scientist's dream of a universal law of energy dominating all other laws seems from the latest data to be an aspiration destined never to be realised, for, as we shall show anon, even gravitation resolves itself into a quite secondary natural law. All energies are perforce so trammelled by necessary accessories, so compromised to the usc of unavoidable agents, so bound by indispensable conditions, so governed by insurmountable environments, and so pushed and elbowed aside by self-assertive coefficients, that no law, thing, being, cause, or atom is individually omnipotent, for each is subject to other equally powerful constituents. Any alleged universal law, therefore, framed for the purposes of scientific exposition, can only be one which comprises, or is the sum of, all the primary forces in the universe. What we assert these forces to be we now enunciate serially. The most fundamental lawe of nature, in the first place, ought to be revealed by the atoms themselves, when they transform from 
the free, separate, and independent state as noumena to the associated, combined, or organised condition as phenomena-in other words, when " natural selection" first ensues among the atoms. But as we cannot see the atoms as noumena, or learn by direct observation how atomic or molecular selection and aggregation occur, our conclusions must be arrived at by analogy from operations in visible phenomena, aided by those processes of reasoning. from effects to causes hitherto employed and validly established by scientists in constructing the unseen from the seen, and the invisible from the visible.

Section I. First Law': Like-Material-Attraction:

Definition: Like atoms and like molecules antomatically attract each other in order to effect suitable productive conditions.

In nature many simple elements, such as gold, silver, and lead, are deposited in solid bodies of visible form. As these bodies are composed solely of particles of one particular element, the affinity uniting them as a solid inevitably belonged to them in, and accompanied them from, the invisible noumenal condition. Suppose we trace the sequence of this affinity in a nugget of gold?

Subjecting the nugget to heat, it gradually passes from the solid to the molten or liquid state. But, as liquid, the atoms are not perfectly free-some bond still knits them together; hence, it is only by raising the temperature still higher that we dissipate the 
molten gold into invisible vapour, in which condition the gold atoms are as free or disconnected as their gascous constitution will permit.

We thus learn that atoms in solid combination grip tenaciously together, and yield up their cohesive force only to intense heat or motion. The question consequently is-What constitutes this cohesion? And the answer is, Atomic affinity, or a mutually selective attraction persisting between like elementary atoms, constituting what we have called Like-MaterialAttraction. Further, as similar effects characterise mixed elementary substances in their cohesion (such as ice, sugar, salt, and alum) molecular affinity, or a mutual attraction between like molecules or particles of compound substance, also prevails in nature; hence, in simple, as in compound substances, the same law governs-Like-material-attraction.

The importance and necessity of this law are obvious, for without it neither gold, silver, nor any other definite substance could cohere; the earth would only be a conglomerate of indistinguishable elements.

In the tumult of laws governing all sorts of bodies, and accomplishing all sorts of purposes, the agent effecting this mutual attraction of like matter seems to have been ignored; while the phenomenon itself appears from its universality to have escaped observation. If any scientist's attention was arrested by it, his curiosity was probably allayed by quoting to himself the law of gravitation. But gravitation, as now understood, is virtually a law of indiscriminate attrac- 
tion between particles of matter; hence it callnot possibly account for phenomena involving discriminate attraction. Every atom may truly possess an attraction for some other atom not of its own kind or class -as when chlorine and sodium cleave together and become salt-but this introduces another law into the fieid, an atomic sexual law with more complex functions, which we shall presently consider.

The main point at issue now is, that like atoms manifest an indubitably greater attraction for each other than for unlike atoms of their own class-that is, either metallic or non-metallic. For instance, oxygen atoms evince a greater attraction for oxygen than for carbon, nitrogen, or any other non-metallic element.

Like-material-attraction may thus be styled the most elementary phase of energy or motion. It is simple attraction, a mere kissing of like substance. It is not production, but the initiatory stage of it. It is courtship, not marriage. Marriage would involve production, and hence include the transformation of the sand into the sandstone, and of the molecules of salt into visible crystals. In atomic and molecular affinity, only that great material love is displayed which fascinates and draws the atoms and molecules of salt or sand to one another in order to execute the next fiat of phenomenal evolution.

A phenomenon, production, or organism is the completed result of combined natural laws ; but likematerial-attraction, as a solitary agent, only lands 
matter on the threshold of production. It is but the shaking of the flour on the baking-table previously to the kneading of the dough and the firing of the loaf. Contrasted with nature's more complex energies, this preliminary law is as the miller filling bags of flour to the baker turning out h's smoking batch of bread.

Like-material-attraction thus necessarily precedes all other natural forces, for no effect happens in matter unless matter is in a suitable atomic and molecular condition and position. The baker could not bakie a loaf with only a sheaf of wheat on his table. Similarly, in the formation of frees.one, an accumulation of sand is necessary. This sand is accordingly accumulated through the agency of likematerial-attraction, aided, doubtless, by accidental causes, and then the other constituent materials and forces combine to convert the sand into stone.

It only remains to be added that like-materialattraction acts automatically in matter whenever the conditions chance to be suitable; for the atoms, as automata, are thoroughly intelligent so far as their functions are concerned, and their performance of them is inviolable. No superintending ar ificer could teach them that which they are quite capable of accomplishing of their own accord; each has its own work to do, and it does it accurately an 1 eternally. 
Section 2. Second Larw: Dual or Sexual-MaterialSelection:

Definition: Like classes of atoms repel, and unlike classes of atoms automatically attract each other in order to effect production.

From the dual classification of the elements into metallic and non-metallic, nature, in all her ramifications, virtually becomes a vast household fundamentally grouped into seventy or more reciprocating families. Fourteen or fifteen of these we may call females (non-metallic), and the other fifty or more, males (metallic). The conjugation of this fertile flux has thus not only evolved the present variety of natural products on the earth, but new products and new varieties in ever increasing complexity must continue to evolve so long as season succeeds season, and the sun rises and sets.

Confirmation of this sexual interaction is overwhelming, for all observation and experiment in every department of chemistry and in every domain of nature prove that a mixture or compound of elements may be prepared, but no veritable production differing essential'y in appearance and properties from the combining elements can be erolred without the union of both metallic and non-metallic elements. For example, common salt contains sodium (metallic) and chlcrine (non-metallic).

Washing soda:-Sodium, with carbon and oxygen.

Saltpetre:-Potassium and hydrogen, with nitrogen and oxygen. 
Gunpowder:- Potassium and hydrogen, with carbon, oxygen, nitrogen, and sulphur.

Plants and animals also contain various proportions of both metallics and non-metallics, the chief being respectively, calcium, hydrogen, potassium, and sodium, with carbon, oxygen, nitrogen, and sulphur.

Lastly, few of the elements are found in nature uncombined with those of their opposite class; while the reduction of many of them, owing to their clcaving so closely together (vanadium and oxygen, for instance), is a work of great difficulty.

This second law thus manifests a dual affinity as distinctive of the least in the universe as of the greatest. Beginning with atoms in their dual chemical structure, it becomes in molecules complicated into a sexual principle, which, increasing in intricacy through the increasing complexity produced by the infinite combinations of matter, at length pervades all natural phenomena until it is cventually as essential to vegetal and animal organisms as to the elements themselves. It is the love of one class of atoms for the other-of the males for the females-the origin of sex, and the cause and foretaste of all love known, carnal and platonic. Without it the atoms would be sterile, the universe a chaos, and nature a cunuch.

Section 3. Third law: Polerity:

Definition: Like poles of magnets repel, ana unlike poles attract each other.

No law, as we said of its parent form magnetism, 
is more familiar than polarity, and yet in its far-reaching consequences probably none is so little understood. The chief facts are as follows :-

If the north pole of a fixed magnet and the north point of a magnetic needle meet, the north point of the needle is repelled and the south point attracted, and vice-versa. This action with all magnets is invariable. Again, if a horse-shoe magnet be dipped in iron filings, the filings adhere and build an armature between the poles. If the north poles of two barmagnets be dipped in iron filings and held near one another, the filings on each magnet repel one another; if opposite poles meet, the filings attract one another. It thus follows that while each magnet has only two poles, its energy is actually quadruple, for each pole exerts a dual energy by both attracting and repelling according to conditions.

What the law of polarity involves shall be best explained in a series of propositions, as follows:-

First Proposition.-If the principle of energy in an iron magnet be polarity, and if the same principle be also resident in an atom of iron, because it is also a magnet, then the force or cohesion which binds atom to atom atomically must also be polarity.

If the evidence heretofore advanced be true, this proposition is indisputable. If an atom of iron be a magnet with two poles, the law of atomic polarity, or the law governing atoms in their aggregation or invisible structural cohesion, must be similar to magnetic polarity, or the law governing visible 
magnets in their mutual manifestations of force. In other words, it is inconceivable that with such an all-sufficient law as polarity already existing, a different law of cohesion, of which we know nothing, should be introduced to bolster up polarity in its operations. Hence, we conclude that the ore of iron in the first place, and all shapes and conditions of the substance afterwards, are cohered into solidity from their foundation by atomic polarity, in conjunction with the other laws of energy.

Second Proposition.-As the earth is a magnet, the carth itself and all its constituent atons and products must be built together, both singly and collectively', by the same law of polarity.

If the proof of the earth's magnetism as already given be true, this sweeping proposition follows as a necessary corollary; for if all the elements are, equally with iron, magnetic, all mist equally be atomically polaric. Consequently, if iron be built together or cohered in its ultimate particles by the law of polarity, all the elements in all subtances must equally be aggregated by the same polaric law. But this deduction, if pressed to its ultimate logical consequences, leads to conclusions so astounding that few have dared to follow them up, for not only does it involve the upbuilding of minerals, the production of crystals, and the evolution, production, and virtual creation of all plants and animals, but man himself is only the crowning apex of the whole series. Yet the proposition is undeniable, for the proof given anon is conclusive. 
Third Proposition.-Atoms, molecules, and aggregates of molecules issuing from the same pole of a magnet become suffused with the same polarity. Hence, as like poles repel one another, a mutual repulsion is manifested by the charged material, which results in the isolation of filaments, stalks, twigs, and branches, all repelling one another.

The facts illustrative of this law are as follows:-

If a number of needles be attached by their heads to the pole of a magnet, all their points repel one another, for each needle becomes magnetised, and acquires at its point similar polarity to the pole of the magnet. The magnet, in fact, is only lengthened. Hence, as like poles repel, all the needle points repel one another. Again, if the end of a magnet be dipped in filings, the bunch thereby attracted and magnetised becomes a bristling mop of mutually repellant filaments. Each minute filing also, could we test it, would prove a complete magnet with two poles systematically arranged, each adhering to the other by opposite poles.

Another beautiful experiment is as follows :-

Lay a flat bar-magnet on a plate of glass, sprinkle over it some iron filings, tap the glass, and if the experiment be carefully performed, the filings at both ends will automatically fall into lines, each line widening as its distance from its own pole increases; the diverging force, as in the previous experiment, being like-polar-repulsion. But the filings do not continue to radiate in straight lines from the poles to infinity; 
instead, they curve inwards from pole to pole by the law of unlike-polar-attraction. By judiciously handling other magnets the filings may be induced to form most intricate patterns and foliar designs.

As all these foliaceous patterns, or forms similar to them, are infinite in number in the mineral, vegetal, and animal kingdoms, we learn that Like-polarrepulsion and its complement, Unlike-polar-attraction, are Nature's Great Designers. Thus we see the same polar principle in frost-ferns, snowflakes, and lead and silver trees; in corals and shells; in every plant and tree, leaf and flower; in evcry wing, fin, and feather on insect, fish, and bird; until even in the animal anatomy the bones, arteries, veins, and nerves radiate throughout the organism on the same invariable plan. Thus does this artistic principle of nature, untaught and unguided by any intelligence outside of itself, bind together the whole arcana of being into one family likeness, prove the similarity of the origin and the inseparability of the unity which links the great phenomenal chain from matter to man, and grows the great Ygdrasil of the universe from its roots in the atomic slime to its branches in the highest heavens.

Section 4. Fourth Law: Like-Central-Repulsion: Definition: Materials dissolving in, or products arising from, the same centre, repel one another.

The law of Like-Central-Repulsion is practically included in the operations of polarity, but for lucidity it is expedient to separate them. Its action may be 
illustrated as follows:-In passing a compass along a level bar-magnet we reach a point where the force is equal, and the needle lies east and west instead of north and south. This point, if measured, proves to be the centre of the bar. If the compass be moved either way even in the slightest, the needle also moves. In a magnetic battery, similarly, the force is from the dissolving materials in the battery to the poles or extremity of the wires. This law is a potent one in organic life, as we shall show in vegetal and animal evolution, for all organisms possess a virtual magnetic battery in their vacuole or stomach, in which all their life or energy is generated, and from which it is distributed to the extremities.

Section 5. Fifth Law: Magnetic Induction:

Definition: Every magnet both attracts and repels every other magnet, but the greater governs the lesser.

By this law the energy of a magnet varies according to its size and density, the greater magnet reversing the polarity of the lesser.

The facts of magnetic induction are numerous and familiar. For instance, a needle suspended near a magnet is attracted by either po.e, and by both head and po.nt indifferently; but by drawing it over a magnet and producing in it magnetic induction, it becomes a magnet with a definite polarity. From thenceforth it is attracted and repelled only polarly. The scientific explanation of induction is as follows :*

* "Magnetism," I'rof. Chrystal. Ency. Brit. 
-A needle, in common with all iron or steel bodies, is magnetic, because it is composed of magnetic atoms; but the force of the atoms is not always manifested uniformly, hence it may not attract and repel polarly. The mixed polarity may have been brought about in several ways. The poles of the constituent atoms, for instance, may not have cohered regularly in the formation of the needle; consequently they would not range regularly from end to end, or if they did, the grinding and polishing processes may have again broken up the polarity. If, however, the needle be brought into contact with a magnet, the scattered polarities of the atoms are mastered and forced to set one way. From thenceforth all act in concert. The ease with which this action is done is comprehensible when we remember that the constituent molecules of even a needle are, according to the molecular theory of matter, separate from one another, as well as in intense motion.

A tube of iron filings may be induced and polarised similarly. A question, however, arises. If, as the evidence involves, every element and substance be magnetic, why cannot we construct magnets of wood, brick, and stone, as well as of iron? Simply because no other element possesses the force so strongly. No natural magnet so powerful as the loadstone exists with which to effect magnetic induction in other substances, for, as iron requires iron to magnetise it, so sticks and stones would also require 
stick and stone magnets to magnetise them.* Iron magnets are also produced by the aid of a magnetic battery; but while few other elements seem to be affected by this means, all bodies conduct magnetism and clectricily, or are susceptible to its infucnees.

This universal prevalence of magnetism suggests a conjecture which should open our eyes to the farreaching effects of magnetic induction-viz., as the cause of animal magnetism, mesmerism, or hypnotism? If all atoms and all combinations of atoms are, as deduccd, magnets, men also are magnets. But some men are stronger than others, have more force, vitality energy, or will; hence when they exert this force over weaker men and induce hypnotism, the influence imparted is undoubtedly an induction of magnetism from the stronger into the weaker, the polarity of the latter being, so to speak, mastered, conquered, or reversed by the polarity of the former; thus rendering the hypnotised person the strong man's second self for the time being-a virtual automaton at his mercy and will. More will be said of animal magnetism anon. In the light of present knowledge it is rather amusing to read of Lord Macaulay, in his essay on Lord Bacon, speaking with contermpt of those people with little brains who believe in "Animal Magnetism," showing how even the babes of to-day could confound the wise of yesterday.

Further, a speculation in astronomy is suggested

* If a lot of chips be thrown into the water, they all altrect each other and form a mass. 
by this law. If science affirms that all the heavenly bodies are magnets, may not the sun, as the larger magnet, govern and control the earth and the planets as smaller magnets; attracting and repelling them by their poles through the medium of their combined reciprocal polarity? May not the planets similarly control their moons, and occasionally avert danger from a colliding comet by reversing the comet's polarity, and thus changing its course? The speculation is not new, but our explanation invests it with additional interest. We shall recur to it again in our chapter on gravitation. 


\section{CHAPTER VII.}

The Secondary Laws of Energy.

Section I. Gravitation.

According to present science, the chief forces of nature are three:-Gravity, Cohesion, and Chemical Attraction; but they oive this pre-cminence simply to the fact that their causes have not been discovered. Hence, if we can attribute their origin to our Primary Laws, they must retire into the background.

As gravitation, in the first place, virtually comprises two distinct laws, we shall discuss these separately.

(a) The General Law of Gravitation:

"Gravitation is a general law of nature, whereby every material substance tends to approach or gravitate towards every other material substance; in fact, that any two portions of matter, whatever the nature of that matter may be, will move toward one another if there nothing to prevent them doing so."

This law, Huxley says, has been "established from an immense number of careful observations and experiments"-observations and experiments misread, 
however, for gravitation would then be, what it is not, a law of indiscriminate attraction between all bodies, mutually manifested and of equal intensity. What are the facts? *

(I) Those instances of magnetic attraction in which iron attracts iron. But as these are solely cases of like material attracting like material, they furnish no evidence of indiscriminate, but discriminate attraction.

(2) Those instances of bodies falling to the earth ; those very facts, indeed, which suggested the law of gravitation to Newton-the apple falling from the tree and the tile from the roof. But careful investigation demonstrates that these phenomena also occur by discriminate, not indiscriminate attraction. True enough, the testimony superficially is affirmative, for the earth attracts all bodies equally and indiscriminately. But the earth itself is an indiscriminate body composed of all elements; hence, as 110 known terrestrial or universal body consists of dissimilar elements to the earth, the earth naturally attracts all bodies indiscriminately and with equal intensity, because all are equally its like.

(3) Huxley illustrates gravitation by saying that "if there were only two drops of water in the universe, no matter how far apart, they would attract each other and meet." $\dagger$ Doubtless for two reasons :- I st. Because two drops of water are alike in substance and pro-

* In fact, gravitation has been, what Huxley always deprecated, dragged out of its true position as a tentative theory, and exalted into an unquestioned and unquestionable scientific creed.

+ Introductory Science Primer, p. 25. 
perties; hence, this supposition does not illustrate an indiscriminate, but a discriminate attraction. 2nd. In a void with neither top nor bottom and no other bodies to induce energy of any kind, two drops of water (with their constituent atoms possessing their present forces) would necessarily fall to one another, because no other things existed to distract them. Each would be the bottom of the universe to the other. The proposition could be more accurately put as follows:-Would a drop of water attract another drop of water with equal or greater intensity to a drop of oil or mercury, supposing a dozen drops of each existed? The question, apparently a difficult one, is practically answered by the fact that an iron magnet will not attract particles of wood, stone, or glass with equal intensity to a particle of iron. Each would preferably attract its like, for all bodies, as already stated, indicate that attraction and cohesion are inore intense between substances of like kind.

Lastly, if atoms are magnets, and if all bodies are (through their atomic composition) necessarily polaric, their additional endowment with such an insignificant force as gravitation would be supererogatory. Particularly would this be the case when, as Sir R. S. Ball assures us, "the attraction of gravitation is not a millionth part of the intensity of magnetic attraction."* Far, therefore, from numerous observaticns and experiments being available to affirm a law of gravitation, they are conspicuous by their absence. * "Gravitation," Ency. Brit. 
Gravitation, as an assumed law of indiscriminate attraction, thus merges into the more verified laws of discriminate attraction, as exemplified in the preceding primary laws of energy.

(b) The Mathematical Law of Gravitation:

"Every particle of matter in the universe attracts every other particle with a force whose direction is that of a line joining the two, and whose magnitude is directly as the product of the masses, and invorsely as the square of their distance from one another."

Gravitation, as so defined, contains no fundamental principle, for, as Huxley well observes, the so-called law of gravitation is not a cause, but a mere statement of how bodies approach one another, not why they do so.* Professor Tait also admits that "the cause of gravitation remains undiscovered."

When Newton conceived the bold scheme of girdling the solar and sidereal worlds into one vast mechanism by the assumed omnipotent law of gravitation, his theory, at best, was a half measure; his power only a drag, not an energy; a tie, not a cause of motion. Planets were regarded by him as arial horses that required to be reined in. Thus the vocation of gravitation was merely to bind the planets, as with a chain, in their orbits at specific distances from their foci, in order to prevent them from rushing out of the solar system on the impulse of another

* Science Primer, p. 25. Commenting on this in a College Lecture, Prufessor Crum Brown, Edinburgh, aptly said, "A statement cannot do anything." 
hypothetical law, centrifugal force, or "primitive impulsion in the direction of the tangent"- - a law of which he knew even less than of gravitation ; in fact, of which he knew nothing save that all sidereal bodies had an unaccountable onward motion. Whatever, therefore, this initial motion was or is, it has an equal, if not a prior, claim to so-called centripetal motion, to the honour of wheeling the planets in their orbits-a deduction overlooked or ignored.

In awarding to the proper source reparation for this oversight, we note that centrifugal motion is obviously the effect of a repulsive force, and centripetal motion the effect of an attractive force; hence, the planets are virtually kept in their orbits by the dual play of opposite yet related forces. When, moreover, it is acknowledged that the sun and planets are magnets with poles and polarity, we are warranted in deducing that it only needs a thorough knowledge of planetary motions and polarities to bring about the complete subserviency of all solar and sidereal motions to a more efficient law than gravitation-to, in fact, its parent law, polarity and its correlatives.*

(c) Hypothesis of an Origin to Gravitation and the Causes of the Motions of the Heavenly Bodies.

Although we cannot conceive of an absolute origin to matter either in motion or at rest, because the con-

* As indicating the tendency of present scientific thought, a paper was read before the Edinburgh Associalion of Science and Art, "attacking the Newtonian theory of gravitation, and supporling the view that the motions of the planets were caused by electricity generated

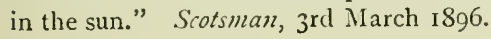


ception would involve the contradictory hypothesis of the creation of conditioned substance from no-substance by an immaterial and unconditioned Creator, yet we can frame a theory by which motion of universal matter appears inevitable under present conditions, and absolute rest impossible.

Firstly: If we suppose the beginning of the universe to be a mere void, absolute emptiness, there would then be neither matter nor motion, Creator nor universe.

Secondly: Assume, for argument's sake, the existence of the void, and further, that a planet, such as our earth, with all its present properties, introduced itself or grew (Topsy-like) in this void. This newborn planet, alone in the universe, would be motionless-at absolute rest; because in a void, with neither top nor bottom, nothing to fall to or revolve around, and nothing to reciprocate with or call into action its potential energies, it could not move. If, on the other hand, it plunged into the void from nowhere, it would maintain the same speed and the same direction eternally.*

Thirdly: Suppose another planet to plunge or introduce itself into the void at a distance from the first, an element of disturbance would then pervade the universe-a point of attraction to both planets, virtually a bottom to both planets, hence somcthing to which both would fall by gravity or reciprocal

* Both hypotheses are, of course, utterly ridiculous, but not more so than the orthodox theory of creation. 
magnetic attraction--rest would then end and motion begin.

Fourthly: What would be the consequence of this unrest and mutual attraction?

If all the planets and heavenly bodies are magnets with poles and polarity, these two planets, on nearing one another, would bring not only their mutual attractions (gravitation so-called) into play, but their polarity as well. Hence, if opposite poles happened to face one another (opposite or unlike poles of a magnet attract one another), the result would be a collision, a crash, and mutual destruction. This, in turn, would be followed by fusion, combination, cohesion, and a return to absolute rest; because the fused plancts as one body would again be alone in the universe. If, on the other hand, similar or like poles of the planets faced each other, the result on their nearing cach other would be mutual repulsion; consequently a sheering off from one another, ending, through the dual play of like-material-attraction and nolar-repulsion (and because rest was impossible to them, for they would be eternally from thenceforth the bottom of the universe to each other, and towards which they must fall or move), in revolving round each other, as twin stars are alleged to do.

Fifthly: It is usually assumed that the centrifugal force, or "primitive impulsion in the direction of the tangent," attributed to all sidereal bodies, would cause a planet, when released from the curb of the sun, to bolt in a straight line into space. But when we 
remember that all the heavenly bodies are constitutionally weightless, that it is merely the presence of other bodies like themselves, which, by attracting them, endows them with weight or gravity, and that, as a matter of fact, the immense distances which separate them from each other render them practically like feathers floating in the currents of the void susceptible to the slightest influences, we can easily perceive how a run-away planet's course would be determined, not by any inherent "impulsion," but by the direction from it of the nearest or most powerful sidereal body coupled with the relative position of each other's polarities. It only requires, therefore, the introduction of innumerable suns and satellites into the void, no matter how created, but all composed of magnetic atoms and endowed with polarities, to constitute such a mysterious universe as our own. A cosmos peopled with bodies falling to one another and sometimes colliding, but usually avoiding this fatality by repelling each other with their poles and joining in a brotherly dance round each other until the planetary day of doom.

As a further speculation:-It the heavenly bodies are magnets possessing magnetic and electric properties, the question may be asked, Is their light as seen by us not more or less electric? Are the stars at night not myriads of electric lamps?

Still further, in the light of hypotheses to follow, may not the Solar System be a vast electric and * See The Evolution of Irorlds. 
telegraphic system, the sun being the central battery from whence the energy is distributed to the planets, as well as the exchange to which messages are sent from all outlying sub-offices? Or may we not assume it to be a huge organism, a firmamental siphonophora floating in the void, of which the sun is the brain and the planets the outlying senses?

\section{Section 2. Cohesion:}

Definition: "Cohesion is the force which binds together the various particles of a body."

Although Tyndall and others have suggested plausible theories of cohesion, no definite cause of the phenomenon is yet endorsed by the world of science. Cohesion is merely a term for that unknown energy which binds bodies together by their invisible particles, a symbol for the effect of some unknown and invisible inter-molecular agent observed to be omnipotent in matter under certain conditions. What we require to learn, therefore, is not solely that cohesion exists-a knowledge present science seems to be content with-but the cause of cohesion. The chief facts of cohcsion indicate the existence of a subtle tie between the atoms or molecules of substance. This tie, according to the nature of the material, is such that sometimes much, and sometimes little force is required to separate the molecules again ; in fact, binding and separating forces are equal. Hence, if the energy which binds atoms together could be discovered, the problem is practically solved. 
This has, in effect, been already done, for by demonstrating how all atoms as magnets attract each other by the laws of like-material-attraction, sexual-materialselection, and polarity, we virtually prove that cohesion is caused by these primary forces.

Cohesion also includes the problems of crystallisation and cleavage. Tyndall practically solved these problems by repeating Grove's experiment of passing an electric current through a glass cylinder containing fine magnetic mud (oxide of iron) suspended in water. Previously to the introduction of the current the water was turbid and the particles promiscuously strewn in the liquid; but the moment the current passed, all set their lengths parallel to a common direction. (In effect, magnetic induction ensued.) By the manner, therefore, in which the atoms and molecules of all substances in suitable condition (all being magnets) combine by polar law, whether in regular sequence or promiscuously, we now perceive how all varieties of cohesion could be effected, all kinds of crystals built up, and all manner of cleavages produced. Tied, however, to the present law of gravitation, Tyndall was reluctantly compelled to relinquish polarity as a cause of cohesion, and to advocate-for slaty cleavage, if not for all-a theory of pressure. For further details of cohesion, see "Mineral Evolution." 
Section 3. Chemical Atraction:

Definition: Chemical attraction is the force which causes different kinds of matter to unite and transform into a new substance.

Chemical attraction, like gravity and cohesion, is merely a name for a cause unknown. Manifested, however, in diametrically opposite ways, and consequently classed into two sections-Chemical Combination, and Chemical Decomposition or Repulsion -an investigation of these phenomena separately shall probably reveal the information required.

\section{I.-Chemical Combination:}

Definition: Chemical combination is reciprocal attraction between two or more specific substances resulting in the formation of a totally different product.

Chemical combination is usually defined in textbooks as "the operation of chemical attraction,". but as this "operation" is itself unexplained, we need hardly say the definition lacks lucidity. The chief facts of chemical combination are:-

(I) It is an atomic or molecular process; that is atoms and molecules must be in a suitable free condition before they can effect combination.

(2) "Only bodies of different kinds rush together and unite after this fashion."

(3) The products of chemical combination, as carbonates, sulphates, or silicates, are bodies manifesting cohesion. 
From these facts it is obvious that chemical combination merely resolves itself into a name for a particular phase of atomic action, for:-

(I) Although the combination of simple substances, such as sulphur, phosphorus, iron, etc., is not attributed by chemists to chemical combination, yet the same laws must govern the aggregation of the atoms of simple homogeneous substances as the molecules of compound homogeneous substances, such as water, sugar, ice. Hence, from our premises, the chemical combination of simple substances, by involving atomic affinity, involves the operation of the primary law, like-material-attraction.

(2) In compound combinations where "only bodies of different kinds rush together and unite," forming first molecules and then aggregates of molecules, a reciprocal combination of metallic and non-metallic elements has occurred. Hence, the operative law in this instance is the other primary law, dual or sexucalmaterial-selection, in conjunction with like-materialattraction.

(3) Lastly, as the solid products of chemical combination more or less manifest magnetism, the cohesive law of polarity must also be involved in their up-building ; consequently, chemical combination merely constitutes the preceding condition to cohesion, both being effected by the primary laws.

As chemical combination necessarily involves production, its causes and modes of operation are, like cohesion, more fully detailed in those chapters which describe the evolution of substances. 
2.-Chemical Decomposition:

Definition.-Chemical decomposition, or chemical repulsion, is the force which reduces substances to a more elementary condition.

Contrasted with chemical combination, chemical decomposition has been almost ignored by chemists.

From our knowledge of the inevitably cyclic nature of all existence, both forces (chemicai repulsion and chemical attraction) must be indissolubly united, for all observation and experiment affirm that every manifestation of energy is dual. Every force pulling one way involves its counterpart pulling the other way. Everything built has to be demolished; everything evolved has to be dissolved; everything living has to die. All actions are but motions in circles, and all products but successions of cycles. The methods and the results, the operations and the effects, may vary, but the transitions imperceptibly glide after one another until the first break comes round again. Like spokes in an ever-going wheel, all different, yet mortised to the one central hub and swinging round the one circumference, all natural laws but dovetail into one all-comprehensive law, and tail to one another endlessly. Thus is individual motion subordinated to universal motion, and individual existence to universal existence, the great cosmos itself being but one vast mechanism ending but to begin again, a ceaseless resurrection of primary elements in primary motion, after ceaseless Days of Judgment. 
The chief facts of chemical decomposition, as commonly understood, involve principally the reduction of substances in solutions, such as sugar, salt, and alum; but the reduction of all substances to more elementary conditions practically involves the operation of the same law or laws. Thus the reduction of substances by fire and by decay are virtually effected by similar laws, more or less changed owing to the difference of conditions effecting the reduction. For example, substances of weak cohesion, easily dissolved in hot water, become atomically separated merely by the increased molecular motion of the water. Denser substances, dissolving in acids or by fire, involve (besides intense molecular motion) the operation of chemical attraction-that is, like-material-attraction and sexual-matcrial-selection. Lastly, organic substances decomposing by decay effect their action through the withdrawal of their aggregated cohesive force, or a reversal of their living magnetic current.

Chemical decomposition is thus the essential obverse principle of cyclic evolution, through which the universe becomes an endless re-creation. It is the autumn principle of universal energy which manures the fields with falling leaves for the new birth of the spring: the law which reduces the world to ashes, so that from the embers of its own decay it may arise phœnix-like, with renewed life, energy, and hope, into an ever beautiful and everlasting reality; for the living must die in order that the living may live. 


\section{CHAPTER VIII.}

\section{The Evolution of Gases and Liquids.}

HAVING learnt the materialistic alphabet, discovered the fundamental basis of existence, determined the fundamental substance of phenomena, established the fundamental agencies of evolution, and detailed the fundamental and efficient laws of energy which govern the earth, if not the universe, we now proceed to trace, link by link, that sequence of phenomena by natural causes which indubitably demonstrates the materialistic character of all evolution. Beginning with the least in production, gases and liquids, we shall gradually rise through minerals, vegetals and animals, until we reach the highest product of organised matter on earth, the most wonderful and enigmatical to man of all natural automata-man himself.

Although gases and liquids have many interesting problems, they need not detain us. It is only necessary to mention some of the more salient facts that affect our system.

In gases, the atoms are in what may be callẹd a 
free state. This is their primary or fundamental condition. All solids may be reduced to the gaseous condition, even as all gases may be solidified. Gases are thus of unparalleled importance as fundamentals, for they are the foundation of universal phenomena. Hence, whatever gases may evolic into, the germ of the evolution, be it mineral, agegetal or animal, may' be traced back to the garses.

Gases are virtually of three kinds: those composed of one element ; those of two or more elements of the same class, that is either metallic or non-metallic; and those of a mixture of metallic and non-metallic elements, constituting a scxual combination.

In nature, gases are merely mixed, like oxygen and nitrogen in the atmosphere. Sexual gases are infrequent, except in the laboratory. Production virtually begins with the sexual union of the elements, hence, when sexual union begins in nature, a liquid or a solid is more apt to be formed than a gas. Thus the all important liquid, water, is a sexual union of oxygen and hydrogen.

A most important fact for us is the homogeneousness of specific gases and specific liquids. This indicates that in the relation of the atoms and molecules to each other in gases or liquids, there must be a definite structure of some kind, showing a definite order, and, consequently, inviolable accuracy in these structural arrangements. This further indicates that all atomic properties are exerted with equal inviolability in the least as in the greatest production. 
According to the "Molecular Theory" the atoms in gases, liquids, and solids, even in diamonds, are in intense motion, this motion being a sort of zigzag millions of times in a second. The motion of atoms will thus be in degrees of intensity from a gas to a diamond.

Gases and liquids in whatever form, as products of the earth, are subject to the action of our Primary Laws.

In simple gases of one element or class, the atoms as magnets must arrange themselves by the law of Like-material-attraction, Unlike-material-repulsion, and Polarity. In sexual gases, the molecules meet, reciprocate, and arrange themselves by Dual or Sexualmaterial-selection and Polarity. Further, while the atoms and molecules are ever in intense motion, order is maintained everywhere and at all times by the ever dominant influence of polarity.

While thus demonstrating the persistent and indestructible energy of gases and liquids, a far-reaching question might arise: Is not this energy the basis of the energy of all bodies composed of the same constituents? If the gaseous atoms are the basis of all animal substance, is not their energy the basis of all animal energy, even of their life? We think so.

Further, from the inviolability with which gaseous molecules act, select, and arrange themselves, a more startling question might be: Is not this molecular accuracy the germ of all animal intelligence? We again think so, 


\section{CHAPTER IX.}

\section{The Evolution of Minerals.}

OUR chief object in this chapter is to show that a mineral, as composed of magnetic atoms, is itself a magnet, and evolved in all its diverse forms through the agency chiefly of magnetism.

A mineral is defined as " an organic body possessed of a definite chemical composition, and usually of a regular geometric form."

All minerals are crystalline, for even amorphous bodies are found to be crystalline under the microscope. Hence, as a marked grade of complexity differentiates these crystalline forms, it shall be advantageous for our system to examine them according to the order of their complexity.

Section I. Simple Geometrical Minerals:

The forms of crystals, though almost infinite, are reducible to thirteen primitive or parent types, of which nine are prisms, three octahedra, and one dodecahedron. Each mineral usually possesses a 
definite crystalline figure. There are, however, some extraordinary exceptions. For instance, calcspar comprises scveral hundred diverse crystals; while fluorite, pyrite, and baryte cach number over a hundred. Such diversity in the same substance is probably due to differing conditions during solidification, although infinitesimal adulterations probably conduce more to this effect. Still, behind all structural cccentricity, the important fact remains that no matter what figure a mineral may "sportingly" assume, the "rogues"-as gardeners would say-are all reducible to a parent type.

The deduction consequently is, that every simple or compound mineral originates from a bottom form or crystal, as already alleged. For example, gold crystallises as an octahedron, and as an element must be built up solely of atoms of gold. Hence, if we split up this octahedron into smaller pieces (a difficult operation with gold, but easy enough with other substances, such as sugar, salt, etc.), each sub-division would also be octahedric, until, after continuing the process by imagination to the smallest particle of gold, we finally resolve the atom, of gold itself into an octahedron. The visible nugget thus accurately represents the invisible and ultimate atomic form.

If this deduction be correct, each element has a special geometrical type-form; thus practically establishing (according to the number of known elements) no fewer than seventy parent types as the bottom constituents of crystalline design. Below this number 
of archetypes we cannot go, unless the elements are reduced in number, for, as atoms are eternal, so also must their forms be everlasting.

Perhaps, however, we are too precipitate. The atoms of two different elements may be otherwise differentiated, for we find unlike substances, similar in form, presenting striated or pitted surfaces. Hence, by these means, vast distinctions could be effected in the appearance of substances without involving the additional dissimilarity of geometric form. How far this masonic differentiation prevails among crystals, observation and experiment can alone determine. The general deduction, however, cannot be vitiated that each elementary atom differs in some way, either structurally or pictorially, from every other atom.

Similar reasoning is applicable to compound as to elementary substance; hence, when a compound substance exhibits a particular crystalline form, the smallest particle of that substance should also manifest the same form. But the smallest particle of a compound substance is not an atom, but a molecule; hence the crystal represents only the shape of the molecule. The molecule, however, is built up of atoms, and as every molecule of every different sub. stance necessarily contains, if not different groups of elementary atoms, at least different proportions of those groups, the molecules of different substances should also be different in form. This is quite possible, for a combination of considerably fewer than seventy archetypes could produce designs innumer- 
able. Ten thousand forms of crystals are now known, new ones are constantly being discovered, and new ones are probably as constantly being evolved.

\section{Section 2. Snow Flakes:}

In these beautiful geometrical designs there is no mere aggregation of molecules and crystals into huge enlargements of their own semblance, but a cohesion of perfectly formed molecular crystals into an artistic device. The law of mere aggregation thus yields to a higher force-a force, moreover, not unacquainted with art, for it produces illimitable designs. The artist in nature, in effect, here steps upon the scene. Who the artist is, and what the artistic laws are, we have already stated, and the following facts reveal.

A snow-flake is composed of oxygen and hydrogen, hence is a dual or sexual elementary compound. It is, however, not globular-like a drop of rain-but a fleecy mass of minute ice crystals. These crystals assume all shapes, from a confused pattern to a definite geometrical model. The perfect form is invariably hexagonal; but its design, barring this restriction, is illimitable. As snow-flakes generate in the upper atmosphere, they necessarily originate from floating particles of vapour. Each of these particles or snow-molecules is in all probability a star or sphere of six radiating points; hence, in the cohesion of those stars or spheres, the final form of snow-flakes inevitably depends upon the chance environing conditions attending their growth. A snow-molecule may thus 
constitute the nucleus of an independent snow-flake or the tag-rag and bob-tail of another. It may evolve into a complete geometrical model, or, arrested in its growth, prove only an abortion; for neither snowflakes nor men are always perfect. The whole lifehistory of a snow-flake, in its cycle from elements to elements, is consequently chance-that is, without Creator, Designer or intention on the part of any of the constituents concerned; the laws being truly irrevocable and fit for their work, but the conditions arbitrary.

What the laws are we detail in the next chapter.

Section 3. Arborescent Mincrals:

By arborescent minerals we mean those which mimic vegetals. Arborescent crystallisation is seen in the upbuilding of three varieties of natural phenomena, each representing a different aspect of the same productive energy :-

(I) Ice-ferns on freezing water, frost-ferns on window panes in winter, and similar vegetal outlines left after the evaporation of glauber salts.

(2) Lead and silver trees.

(3) Snow-shrubs.

I. Ice-Fcrns, etc.-All illustrations of arborescent crystallisation, as of mineral production generally, reveal a somewhat similar mode of formation-viz., growth by the aggregation of particles without, as distinct from assimilation among the regetals by the intussusception of particles within. 
Ice-ferns form on shallow pools of water in the street gutters or elsewhere during a slight frost, and look like feathers floating on the surface. As they are similar in appearance and in mode of formation to the frost-ferns on window panes, a description of the latter shall serve for both. The facts regarding frost-ferns are as follows :-

(a) On steaming the inside of a window pane during a hard frost, a crystal appears at various points, and grows with the rapidity of lightning by the accretion of other crystals. In every case, a central mid-rib first darts forward in a direction obviously dependent upon the depth of moisture in the area around it; but keeping pace with it, branches shoot from its sides, and from these again sub-branches, until the whole intervening area is traceried with an artistic net-work of ice-needles resembling the venation of a leaf.

(b) If several mid-ribs shoot out from one centre or root, each leaf parts company with the others.

(c) If two fronds approach from separate starting points they mutually attract, curve round and merely touch points, or lock each other in an embrace.

(d) Fronds growing downwards from the upper edge of the pane attract lower ones growing upwards.

(e) Two fronds budding from the lower edge or from a similar pole, with well-defined points and beautiful outlines, have been observed on nearing to repel and shatter each other's extremities.

(f) No ordinary objects seem to influence the 
motion of the fronds, not even an iron magnet. The energy seems to originate and end in the crystals themselves. Perhaps, however, an icicle discriminately handled might affect them.

See next chapter for an explanation of all the above phenomena.

II. Lead Trees.-If a piece of zinc be suspended in a solution of acetate of lead the invisible atoms aggregate into visibility, attach themselves to the solid metal, and gradually sprout into a miniature tree, each branch and twig repelling the other. Or, if an electric current be sent through the solution, the lead atoms instantly liberate themselves from the water particles and grow together like sprouting ferns.

The one experiment is the key to the other, for the artificial electric current constructs suddenly what the natural electric energy does slowly through the agency of the polaric laws, as we shall show anon.

III. Snow-Shmbs.-Perhaps the closest link between the mineral and vegetal kingdoms is that minute mimicry of vegetation-the "snow-shrub." Growing to the height of half an inch to an inch under abnormal conditions, its existence seems hitherto to have escaped observation. On a frozen pond, over whose dark treacherous surface the tiniest flecks of drifted snow are swept by a piercing wind, some slight excrescence of sand or pebble stops a few flying flakes and fastens them to itself. These, pining for company, snare other flying drift, lock them in their 
embrace, and build each particle as it comes in regular order and sequence, until a mimic bunch of ferns or feathers of charming design and skilful workmanship sprouts into being and defies the strength of the fiercest gale. Thus the whole ice is eventually dotted over with choice specimens of this wondrous but evanescent virgin shrubbery, ${ }^{*}$ for, on the slightest change in conditions, they tumble like toy castles into tiny cairns of crystals.

There may seem scant connection between the snow-shrub and a salt crystal, for few would dream that the same laws which built the cube of salt formed the shrub of snow; but when we learn the intervening links the conclusion is inevitable. Although we have already indicated the laws and causes of mineral design, we shall now enter more into detail.

* Something similar is seen when a thick rime encrusts the grass, but the forms are more geometrical than as borescent. 


\section{CHAPTER $\mathrm{X}$.}

\section{The Causes of Mineral Evolution.}

\section{Section I. Substance:}

Minerals are composed chiefly of metallic elements, gold, silver, iron, etc.; hence they are but a visible aggregation of the invisible atoms of the elements. In crystalline substances like ice, salt or sugar, composed of more than one element, a sexual combination of the atoms into molecules of these substances must occur before aggregation takes place.

\section{Section 2. Structure:}

From the fact that a crushed crystal only reveals lesser crystals of the same design, we assume that the atoms of each element possess a special shape. The ultimate unit of a simple elementary substance is thus a crystalline atom; and of a compound elementary substance a crystalline molecule. The basis of crystalline structure is thus a crystal of a special shape for each and every mineral; and, no matter how large the crystals may be, they are all built up of innumerable 
microscopical crystals of the same family type, solidly cohered together. Thus is inviolable likeness obtained in each mineral in the only way possible. Likeness in every plant and in every animal is also assured through a similar process, but the unit in their case is a cell.

\section{Section 3. Energy:}

The energy of simple crystals is rudimentary. The whole process consists in a mere accretion or cohesion of the ultimate atoms and molecules of crystalline substance. Still, two ways of building up material are open, an orderly and a disorderly ; the two methods constituting the difference between a labourer who only dumps stones on the ground, and an architect who constructs a magnificent temple of the same. Nature counts both labourers and architects among her subservient and omnipotent automata (her laws), each of which she uses discriminately and indiscriminately (though never intentionally) to an end. Consequently she exhibits, through her automatism, both her orderly and disorderly proclivities even in the evolution of simple crystals. Thus in the amorphous deposits of quartz, Iceland spar, and rock-salt, mere indiscriminate piling up of the ultimate atoms or molecules of each substance takes place. On the other hand, in the internal structure and design of these substances, we see method, order, and the evidence of a discriminate designing force.

The law's which rule this order and disorder in all 
crystals may here be summarised and their action beautifully illustrated by evaporating solutions of sugar, salt, or alum. If these substances be allowed to cool slowly, the crystals are large and transparent; if suddenly, they are minute and opaque. Again, if powdered alum and sulphate of copper be mixed and then dissolved in hot water, the solution, on cooling, shows the colourless crystals of alum and the blue crystals of copper sulphate neatly separated from one another.

(a) All laws in their effects are swayed by controlling conditions. Like laws operating in like materials produce different results at different times-small or large crystals for instance-solely because environing conditions differ. Slow motion involves slow selection, rapid motion rapid selection, with the consequent corresponding productions, perfect and imperfect. In crystallisation, as in other effects of the primary laws, a law of selection obtains. Thus alum and copper combine into distinct crystals by the simplest and most fundamental law in nature-like-matcrial-attraction (.r selection. This law also undoubtedly accounts for the occurrence of separate beds of calc-spar, fluorspar, heavy-spar, fel-spar, quartz, etc. ; for in all probability the earth during the formation of those constituents of its crust was a slowly cooling body, thus allowing like-material-selection ample time to assert itself.

(b) The fact that alum and copper sulphate are compound substances evinces the influence of another 
law in their crystallisation. Alum is composed of three metallic elements-aluminium, potassium, and hydrogen; and two non-metallics, oxygen and sulphur. It is thus a dual or sexual substance, built up of compound molecules. In an evaporating solution of alum, consequently, the separate elementary atoms, discovering their affinities, rush together in certain proportions and form molecules of alum: the acting law being the dual one of sexual-material-selection. Nextly, the molecules in turn aggregate into alum crystals by the primary law of like-material-attraction, the process and the results throughout being wholly automatic. Further, when we realise that the same laws in a compound solution build up, besides alum crystals, separate crystals of copper sulphate-each law, so to speak, interpenetrating the other-we are filled with wonder at the infinite diffusion, unerring accuracy, and infallible "intelligence" of natural automata.

(c) The fact that better order, larger crystals, and more beautiful forms are produced by slow than fast selection indicates, in addition to the preceding laws, the influence of a methodical form-selector or designing power in nature. This power, as already demonstrated, is the other automatic law-polarity.

All substances through their atomic, magnetic, or primary constitution are themselves magnetic; hence, when any substance is in a condition to indicate form, as in a slowly evaporating crystalline solution, the polar laws strike in between the laws of like and scxuch-matcrial-selections, and direct that while these 
laws are operating, the crystalline cohesion shall be polar.

For example, in the hot solution of alum the constituent atoms are more or less in disorder owing to the excessive motion and antagonistic affinities; but on cooling slowly down, solidification begins, at some point accidentally determined upon by conditions, and a molecule crystallises. From this crystal magnetic induction practically commences, pervades the molecules next it and attracts them polarly. Thus cohesion proceeds, linking like pole to unlike pole in regular order and sequence until it converts the liquid not only into a large clear solid, but a beautiful geometric crystal.

(d) Although scarcely a law, the element of time obtrudes unbidden in the above experiment, as a potent factor in natural production. Nature is truly equal to all emergencies, and builds both quickly and slowly, but the medley of precipitation rivals not the masterpiece of deliberation. Deliberate operations involve the element of time. If particular products be required, nature can no more be hurried than any other machine; and if time be not granted, abortion is the result.

But time is only regular and deliberate motion; hence, as every formation is the result of a certain series of motions, this series must be uninterruptedly performed, or the product correspondingly varies. This element of time, in its relation to motion as heat, constitutes an important factor, even in such a 
prosaic thing as cooking; showing how artificial as well as natural products are subject to the same inviolable laws.

The importance of time in natural operations has hitherto been ignored, save by evolutionists, yet its causal effects are startling. As a rule, the complexity, size, and beauty of a product are in a corresponding ratio to the time of its formation. Simple products, because involving few and simple motions, require a short time; while complex products and organisms, involving innumerable and intricate motions, require a long time. For example, a salt crystal may be deposited in a second, while a baby in its metamorphoses occupies nine months. In pre-evolution days, men credited a Deity with creating a man in an instant by the word of His power; now, we know that the machinery of nature itself would stop before such a miracle could be accomplished.

(c) The immutability of law and form is well exemplified in crystals, even in seeming exceptions to the general rule. For example, in the hundreds of diverse forms displayed by calc-spar, the parent type is not lost, but hidden, for cleavage invariably reveals it. It is thus worthy of note, that the phenomena of "variation and reversion to an original type" appear for the first time in crystalline production; a fact conveying a significant bearing on present evolutionary problems. 
Section 4. Form:

From the context it will now be realised that form eternally exists in nature. Form is a necessity of the mere existence of atoms having form. As nature thus works with material inherently possessed of form, her difficulty in evolution would be, not to produce something with form, but something without form. Hence natural forms are necessary and illimitable, for the mere mixture and aggregation of substances possessed of seventy different forms, would, like a natural kaleidoscope, produce crystalline designs innumerable.

Section 5. Design:

While the simplest mineral forms, such as the crystals, are produced solely by accretion; the snowflakes, frost-ferns, lead trees, and snow-shrubs are complex designs, produced by the great natural designing law Polarity. The omnipresence of design in nature has long been one of the great arguments of the ignorant in favour of the Divine creation of the universe. "Design," they say, "involves a Designer." This may be true enough but it does not involve a Deity. Design certainly involves a canse of design, but this cause as we have shown is a mere law.

Design, moreover, is a term coined by man to signify a certain order or arrangement of forms. But this order may arise quite unintentionally on the part of the agents concerned: a point overlooked. Thus the dropping of water on a basket on 
a frosty night produces a beautiful arrangement of icicles. The print of crows' or gulls' feet on the wet sands produces a beautiful gothic enrichment. The lapping of the waves on the sea-shore forms a glistening fringe of many curves; and the receding tide ploughs the sand into many picturesque furrows. These, however, are only designs because man calls them so. Nature does not intentionally produce designs for her own delectation, or for man's admiration, as some child-like theologians assert. The object of nature, indeed, is not to produce a design, but a "something" whether it be a design or not. The design is a very secondary consideration to the "something." It is the "something" alone which is of importance.

Seeing, however, that theologians have invested design with quite unnecessary moment-chiefly as a means of deluding the credulous-we shall endeavour to minimise the consequences of their wiles by showing how even snow-flakes and the higher crystalline designs are produced by the automatic laws.

A snow-flake is evolved from a, snow-flake molecule, which in turn is evolved from a chemical union of dual atoms-oxygen and hydrogen-by the law of sexual-material-selection. This molecule we deduce from analogy to be six-pointed.* Further, as the molecule is composed of atoms, it acquires, according

* Ice, as Tyndall demonstrated, is a structure built up of hexagonal figures, resembling six-petalled flowers. 
to its constitution, molccular affinity or like-materialattraction; consequently, it attracts and attaches to itself other like molecules. But, as atoms are magnets, the molecules themselves also become magnets with polarity; hence, our nucleus molecule does not attract and cohere other molecules indiscriminately, but discriminately or polarly. As the nucleus molecule is six-pointed, it practically possesses six poles or points of force, for each limb of the star manifests equal energy of attraction and repulsion; consequently, in a condensing or crystallising medium such as vapour, all the limbs of the flake attract and aggregate the molecules equally, thus preserving the typical star-pattern; although the ornamentation or design of the spokes may differ infinitely in detail.

This fretwork, however, is still the effect of the same law, for, as shown by a magnet and iron filings, the same pole which attracts the filings also repels them, each filament also repelling every other filament on the same pole. Similarly with the star limbs on a snow-flake; each limb not only attracts the crystals, but repels them when attracted and attached. Thus, this alternate or clual attraction by one end of a crystal and repulsion by the other end, if undisturbed, eventually produces-though unintentionally on the part of the snow-flake or any of its constituentswhat man calls a "design."

In frost-ferns the design of the crystals is also effected by polarity. That is, the crystals in the mid-rib of the frost-fern and all the branches are, on 
being attracted, polarised or magnetically induced, hence they assume the polarity of their particular rib and branch. In a perfect magnetic body the constituent atoms are polarly arranged from end to end; the positive poles pointing one way, the negative poles the other way. Hence, when a crystal becomes attached to the main body of a frond, its projecting end becomes a pole and assumes the same polarity as the end of the frond to which it is attached. All projecting ends on the one pole being thus of like polarity, polar law supervenes and causes them and their attached crystals to repel one another; the result and effect being designs of infinite complexity.

In that parody of regetation, the snow-shrub, we obtain the clearest glimpse of the transition between mineral and vegetal energy; for here, more than in any other mineral, gravity is disregarded and a stronger force manifested. Here too, as in frostferns, the family form is discarded, and the primary crystalline type developed and improved by the action of like-polar-repulsion. Still the hexagons are not altogether abolished, for they still exist in the minute crystals or molecules themselves; as is demonstrated by the experiment of casting a beam of heat through ice. The problem, however, remains: How do we account for the stiff geometric figures of the simpler crystals being abandoned in favour of the freer forms of the vegetal kingdom? What determines the aggregation on vegetal rather than on mineral lines? To answer these questions 
fully we require to enlarge our basis of energy. This we do as follows :-

The earth as a magnet exudes energy from its entire surface; in most intensity, however, near the poles. This upward force is ever at work converting every projecting point of matter above the local surface of the globe into a pole of either north or south polarity: a fact well exemplified by all stationary iron work-gates, railings, lamp-posts, rain-conductors, railway bridges, even the Crystal Palace and the Forth Bridge-manifesting, in our latitudes, a north polarity at their tops and a south polarity at their bases.*

The pebble or excrescence raised above the surface of the ice is thus a minute pole to the earth, not truly exuding much force, but sufficient to attract and repel minute objects. This force is increased when ice or snow particles accidentally drift in behind it : for the strength of a natural, as of an artificial magnet, is according to its size.

The mid-rib of a snow-leaf, accompanied by sideribs as in the frost-fern, thus shoots up by polaric law, and is added to by like-material-attraction from the clouds of flying drift until, as described, a complete leaf or feather is formed by the concerted influence of the primary laws. Other mid-ribs and leaves from the same root also shoot up and become completed, each leaf necessarily repelling the other (like poles

* Every mountain, consequently, should be a pole, and ought to deflect slightly the needle of a passing balloon. 
repelling) until eventually a magnetised bunch of ice particles is formed.

It will now be obvious that the cause of the mimicry of tree growth in the mineral kingdom is strikingly suggestive of the cause of genuine tree growth in the vegetal kingdom, a coincidence also noticed by Tyndall, in his lecture on "Crystalline and Molecular Forces." Whether there is more in the phenomenon than a coincidence remains to be seen.

\section{Section 6. Life:}

The term "life" has not hitherto been associated with minerals, yet if a frost-fern, a lead tree, or a snow-shrub grozes, there can be no fundamental distinction, for all life at bottom is merely motion. 'The processes of growing may differ, but the laws are the same. This admission, however, would dispel one of the great mysteries of existence, the "Origin of Life."

The solution of this problem has always been the ultima thule of science, and its mystery, the Zion of all human superstition. Its insolubility is responsible for heaven as well as for hell, and is even god-father to the devil. Naturally enough its non-discovery is a standing reproach to science and the highest human intelligence, although a godsend to bigotry, priestcraft and cant.

That the origin of life has remained an enigma until the present day, is as much owing to the 
fantastic methods scientists have adopted to unravel it, as to the fear of the superstitious to approach it. If a traveller exploring the Nile stopped at the First Cataract and declared any other source undiscoverable because his boat could ascend no higher, we should call him a fool. Similar measure ought to be meted out to those specialists who adopt similar tactics while professing to discover the source of life. Scientists have probed, massacred, and dissected innumerable living things to the horror of the antivivisectionists for years, and because the death of the animal stopped further examination, or its bared bones and muscles showed no mysterious stream of vitality leading from the known into the unknown, or from the organic into the inorganic, the origin of life was dubbed a mystery, its ken transcendental, its source supernatural and undiscoverable, and any attempt to penetrate its secret dangerous.

Life has thus ever been erroneously restricted to vegetals and animals, because men persisted in ignoring the fundamental basis of all life, material encrgy. That life reduced to its elementary form, as a mode of motion in matter, must be related more or less to all modes of motion in matter, is inevitable. Hence, it must exist rudimentarily, not only in minerals, liquids, gases, and molecules, but in the atoms themselves. In other words, encrgy and life are fundamentally identical.

As man writes his science and philosophy solely for himself, to suit himself, and to coincide with 
either his wisdom or his ignorance, he is indeed quite at liberty to restrict the term life, as a secondary or complex natural energy, to vegetals or animals or any other organisms he chooses. But when a scientist refuses to trace life's origin below vegetals and animals, either he is wilfully trying to blindfold humanity, or he is exposing his ignorance, vanity, and incapacity.

The striking parodies of vegetal forms by minerals should warn us against a too exclusive classification, for nature does not produce a likeness in form without a likeness also in the law of form. Man, however, and particularly a specialist, is terribly conceited in his opinions. He invariably forgets that he but stands on a transitory pinnacle of knowledge. His horizon may truly be to-day unbroken, and his learning the apex of his century; but to-morrow and succeeding days other pinnacles shoot up and overshadow him until he is left as but a gargoyle in the depths of ignorance below.

Consistently, therefore, with our materialistic system, we class energy and life as identical in origin and evolution, no matter what differences may arise in their subsequent manifestations. We have thus no need to trace the origin and evolution of life separately from the origin and evolution of energy. But in our investigations into the evolution of vegetals and animals in succeeding chapters, we shall eventually show that life in them is but an evolution of the simpler energies of the minerals, the chief being magnetism. The so-called mystery of life s'all thus 
be seen to consist solely in the web of artifice and chicanery which ignorant and interested men have woven around it.

The picture which this view of life thus presents of a cosmos alive even to its crystals, its molecules, and its atoms, is a conception fraught with disaster to those paracletes of dogma and creed who batten upon superstition. But it is strictly in keeping with the grandeur of existence itself as a mighty whole, in which man and all his works shall prove but transient shows over which the dust of ages shall silently snow, until he and they are shrouded for ever in the debris of eternity.

Section 7. The Erolution of Mincral Intclligence:

That a mineral has intelligence seems preposterous, but the preposterousness may lie solely in the vanity and ignorance of those wiseacres who, from an inadequate comprehension of the phenomena really involved by, and included in, the operations covered by the term mind, entertain a ridiculously conservative notion of its limits and meaning.

That a mineral is self-conscious-that is, conscious of its own existence and action as a mineral-does not seem possible; yet that it is in a sense conscious (or call it by what other name we choose) of other matter, and especially of other matter like itself, cannot be clenied. Thus its power of discrimination in selecting the right and rejecting the wrong substance in crystallization, shows a virtual knowledge of the 
difference between one substance and another. This is even extended to the porver of sexual-materialselection for the purposes of production, as already explained. That those actions are reflex, produced automatically, does not vitiate our postulation, for no accurate definition of automatism could be enunciated which did not include 99 , if not I00 per cent. of even man's intelligent actions, as we shall show anon.

We thus assert and shall eventually prove that intelligence at bottom is merely the accurate automatic action, or selective attraction and repulsion, of the atoms.

Intelligence trı all phenomena truly differs infinitely in complexity, yet this complexity is a difference in degree, not in kind. It is simply that difference which is inevitable between an atom and its simple mind, and a body composed of innumerable atoms and its complex mind. The structure of the complex body and complex mind of course introduces infinite and wonderful complexities, but these do not affect the fundamental origin of intelligence. There is the same relation between them as between a dictionary and a philosophy: as infinite philosophies may be produced from the one dictionary, so infinite intelligences may be evolved from the one alphabet of elementary atoms and their energies. There is thus no necessity for postulating a Divine Mind in nature, when all nature is constructed of atomic minds, which are both eternal and indestructible, and in a sense both omniscient and omnipotent. By this viev, 
the whole cosmos glows with intelligence, the continued accretion of atomic minds evolving into higher and ever higher grades of being, adorned with ever brighter and subtler halos of intelligence and cunning, until they culminate in those rarest intellectual exotics known to man-metaphysicians. 


\section{CHAPTER XI.}

The Evolution of Vegetals.

REGARDING the evolution of the contents of the vegetal kingdom, our object shall be to show that plants like crystals are automata, that they grow by automatic laws, and that these laws are the same as those which govern all things in the universe. The plants to which we shall in brief fashion call attention, and the lessons to be drawn from them, shall unmistakably reveal the materialistic nature of their origin, their unintentional design, the devious modes of their haphazard natural development, and the reason why their mode of living raises such a barrier between them and other natural products, that it precludes their progression beyond the confines of the vegetal kingdom.

Man's beliefs are generally, but not always, according to his knowledge, hence, if his knowledge be scant, his opinions are correspondingiy grotesque. With the exception of specialists, few average men of intelligence know more about plants than a kitchen garden reveals 
and until they are led to read up the subject have no notion of the wonderful world of plant life in the planet and unconscious that they have even incipient rivals in intelligence and attainments among the vegetals.

In order to dispel this ignorance to a certain extent, and help at the same time to demonstrate the accuracy of our contentions, we shall give a rapid survey of the more curious species of plants, their forms and functions, from the simplest to the most complex.

(I) The lowest class of vegetals are the fungi, yet some, through their highly specialised functions, approach nearer to animals than many flowering plants.

All fungi are either saprophytic (feeding on dead or decaying vegetal and animal matter) or parasitic (feeding on living plants and animals). The saprophytes are the vultures of vegetal existence, living solely upon vegetal carrion. In a sense, therefore, they are not noxious and useless, for, like the vultures in the tropics, and the dogs in Constantinople, they are the scavengers of regetalia. The automatic cause of this mode of life is their non-possession of chlorophyll (the green pigment of vegetals). Being unable, without chlorophyll, to assimilate carbon compounds for themselves, they are forced to rob it from dead or decaying plants.

Few fungi attain to any great size, while many are microscopic. Though the lowest fungus (phycomycetes) consists of one single densely branching cell, fungi 
generally are built up of a series of cells placed end on end. The forms of fungi are infinite; but few represent the ideal vegetal type, with roots, stem and branches, save rudimentarily.

The number of species of fungi is, from their microscopic character and their universal distribution, necessarily unknown; but as over a thousand species of one class alone (mushrooms) grow in Great Britain, we may infer their number to be legion.

(2) Seaweeds, of the order algæe, are composed entirely of cells, which become in some cases like elongated tubes. The species macrocystis is of immense size, some plants occasionally measuring from 300 to 700 feet long. A tree seaweed off Patagonia is ro feet high and 12 inches in circumference. Many algæ, on the other hand, are microscopic-diatoms, for instance. These minute plants were, like bacteria, once classed as animals, but they might now be more advantageously enrolled among a number of organisms (including corals) which are representative of the forms and energy of the whole three kingdoms of nature-mineral, vegetal and animal. Thus they are connected with the mineral world by their beautiful silicious and flinty coatings, strangely marked and wondrously designed; with the vegetal, because containing cellulose and chlorophyll; and with the animal, because they conjugate and generate motile spores. They are thus "a materialised trinity."

The corallines, again, illustrate the transition solely 
between the mineral and vegetal kingdoms, for a coating of calcareous inatter conceals their cellulose tissue. In some algæ the cells contain not only vacuoles - cavities containing cell-sap (water with various substances in solution) - but pulsating or contractile vacuoles, common also to the amøba-virtually the stomachs of the cells. These phenomena still further indicate the close relationship subsisting between vegetals and animals.

One of the simplest of algæ is the minute red snow plant (protococcus) whose whole organism consists of a single cell. Root, stem, and leaves in one, it absorbs nourishment through its cell wall. As the cells often adhere in a viscous mass, they probably reproduce by conjugation; or perhaps, like amœbæ they contain within themselves the discordant elements of their own disunion. In any case, they multiply by celldivision, the cell splitting up into four parts, each with a nucleus, and each eventually becoming a full-grown plant. Lichens have recently been shown to be a combination of two plants, algæ and fungi, bound together in intimate union.

(3) To leave the cryptogams and enter the higher sub-kingdom of phanerogams, we are attracted by the climbing plants, of which there are many kinds.

Climbing plants may be classified under five heads :-

(a) Rootlet climbers; (b) hook climbers; (c) stem climbers; (d) leaf climbers; (e) tendril climbers.

(a) The rootlet climbers are the ivy and a kind of 
fig, investigated by Darwin, which secrete a viscid fluid by their rootlets and so stick and climb.

(b) The hook climbers are the roses, brambles, yellow bedstraw, etc., whose hooks are familiar.

(c) The stem climbers are the hop and convolvulus. Here the climbing is effected by "circumnutation"; the growing stem swings slowly round in the air, and describes a complete circle in two hours and eight minutes. If it strikes a support it continues to twine until it clasps it.

(d) The leaf-climbers are the gloriosa, clematis, nasturtium, etc. These clasp supports with modified tips of the leaves and with the leaf-stalk, circumnutation assisting.

(e) The highest grade of climbing plants, the tendril-bearers, comprise the passion-flower, grapevine, virginia creeper, pea, sweet pea, sarsaparilla, bignonia, cucumber, etc. When we see the tendrils, like the feelers of a snail, searching in all directions and clutching supports, we are inclined to accord to these plants the attribute of consciousness and of intention to seek for assistance; but investigation proves that the motion is only mechanical and automatic. The tendril does not instantly clasp a support as if it knew it for such; yet that it does in its own way know a support is evinced by its ultimate action in clasping it. That vegetal knowledge or consciousness is not animal intelligence is of course understood, but that a climber's intelligence (or call it by what name we choose) is higher than the equivalent of the same 
functions or attributes in simple flowerless or flowering plants, is not to be denied.

In this evolution of vegetal mechanism and function, the higher classes of climbing plants may or may not be evolved from the same parent types as the lower. Each species could quite independently evolve the climbing habit, even although it was absent in the parental type. Varying conditions, for instance, could by natural selection gradually evolve modifications in the structures of different species of plants which would be quite able to effect that special purpose. Thus, all the climbing organs in vegetals are but modifications of normal organs. The rootlets are but modified roots, and the hooks and spines but metamorphosed leaves; the tendrils of the passionflower are a whole branch transformed; those of the vine, a flower peduncle; those of the ordinary pea, a modification of certain of the leaflets; those of the sweet-pea, the whole blade of the leaf; and those of the sarsaparilla and cucumber, simply an alteration in the stipules. Lastly, the common grape-vine displays the whole series of gradations between the ordinary flower-stalks and the tendrils of the vine, while the berberry shows all the gradations between a leaf and a spine.

Many plants, such as the whin, gorse, or furze, modify their foliar organs into spines and prickles, although non-climbers. We thus see that as variation and modification of organs happen accidentally in all plants, climbing plants need not be correlated, much 
less evolved from one another. Intelligence has no aristocratic pedigree, still less a divine origin; mind is not transmitted by inheritance, even as genius does not run in families. Condition, position, and opportunity are the chief as they are also the chance elements of success with vegetals as with animals.

(4) Mechanism is usually associated with artificial machinery; but the physicist recognises mechanical operations in, and applies mechanical terms to, the simplest natural processes. Every plant, scientifically, is more or less of a machine, the more complex necessarily containing more parts, and consequently evolving more complex and numerous motions.

The genesis of vegetal mechanism and motion commences low down in the scale, and may be strikingly seen in the sunflower slowly turning its huge head sunwards as our great luminary travels from east to west; ${ }^{*}$ in tulips and innumerable other flowers and leaves sleeping; and in twining plants circumnutating. In the orchids, however, the highest flights of mechanical genius are attained. Their mechanisms indeed remind us of mouse-traps, gins, snares, and other human contrivances. All are associated with the processes of reproduction, especially fertilisation, and, strange to say, birds and insects are introduced as unwitting partners in the business. One of the simplest contrivances (in the salvia) displays a cross-bar lightly balanced on a filament, loaded with pollen in an anther at one end. The associate insect

* Undoubtedly a magnetic attraction. 
on entering the flower strikes the empty end of the cross-bar with its head, tilts it over, unconsciously tips the pollen on its own back, and then so loaded, flies away and fertilises another flower: for the stigma of the orchid brushes off the pollen on the insect's entrance, and so becomes fertilised.

In the catasetum, when a bee lands on the labellum of a male plant, a sensitive projection is touched; this in turn ruptures a certain membrane, which again sets free a spring, and this spring automatically shoots a mass of pollen on the bee's back. This pollen is brushed off on the next female plant visited. In our native orchids, although hermaphrodite, the pollen does not fertilise its own stigma, for Darwin discovered the pollinia sticking by viscid disks to the heads of visiting butterflies and moths. These pollinia thus fertilise the stigma of the next flower entered. The process, however, is all automatic, not intentionally performed by either butterfly or flower, for if a fine pencil be inserted into the orchid the pollinia adhere also to it. The plant thus possesses no discrimination; its intelligence is solely automatic, and is the result of ages of imperceptible modifications, automatically developed by it in its automatically going machinery.

The large orchid caryanthes displays the most remarkable contrivance, in the shape of a bucket in its labellum into which water is constantly dropping from secreting horns above. When half full, the water overflows by a spout on one side. In the arch of the 
spout lies the viscid stigma, and next it the viscid glands of the pollen masses. Above the bucket bees come to feed on the fleshy ridges of the labellum, and as they crowd one another some tumble into the water. As they cannot fly away with wet wings, they crawl out through the spout, brushing some of the pollen off in their exit. On tumbling into the bath of another caryanthes, they thus fertilise its stigma on their road out again.

The evolution of such complicated mechanisms seems beyond the compass of the slow automatic improvements accomplished by natural selection alone, and would appear to involve a Designer. But all evidence demonstrates that even the most wonderful natural contrivances are quite capable of being effected by unconscious automatic agencies, provided we only grant time enough. And of time there is ever a plethora in natural operations.

(5) Leading biologists lately distinguished vegetals from animals by ascribing only to animals the possession of nerves and a nervous system. But further researches demonstrated that nerves were no more indispensible to nervous action than muscles are to organic motion. If nervous action be simply the property of transmitting influence from one part of an organism to another, then plants, if not as nervous as animals, are at least as much so as their mechanism permits. As Huxley says, " a nerve is in essence nothing but a linear tract of specially modified protoplasm between two points of an organism, one of 
which is able to affect the other by means of the communication so established. Hence the simplest living being may possess a nervous system." * From experiments performed on the growing roots of the common bean, pea, scarlet-runner, etc., Darwin demonstrated that the radicles are sensitive to obstruction, and communicate influences which cause parts of the radicles higher up to bend away from the obstacle. By applying caustic and cutting thin slices off the radicles, he also induced them to swerve from the side of irritation. The most striking instance of nervous action is, however, witnessed in the well-known sensitive-plant which crumples up at a touch.

For our purpose it is unnecessary to enlarge on this subject; for; whatever be the mode by which these nervous-like influences are transmitted, the genesis of nervous action undoubtedly reveals itself in plants. Nerves are unnecessary if media exist which act as nerves. In support of our contention that plants are magnets, Huxley says, "the act of contraction is accompanied by a disturbance of the elcctrical state of the contractile substance," even as it similarly affects the muscles of animals. Further, as words of pregnant meaning, he says, "it does not seem to be distinguishable from what is called reflex action in animals." $\dagger$

(6) Parasitical Plants. - The lowest vegetal parasites are the fungi, and by their likeness in function to animal parasites, in preying not only upon other 
vegetals but on animals, they rival the highest vegetal carnivora. The habits of the two, however, are quite dissimilar.

One fungus (chytridica) consists only of a sporangial cell which attacks fresh water algæ and infusoria. It is maintained in position by, and draws its nourishment through, a haustorium (or rootlet) which penetrates the host cell. (The victim of a parasite is termed the host).

Empusa musce is a fungus common on the ordinary house-fly which ramifies its rootlets through the insect's body. The salmon disease is caused by the saprolegnia ferax-a fungus both saprophytic and paràsitic, for it attacks the salmon alive or dead. Besicles fungi, other vegetals more exalted in the scale of life are equally dependent upon other plants for subsistence. Thus the dodder (cuscutur) first entwines its victim, then penetrates it with its haustoria as far as the vascular system, and thenceforth draws all its nourishment from it, its own root dropping off and connection with the soil entirely ceasing.

The mistletoe adheres by its viscid fruit to various trees (apple, lime, elm, maple, willow, thorn, pop!ar), and on the seed germinating, its rootlets penetrate the wood and absorb the juices; the robbery often causing the deformation of the limb to which it is attached.

The dependence of vegetal parasites upon hosts results, as already said, from the absence of chlorophyll, and consequently from an inadequate supply of assim- 
ilative power. In other words, not being able to digest their food raw, they seek it cooked. They are thus the vagrants or tramps of vegetal existence, with no fixed home, and preferring stealing to working. Sometimes, however, they entail on themselves retributive justice, for not infrequently the vampires ensure their own death by exhausting their food supply in sucking out the life-blood of their victims.

(7) Insectivorous Plants.-People are now familiar with the story of the sun-dew and its allies: the highest class of vegetals from an evolutionary point of view, because they perform functions akin to those of animals. The transition from the vegetal, which only absorbs inorganic materials through its root and leaf-cells, to the sun-dew which bolts its food whole, is, however, by no means sudden. A gradual taste for flesh develops itself far down in the scale of plant life, but it only attains its climax in the real vegetal carnivora. The complexity of mechanism, too, which culminates in the sudden closure of the Venus's flytrap at the slightest touch, has also its source in a lower grade.

The power of digesting solid matter commences with "London pride" (saxifrages), primula and pelargonium. These plants have gradually evolved absorbent glandular hairs upon their stems and leaves which possess the property of rapidly absorbing animal matter. Nextly, the butterwort (pinguicula) secretes a viscid fluid on its hairy leaves, and digests dead matter dropped on them by the wind or otherwise. 
Then follow the pitcher-plants of America, East India, and China, with mechanisms which entice unwary insects into their reservoirs, then drown and absorb them.

The aquatic bladderwort (utricularia) has cunningly devised bladders attached to its leaves for entrapping inquisitive insects. The entrance to the bladder is guarded by bristles and fitted with a valve or trapdoor opening only inwards and sloping downwards into the well. Once an insect forces its way in, the trap-door closes, escape is impossible, the prisoner drowns in the tank and another meal has been earned.

Another similar plant (genlisea), a native of Brazil, has a long neck leading to the bladder provided with sharp hairs pointing downwards, which invite the animals to walk in, but effectually bar their passage out.

Omitting some intermediate insect-eaters, we come to the celebrated sun-dew (drosera). This tiny plant has six leaves spread open, upon which are stalks projecting upwards, each tipped with a drop of viscid fluid. On an insect touching one of these glistening glands it sticks, more fluid is secreted, the animal sinks down clogged, the leaves rise up and close upon it, and the unlucky trespasser is slowly suffocated, digested and absorbed.

Lastly, the highest development of the vegetal carnivora is reached in the Venus's fly-trap (dionea muscipula). Here the leaves double up, and on their 
edges are rows of spikes which interlock when closed. Each half of the leaf contains three filaments, sensitive to the slightest touch. On an insect alighting and touching one of those filaments, the two halves instantly clasp together and interlock. Small prisoners thus caged may still escape, but if the prey be large and worth digesting, the leaves tighten, the glands secrete more fluid, and the victim is slowly suffocated and absorbed as before.

The sun-dew and fly-trap possess considerable discriminative power. Water and dry leaves dropped on them are unnoticed; pebbles and such like are rejected; but meat, white of egg, and nitrogenous substances are quickly seized and assimilated.

Although thus possessing the functions of the lowest animals these bloodthirsty insectivora are still vegetals. They have roots, stems, leaves, and absorb nourishment in the usual way; but they are epicures, and having acquired a taste for flesh indulge it to the full.

(8) The most curious and in some ways the most highly developed of the vegetals are the Protophyta, a half-vegetal, half-animal organism, which constitutes the "missing link" between plants and animals. We shall only notice the more curious of the order.

(a) Bacteria.-Dr Bastian alleges that a bacterium can, at the will of the experimenter, be resolved either into a vegetal or an animal, according as its conditions of existence are prepared.* In some cases an addition of more non-metallic elements, or more light and heat, 
is sufficient to transfer the organism from the one kingdom to the other. Their fecundity is extraordinary, for Cohn calculates that a single bacterium could in three days produce uncounted millions.*

(b) Swarm-spores.-Many simple organised cryptogamic plants generate peculiar fertile and locomotive asexual cells, called swarm-spores or oosphores, virtually the egg-seeds of those plants. Sometimes they mimic amobre in their motions, but more frequently, provided with minute vibratile cilia or strongly developed flagella of their own protoplasm, they lash the surrounding water and travel rapidly from place to place.

These cilia and flagella are indistinguishable from similar structures in animals, only, instead of remaining transitory films of jelly, they develop into clearly defined organs of constant form. Thus, in man (whose wind-pipe and bronchix they clothe with a continuous layer), the vibratile cilia are simply prolongations of the cellular protoplasm, which, having lost the faculty of changing form, yet preserve the primordial function of movement.

Swarm-spores avoid obstacles, advance and retire at pleasure, and are sometimes fascinated and sometimes repelled by light. Sooner or later they anchor themselves to a rock, become comatose, roots spring

* Man's alimentary canal is thronged with bacteria which prepare the food for its passage through the intestines into the blood vessels. Some biologists thus facetiously ask if man is an individual or a colony of individuals. 
from them, and the animal through a deathless resurrection revives as a vegetal.

In adogonium, one of the fresh-water algæ, swarmspores originate by "rejuvenescence." Thus an adult cell contracts, changes from the cylindrical to the globular shape, shoots out vibratile cilia, ruptures its cellulose wall, escapes as a swarm-spore, enjoys for a time the free life of an animal, but eventually rests, becomes paralysed, and grows into a plant.

(c) Antherozoids.-In those cryptogamic plants which generate sexually, the female element is called the spore, the male the antherozoid or spermatozoid. In the marine alga (fucus vesiculosus) the antherozoid is an ovoid body with two vibratile lashes, and very active. In ferns and horse-tails (equisetum) the antherozoid is wound like a cork-screw and provided at its anterior part with quite a number of long vibratile cilia. Mosses and chare generate similar antherozoids, rolled like a helix and furnished with two vibratile cilia. In all respects nothing essential distinguishes these motor cilia of cryptogamic seed elements from the cilia of the zoospores of the protozoic radiolarians.

In many spores the strange phenomenon termed "alternation of generations" is witnessed. Here we see the curious anomaly of an organism transforming through a series of animal and vegetal moults, until it ultimately reverts to the parent type of plant. It is, in fact, the first appearance on the stage of life of the important phenomenon of metamorphosis, so 
common to higher animal forms, and of immense importance from the materialistic point of view, as we shall see anon.

(d) Motor Colonies of Plants.-Among the algæ, the plants volvoces, stephanospherce, and gonia form gelatinous masses of diverse shapes, and so constitute virtual motor colonies of protophyta. Beneath their rounded surface numerous green cells, provided with vibratile cilia, lash the surrounding water until the whole colony voyages along. Anon the mass fractures, the cells become free, each protophyte propels itself as an independent animal, and eventually, after undergoing various metamorphoses, they stiffen and revert to the ancestral vegetal type.

(e) A Vegetal an Imprisoned Animal.-In the hairs of the tradescantia virginica, stinging hairs of nettles, stellate hairs of althea rosea, etc., the protoplasm in the cells confined by the cellulose wall does not project its pseudopodia outside but inside; while it also crawls about like an amœba and stretches its thin filaments across the internal cavities of the plant. Prevented from fishing without, it fishes within, and is thus in all essentials a closely imprisoned protozoon ; for if the protoplasm be liberated, as in rupturing the unicellular alga vaucheria, it throws out pseudopodial projections and exhibits amoboid movements.

This vegetal bondage anon develops into a similar kind of animal bondage; hence slavery finds ample warrant throughout the whole vegetal and animal 
kingdoms, until it reaches an uncomfortable climax in man himself, unconsciously imprisoning hundreds of thousands of living animals (white corpuscles, virtual amœbr) in his blood. Again it may be asked, is man an individual or a colony?

(f) Twin Vegetal and Animal Life.-Perhaps the most curious organisms in nature are the young gonophores of vilella. These animals contain plants, and, strange to say, virtually live upon one another by feeding each other with their waste products. Thus the young gonophore, after budding from the parent, starts existence with a life-long provision of algr; for the living vegetal is a veritable widow's cruse, whose store of oil never runs dry, because it is ever renewed from its comrade's waste. Both the animal and the vegetal undoubtedly partially feed upon the inorganic elements in the surrounding water, but each also supplies the other with solid food. Thus the animal cell furnishes the vegetal cell with abundance of carbonic anhydride and nitrogenous waste (and is sufficiently transparent to admit the necessary light), while the vegetal, in return, yields oxygen and starch, and is itself digestible should it unfortunately die before its partner. No morè ideal animal existence could be conceived of, for it is a development of organic conditions the most provident possible for living beings under present conditions of supply and demand; but the system is a protophytic monopoly.

As regards the nature of the dual existence common to protophyta, a trifling circumstance seems to turn 
the scale for either animal or vegetal life, viz., the composition of the organism's external membrane. If this envelope be albumen-a flexible substancethe protoplasm manifests motion externally through pseudopodial projections; hence the organism appears as an animal. If the membrane be cellulose-a firm, tenacious substance-external motions are impracticable, internal motions alone supervene, and the organism develops as a plant. A more important magnetic distinction, however, is noticed anon.

(9) Functions of Plants.-The chief functions performed by all plants are nutrition and reproduction. The organs of nutrition are the roots, stem, and leaves; while the organs of reproduction are the flowers, or their equivalent inflorescences. In the lowest plants none of these organs are adequately represented, yet all absorb nourishment and reproduce.

(a) Nutrition.-Nearly all flowering plants have the usual organs of nutrition, but infinite differences pervade their forms. The root absorbs liquid food containing nitrogen, phosphorus, sulphur, potassium, iron, etc. These elements, either pure or combined, it first extracts from the soil, then absorbs, and finally flushes through its whole organism; the ducts being the cells, the cell-walls, and the vessels. The root, like the rest of the plant, is composed of cells, but the nourishment is imbibed by the root-hairs, which are merely prolongations of those cells which form the epidermis of the root-fibres. The stem and 
leaves absorb carbonic acid gas by their cells and through chemical action, by means of chlorophyll, retain the carbon as starch, but reject the oxygen. The starch is then digested in the vegetal organism like food in the animal body.

All plants contain about fifty per cent. of carbon in their composition, but the vital constituent of every plant, and the chief content of every cell, is protoplasm. In some plants, if not in all, it maintains a constant circulation throughout the organism, thus corresponding to blood in the animal system.

Protoplasm is a viscid granular matter composed of carbon, hydrogen, oxygen, nitrogen, and sulphur, in proportions not yet determined. Seen under the microscope it exhibits spontaneous movement, waves traverse its surface, threads and lobes project from it, and ceaseless motions of all kinds distract it. Examined in minute pieces it reveals no regular shape, no visible structure, no perceptible organisation, and no apparatus for feeding. That it has a shape or rather shapes is inevitable; that it has a structure though unseen by us is indispensable to its existence as compound substance; that it has an organisation, however elementary, is obvious from its motion, irresponsible and ungoverned as it seemingly is ; and that it feeds or performs some chemical action equivalent to feeding is incumbent on it as a body endowed with life.

Circulation of water occurs throughout plants, for they transpire, or part with water through pores in 
their leaves and stems. As the water is absorbed by the roots, it thus traverses their whole system.

Plants, like animals, also breathe or respire, for oxygen is essential to their existence. Respiration involves the riddance of superfluous carbon, which is accomplished by the carbon combining with the oxygen of the air, after which it is exhaled as carbonic acid.

(b) Reproduction.-Cryptogams practically reproduce similarly to flowering plants. The fructification is necessarily more insignificant, but the mechanical operation differs only in details. Some cryptogams, like phanerogams, are hermaphrodite, that is, they generate buds or spores which of themselves reproduce the parent plant. Others are monœcious, that is, male and female organs grow on the same plant; while others are diœcious, that is, male and female orgains grow on separate plants. All cryptogams exhibit two modes of reproduction:-(a) Asexual (without distinct sexual organs of reproduction); $(b)$ sexual (with distinct sexual organs of reproduction).

"Alternation of generations" also occurs in plants. Thus spores are emitted which on maturing do not reproduce the parent plant, but a different form. This, on germinating, may either evolve a spore reproducing the parent type, or the metamorphosis may continue through several more generations before completing the cycle. Many cryptogams reproduce both asexually and sexually, as well as by cuttings and shoots. Indeed, the only requisite for vegetal 
reproduction seems to be a complete cell of the plant, for the vital inbeing, essential individuality and class characteristic of every organism is contained in this almost microscopic germ and its nucleus. Nor is this wonderful, when we reflect that each cell contains millions of atoms, and millions of molecules, all necessarily arranged in some structural order; and further, that all cells are not only motile automata, with infallible likes and dislikes, attractions and repulsions, but virtnal antomatic chemical laboratories ceaselessly occupied in evolving the same specific products.

The simplest mode of asexual reproduction is spontaneous cell-division or fission. A growing cell splits into two or more parts, each part, on separation, reproducing the parent type.

A higher mode is gemmation or budding. A bud shoots out of the fungus which divides into four or more parts; these either produce cells which become plants, or protophytic spores which, after a preliminary canter as animals, stiffen, settle down, and develop into vegetals.

The lowest plant (and animal too, as we shall learn) is thus probably a hermaphrodite, its reproduction being effected by internal conjugation. That is, a single living productive cell contains, in some way, dual or sexual elements which, at a certain crisis, automatically combine internally and afterwards repel (generate) the like products of their sexual combination.

The simplest mode of sexual reproduction is by 
external conjugation. Two cells on adjoining tiers or stalks of cells bulge out their cell walls, meet, coalesce, and form a connecting tube. One cell, probably the female, drains the contents of the other, the male cell; the former then enlarges, bursts, and discharges numerous spores which germinate into new plants.

The usual sexual mode of reproduction is effected by means of sexual receptacles, the male containing motile bodies, spermatozoids (as in the protophyta), which on emission, propel themselves in the water and fasten on the female receptacles, which they pierce and fertilise with their protoplasm. Ultimately the female receptacles rupture and emit spores, or zoospores, generally provided with vibratile cilia, by the aid of which they move about until they eventually settle down and grow according to their type.

The chief point to remember about reproductionand it is the same in all the kingdoms-is that it is automatic. No plant intentionally forms a definite number of seeds, any more than it constructs a definite number of leaves or flowers. A plant can thus no more help reproducing itself than it can help growing, provided its natural conditions prevail.

Fertilization is thus a combined mechanical and chemical process, and consists, firstly, in the protoplasm of the pollen cell-the male-penetrating to the protoplasm in the embryo sac of the female; both substances then coalesce, grow by chemical 
action into a complete germinal cell, and eventually by cell-division evolve into a new plant.

Even as a galvanic battery is incomplete without the two reciprocating metals in the proper sexual solution, so the germ or seed of a plant is incomplete and void of energy until it contains the dual or sexual elements. In the locomotion and complex functions performed by the pollen grain in seeking a mate, we are reminded of the complex animal functions of the protophyta and the swarm-spores of cryptogams. Thus, a tube is emitted from the pollen grain which descends through the stigma and the style, enters the cavity of the ovary, selects an ovule, traverses the canal of the micropyle, penetrates the nucleus, and at last empties its protoplasmic contents into the embryo sac. Thus, chance conditions being favourable, the whole process is chemical, mechanical, and automatic.

The automatic character of vegetal reproduction is further illustrated by only one ovule in the ovary of a flower, out of hundreds, becoming fertilized. Many ovules thus have their normal functions unfulfilled, their automatic preparations for becoming fecundated nullified, and their preliminary arrangements for perpetuation blasted, solely through untoward conditions. This waste of reproductive elements is incomparably greater in the male than in the female organs. For example, wistaria senensis contains 7000 male pollen grains to each female ovule; a dandelion contains 243,000 male pollen grains; a prony 3,654,000; 
while a fir-tree disperses uncounted millions. While the profusion of sexual elements and organisms thus indicates their simple generation, their automatic growth and their haphazard origin, the sterility of the vast majority shows that their fertility is a matter of no moment, an accident quite immaterial to nature, man, or the universe. For if one plant dies out another comes in.

In conclusion, with flowering plants as with flowerless, all develop from a single cell automatically, provided the necessary conditions for regetal life be present-heat, light, moisture-without these they also automatically die. In flowers, equally with all natural phenomena, consequents invariably automatically succeed and are determined by antecedents: change the antecedent conditions and automatically the consequent effects vary. The evolution of flowers, fruit, and seed is but the completion of the usual cycle of life. Starting in the first place from the seed, or primarily from the cell, all flowers are but modifications of the foliar organs. Though the flowers are developed on the same plan as the leaves, they are diverted by their environments, assume different shapes, and perform different functions. Indeed, the whole purpose of the complex machinery of fructification and consequent reproduction in plants, is merely to isolate or detach from themselves a complete cell. This accomplished, the cell works out its own salvation. 


\section{CHAPTER XII.}

\section{Causes of Vegetal Evolution.}

In this chapter our object shall be to show that all plants are magnetic organisms, and that all their life, growth, production, and reproduction are effected automatically and chiefly through the magnetic laws.

Section I. Evolution of Vegetal Substance:

Vegetals differ from minerals both in the nature and number of their component chemical elements. Minerals seldom contain more than four or five elements in combination; vegetals twelve or more. Again, although several distinct vegetal substancessuch as cellulose, chlorophyll, and starch-are found in plants, all are reducible to simple elements. These elements are:-Non-metallic-carbon, oxygen, nitrogen, sulphur, phosphorus, iodine, chlorine, and silicon; Metallic-hydrogen, iron, calcium, potassium, sodium, manganese, magnesium, and aluminium. Vegetals are thus composed of sexually combined matter.

Investigation into this field of the elementary con- 
stitution of vegetals has, however, hardly been begun. That the number and kind of commingled elements in a plant bear an important relation to the nature of the product evolved is undoubted. Indeed, so far as the phenomena of evolution are concerned, probably as much variation is induced by chemical affinities and antagonisms as by histological and morphological displacements. Judging from analogy, the simplest plants contain the fewest chemical elements in combination, while the most complex contain the most numerous. Here, however, we wait for proof. Still, it stands to reason that as increasing complexity of moving substance involves more and more complex motion of parts, the greater the number of elements in an organism the greater will be its internal disturbance, and consequently the greater visible manifestation of this disturbance in external form and function. As M. Lefevre says :- "The vegetal elements constitute a veritable vortex of atoms of unstable components, because nitrogen, carbon, and hydrogen possess but few and weak affinities of combination, consequently do not form aggregates solidly fused together." *

Some of the constituents of plants are equally common to minerals, but they do not combine in the same proportions. The metallic elements in a mineral necessarily preponderate over the nonmetallic. Hence, the kind of elements does not constitute the sole difference between hard, unyield-

"Philosophy. Eng. Trans. P. 47 I. 
ing mineral substances and soft pliable vegetal substances, for their proportion and structure have to be taken into account.

Something, also, must be attributed to present planetary temperature for producing the normal manifestation of things, for under polar conditions many organic substances would be crystalline; under torrid, some organic substances might spontaneously (or automatically) evolve vegetals and animals, while under solar conditions all things would be burning.

\section{Section 2. The Evolution of Vegetal Cells:}

A plant does not evolve from a mineral, but from the same constituent basis as the minerals - the atoms. In the evolution of a plant therefore from matter by unintentional materialistic laws, the first step is to form a cell, the fundamental unit of the whole organism.

The vegetal cell, although microscopic, is composed of millions of atoms. As these atoms are both metallic and non-metallic, and all endowed with infinite possibilities in both form and function through their inevitable combination, the clash of complex affinities, attractions, and repulsions, in solutions particularly, is bound to produce something. Minerals being simplest are easiest and oftenest formed, but nature cannot stop there. The fertility of her womb is illimitable. Hence, under suitable conditions of heat, light, and moisture, a chance flux of suitable atoms combines sexually into vegetal molecules. 
Like-material-attraction and the other primary laws then come into play, several molecules attract each other and form a molecular aggregate. This aggregate, as a combination of magnetic atoms and molecules, forms also a magnetic aggregate. This magnetic aggregate is the cell, a virtual magnetic organism having a definite structural arrangement, and fitted in proper suicidal cell fashion to increase and multiply and reproduce itself indefinitely, by eternally dividing itself through the law of likecentral-repulsion.

Many minute crystals of oxalate of lime collect in cells. This indicates that crystalline like regetal energy asserts itself in matter whenever conditions are favourable; and also that the creation of a cell by automatic generation is no more miraculous than the creation of a crystal by the same or similar laws. Hence, to carry the argument further, the evolution of a plant is no more supernatural than the evolution of a diamond. The operations differ in complexity, but the magnetic laws are equal to all emergencies.

\section{Section 3. The Evolution of Vegetal Structure:}

Although all cells seem from our defective vision to be more or less alike, yet every species of plant must possess its own structurally distinct cell, which it multiplies and reproduces by its own vital machinery until, under certain environments or conditions, it becomes a special plant. In a cross section of a plant the cells evince no set figure, but they are often hexagonal. 
The cell itself usually consists of a cell-wall composed of cellulose (oxygen, hydrogen, carbon), enclosing protoplasm. Within the cell a dark or light globular material is invariably present, called the nucleus - the germ or breeding-place of another cell.

When unicellular vegetals like the snow-plant reproduce, or multicellular vegetals increase in size, the structural operations in both instances are effected by cell-multiplication. This is accomplished in various ways secondarily, but all reveal in a striking manner fundamentally the source whence vegetals derive their structural energy. For instance, from observations on the coniferæ (Strasburger), the nucleus in a pregnant cell assumes a spindle shape (becomes, in fact, a bar-magnet) and parts into parallel filaments from end to end (commencement of like-centralrepulsion). From the thickening of the filaments in the centre, a "nucleus plate" then forms, which anon splits into halves, and (by like-central-repulsion) each half recedes to the poles of the spindle. Here they constitute two nuclei, and soon after the whole protoplasm of the cell divides, each half surrounds the two new nuclei, a cellulose wall encloses them, and through this virtual parental suicide two daughtercells are born. Fundamental magnetic action could not be better illustrated with a bar-magnet and iron filings than by those microscopic cells acting automatically, thus furnishing an apt illustration of the truth of our theory and of the continuity which 
subsists between mineral and vegetal structure and energy.

The above process is repeated indefinitely in the unicellular vegetal. When cells aggregate, and aggregates aggregate into larger vegetal structures, a physiological specialization automatically occurs whereby different groups of cells drift apart for the efficient administration of the plant's assimilative, supportive, protective, and reproductive functions. In a sense the plant becomes a colony of cells, each group undertaking some special work. Growth in all vegetals, however, proceeds in the same fundamental suicidal fashion, each cell increasing and dividing itself, and so on interminably. The likeness of each organism is thus inviolably maintained and perpetuated in the only way in which likeness could possibly be secured.

\section{Section 4. The Evolution of Vegetal Energy:}

We have said that a plant as composed of magnetic atoms is also a magnet; hence its energy is also magnetism. A plant, however, is a living and growing magnet only when it is under normal life conditions. Thus a plant lifted out of the soil may remain alive for a time, but it will not grow.

A horse-shoe magnet is what we may call a $d r y$ magnet, for it attracts matter or iron filings in a dry state. But a plant is what may be called a wetmagnet, because it can only attract matter and grow under moist conditions. All plants thus have their roots embedded in the soil, a moist habitat containing 
material or elements similar to itself. But what is the soil?

The soil forms the surface-covering of the earth. But the earth itself is a magnet. Not only so, but according to our definition of life it is a living magnet. It contains huge internal fires in which magnetic materials are continually dissolving, thereby generating vast magnetic forces or vitality, which find sudden vent in volcanoes and earthquakes, as well as an imperceptible outlet over its entire surface. These huge internal fires are virtually the earth's magnetic battery, through which it is kept in life as a living planet tenanted with vegetal and animal life ; hence, when all conditions are suitable, and the soil is properly saturated with water, thereby inducing suitable chemical action, the internal magnetic forces throw up a clotted vegetation on every available spot of ground on the globe. This vegetation is but a bristling beard of earthly material ejected by the earth's magnetism; filaments of matter, having the same relation to the earth as a man's beard to his chin, or as the bristling iron filings on a horse-shoe magnet. Strange and startling as this revelation is, no other interpretation is available.

By every plant thus growing on or in a magnetic battery, a battery becomes an absolute essential to vegetal growth. But this battery need not always be the earth, for, by means of flower-pots into which suitable moist soil is placed, we can construct artificial plant-batteries, so that not only may plants be grown in them as well as in the earth, but by enabling us to 
move them about, we can place them in hothouses under better conditions for growing than in the soil itself, and move them about from one continent to another.

This discovery, that every plant is a living magnet with complete magnetic apparatus for supplying it with food, keeping it in life and causing it to grow, is of the utmost importance to the science of to-day. For, through what we may call the cross-bred protophyta, it shows us how evolution has proceeded from the plants to animals, links the life-chain between them, and reveals to our gaze the cause and acting principle of animal life itself.

Thus the protophyte begins life as an animal, and has the independent existence of an animal by moving about in the water from place to place. But this life is a short and merry one, for ere long its spirits depart, it becomes depressed and lazy, and anon takes a seat from which it never again rises; for now it has taken root, its animal life is ended and its plant life begun.

The only explanation of this strange dual existence seems to be that on emission from the parent organism, the spore is provided with an ephemeral or false stomach supplied with a temporary food store (like a chicken leaving its shell). So long as this internal larder lasts, the protophyte has an active existence; but having no mouth or other means of recharging its stomach, when the contents are exhausted, so is the animal; and were it not provided 
with embryo roots which find another but a different kind of stomach in the soil to which it becomes attached and through which it feeds, the protophyte would die.

Herein, therefore, we obtain the distinction so often sought for between a plant and an animal as well as the link of connection between them. Both are magnets with magnetic apparatus, but the power or life-giving central organ, the stomach or battery, is differently arranged. In the plant it is outside of it, but grasping firmly its lower poles. In the animal it is inside, with all the mechanism surrounding it, as a boiler continually generating steam. And as it is the steam which lifts the lid of the kettle, or drives the huge mechanism of the locomotive or steamship, so it is the same energy which fires the tiny engine of the microscopic spore, or inflates the expansive mechanism of the human fool.

The sequence of energy in a plant thus simply is, that suitable materials are chemically dissolved by every plant in its own soil battery: these materials are absorbed by the root-hairs through the law of like-material-attraction, and are distributed throughout the plant by the plant's own mechanism, from the battery as one pole to the upper pole or extremities, or from the axis of the plant as a magnetic centre to the roots and branches as opposed poles; the design of both roots and branches being superintended by nature's sleepless artist-Polarity. 


\section{Section 5. The Evolution of Vegetal Form:}

The forms assumed by plants are infinite; but, in normal outline, all adhere to a general type-plan, which may be capitally parodied by a bar-magnet with iron filings attached to both poles, especially if one end be thrust into the ground, or, better still, into a dish of water. Thus underneath the surface the lower filings in out-stretching filaments represent the roots; above, the bar represents the stem, and the upper outstanding filaments the branches and leaves. But the bar-magnet is not altogether a parody, for it clearly reveals the cause of vegetal design. Every plant as composed of magnetic atoms, and possessed, as shown, of a magnetic battery in the soil, is in effect a living magnet; hence the roots and branches are but opposed magnetic poles. This is well illustrated in the banyan-tree, and many small plants where the branches or stalks are drawn to the ground, take root, grow up again, and so complete the magnetic circuit.

Throughout the vegetal kingdom the influence of polarity thus shows itself from the least to the greatest. Every root and root-hair repels each other and penetrates independently into the soil ; every branch, twig, and leaf fights shy of each other and pursues its own course to the sunshine; every petal in every flower spreads its own gorgeous canvas to the bees; while the ovules in every ovary, the pollen on every anther, the veins in every leaf, the vessels and cells in every tissue, each and all indicate the same predominating principle of polarity, leading us by analogy to deduce 
that even the invisible molecules and atoms in the ultimate vegetal structure itself bow themselves in bondage to this irrevocable and infallible law of design.

Section 6. The Evolution of Vegetal Sex; or The Duality and Sexuality of Vegetals:

While the inner cycle of evolution-from seed to seed-is generally predominant, it is not invariable. All plants do not reproduce or perpetuate their kind, for some become extinct, which means reversion to that natal outer cycle of the elements from which they originally sprang. Assuming, therefore, the automatic production of primordial plants from inorganic constituents, reproduction, as a more or less complex process, would not be a sudden but a gradual development. Hence those plants which accidentally developed sexual organs through natural selection and produced seed would stand a better chance of establishing and maintaining themselves than others failing to do so. Many plants, through inability to perfect successful modes of reproducing themselves or of adapting their mechanisms to changed conditions and environments, have thus perished. Reproduction, again, even granting the perfection of the sexual organs, is dependent upon various essential conditions, the chief of which is the absolute necessity of fertilisation.

A most important question in vegetal evolution thus is-What is Sex ?*

* See an interesting book called The Sagacity and Morality of Plants, by Dr J. E. Taylor. 
Sex in vegetals is, fundamentally, nothing but duality, and it is manifested as a reciprocity between organisms which, formed differently but constitutionally alike, require this reciprocity in order to effect reproduction. Sex in plants is indicated by infinite differences in the floral organs, and reproduction follows on those organs fertilising each other; but as numerous potentially fertile receptacles evolved on plants often remain unfertilised, this demonstrates that their production is solely automatic, their functions an accident, and their germination a contingency dependent practically on chance. Fertilisation, however, is to some extent ensured in all plants by the excessive number of agents of generation evolved. This unmistakably indicates that their origin is due to some general fundamental principle in nature itself: the duality already mentioned. The significant fact in fertilisation and reproduction thus is that the acting energies and agencies are automatic and unintentional. Even those complex mechanical modifications in orchids, familiar to us through Darwin's experiments, which seem to indicate intelligent design, are only the chance modifications of chance organs happening through the chance perturbations of chance conditions. For all plants do not necessarily reproduce, neither are all their evolved improvements continued by habit and confirmed by natural selection.

The origin of sex thus needs no lengthy argument. It indubitably arises from the fundamental duality or sexuality of primary matter itself. The atoms are 
themselves dual-metallic and non-metallic. From the affinities of these two classes of atoms the gradually increasing complexity of sexual mechanism and action may be traced, from the simple union of oxygen and hydrogen into water, to the fertilisation of the vegetal female ovule by the protoplasm of a male pollen grain.

Again, although sex in the higher organisms seems chiefly a differentiation in form, yet fundamentally its action, as in impregnation, is solely a chemical process; hence, if we traced all the phenomena of vegetal reproduction from conjugation in algae to cross-fertilisation in orchids, the fundamental function of sex in each and all would only resolve itself into a chemical or sexual union of dually reciprocal elements.

\section{Section 7. The Evolution of Vegetal Species:}

That infinite varieties of every species of plant exist is admitted; that many of these varieties have been evolved by natural selection is known; that some even of the more striking varieties have been differentiated during the march of time into distinct species is also probable; and that all genera, orders, and classes of vegetals have been-as Darwinians allege - transformed from the one into the other by regular genealogical sequence and solely from one primordial cell, may be granted as possible: but on the wider assumption that each plant possessed numberless parent types capable of infinite variation, we stand on more solid ground. According to the accepted "cell 
theory," the nature of the first cell fixes the character of the future organism. Hence, granting the spontaneous or automatic evolution of plant cells or germs, as already described, it seems at least probable that the majority of plants were evolved from original cells fortuitously created.

We thus infer that hundreds of thousands of living germs or cells of plants sprang and still spring spontaneously and contemporaneously into being, whenever and wherever the organic conditions of the planet are suitable for their automatic evolution. That the organic springs from either the inorganic or the organic as inconsequently as life follows death or death follows life. For the only immortals are the atoms and the only Gods the living. Each germ again may have had only one centre of evolution, for all genera could not have originated from one centre. From the wide distribution of fungi, mosses, lichens, sea-weeds, ferns, etc., we would be warranted in according to such simply organised plants many parent types automatically and contemporaneously evolved all over the earth's surface, provided the necessary conditions for generation and growth were present. Conditions conceivable everywhere, for the vegetal constituents-carbon, oxygen, nitrogen, hydrogen, etc. - are universal; and as the elements are bound by the inexorable law of their magnetic destiny to assimilate in some form, there is nothing in such simple forms as fungi to prevent them from assimilating repeatedly in the same form, especially when 
the inviolable chemical law of "combination in definite proportions" restricts, to a certain degree, the number of possible combinations and assimilations. At the same time, slight differences in the proportion of the combining elements of a plant might and probably does involve differences in form and function sufficient to constitute a new species.

We thus assume that only the simplest plants were automatically evolved in numerous centres; while the higher genera, those producing special flowers and fruit, no matter how widely distributed over the world now, had only one genital centre.

\section{Section 8. Life:}

As in the mineral kingdom so in the vegetal kingdom, energy and life are alike; hence what we have described as the origin and cause of a plant's energy must also be accepted as the origin and cause of its life: a conclusion which shall inevitably raise an ecclesiastical and philosophical storm; not so much on account of its falsity, as on the unpalatableness of its truth, for the business and bread and butter of our priests and prophets largely depend on the acceptance or rejection of this materialistic origin of life by the world at large.

Darwin, to our present wonder, characterised the origin of life "a hopeless inquiry." Here he committed the common error of speaking for futurity. He assumed that the knowledge of his day was ultimate and for all time, instead of only transitional, 
and for his day. Life was truly a hopeless riddle to the men of his age, as it is still to his great evolutionary contemporary, Mr Herbert Spencer; but Darwin no more than any man could speak for his descendants, for any man at any time is in the knowledge of the future as the babe unborn.

Another mistake people often make is in accepting their leaders of science as infallible authorities. If they were only regarded as fallible authorities the world would progress much quicker. Thus, while Darwin, Huxley, and Tyndall were conspicuous authorities for their own day, it was inevitable, unless the race was to run to seed, that men as great, as gifted, and possessed of wider knowledge were bound to arise in the future as greater authorities. And thus it shall be to the end. When men swore by Aristotle for centuries, intelligence was a fool's paradise.

In the Origin of Species the problem of life was truly only an aside, but in any consistent system of universal evolution suitable for the advanced knowledge of to-day some reliable hypothesis of the origin of life is an absolute necessity. It is also an enigma bound to be solved if man's ingenuity is ever to correspond with his intellectual pretensions. Man cannot call himself wise if he writes himself down a fool on this subject.

To Darwinians the only possible alpha, in life, is a "germ." But as Tyndall shrewdly said, "This hypothesis is not final, we must look behind the germ and inquire into its genesis." 
The chief difficulty in comprehending life and unearthing its purely materialistic origin has arisen hitherto from human unwillingness, cowardice, or incapacity to trace consequents from antecedents. Men seemed to think that natural puzzles were not simple but difficult problems, which could only be solved by extraordinary means, by preternatural agencies and preternatural gifts.

The great orthodox argument is, "life from life, and organic substance from organic substance." Thus it is asserted that a cabbage can only spring from a cabbage, and a plant from its seed. This is true of the cabbage at the present time under present conditions; but at one time far back in the planet's history, a cabbage or its prototype is admitted to have been evolved from something neither a cabbage nor a plant-viz., inorganic elements. Hence, if nature fails to grow cabbages fortuitously now from inorganic matter, it is not through her inability to do so, but simply because the land and water are already overcrowded with the germs of other plants and animals. Further, as new conditions and environments in the world must happen more often than old ones, it is more likely that, in any vacancy, the germs of new plants should be evolved rather than that old ones should be reproduced.

Again, "life only from life" is fallacious when it is inevitable that all organic substance must be renewed from and revivified by inorganic substance. The living things of to-day were yesterday and preceding 
days but dust or inorganic elements, and to-morrow and succeeding days shall again return to dust and inorganic elements; for without such origin in and return to the outer cycle of inorganic elements, the inner cycle of organic matter and life would be impossible. The constituents of a seed no more cycle onwards and then back again to a seed than a dinner returns to the kitchen to be re-cooked.

As a rule, men thoughtlessiy accord to seed energy only one outlet, growth and reproduction; but few notions are more fallacious, for its vital phases constitute only one of numerous vents of force. For instance:-

(I) Throw a seed into the fire and it will not grow but burn. Instead of the environing conditions conducing to addition or growth, the seed is itself subtracted, molecularly split up, and dissipated. In burning, the seed truly manifests energy, for its combustible constituents contribute to the motion of the fire ; but its organisation as a seed avails it nothing in this auto-da-fé; a chip of wood under similar circumstances would burn as well. The potentialities of a seed are thus unbounded, its capacities magnificent, but its destiny a peradventure. In the burning, its constituents are neither lost in substance nor annihilated in energy, but they battle no more to produce a plant; and yet in the cycle of their eternal indestructibility some of those self-same atoms may yet meet together again within the integument of a wheat seed. 
(2) The seed by certain chemical processes in a laboratory may be converted through its own and other energial resources into substances altogether different in appearance and properties to itself: such as gluten, albumen, starch, sugar, fat, silicon, etc.

(3) The seed may be planted in a manure heap, and its energy shall simply develop itself in rotting and adding to the compost.

(4) The seed may be masticated by an animal, and its energy shall manifest itself in becoming flesh and blood.

(5) The seed may be planted in proper time and in good soil, but if the weather be unpropitious and the season short, it will only grow into a stunted and barren plant.

(6) Lastly, under favourable circumstances the seed may grow, develop, and produce its kind, all in due rotation, thereby evincing the orderly sequence of natural phenomena automatically accomplished by the inherent energy of the seed under suitable conditions.

Another important point seldom dwelt on is that a plant's energy and life are dual. For example, by means of a magnetic battery we may convert a soft piece of iron, already a weak-magnet, into a very powerful magnet capable of attracting iron filings and shooting them out into long filaments from its poles. So long as the current is maintained, filings may be added and a miniature tree grown; but cut the connection or reverse the action, and the filings instantly drop. Why? Because the life of the 
magnet-that is the magnetic force superimposed upon the normal magnetic energy resident in the piece of iron itself-is withdrawn or reversed, decomposition, so to speak, takes place, and the rapidity of dissolution corresponds with the rapidity of growth, both being almost instantaneous.

A similar duality pervades the plant-magnet. A tree brought from a distance has an energy which is the combined energy of all its atomic constituents, but it shows no sign of life, that is, it does not grow until it is planted in the soil. The tree thus practically possesses both energy and life, but the life is dormant, like the seed in the Egyptian sarcophagus, until suitable conditions cause it to be manifested, that is, until it has been supplied with its stomach and battery by being planted in the soil.

Similarly, when a plant dies it is only this superimposed energy or special manifestation of energy, called life, which is withdrawn; that energy, namely, which is the evidence that the plant is a growing magnet suffused with magnetic influences. Hence, though the inherent magnetic energy of the atoms contained in the withered plant still remains an energy sufficient to exhibit gravity and cohesion, it cannot manifest life as a whole, because through some failure in its mechanism its combined magnetic current has been broken. Still, new magnetic centres may be set up in the rotting stalk sufficient to evolve and maintain life, though on a much smaller scalemould and other parasitical fungi. 
By thus revealing plant life to be merely a special manifestation of normal plant energy, automatically altered by the constituents of the plants themselves to suit the special conditions of its growth, we rob the problem of life of all its paltry mystery, shatter the fabrics which have ever led the unscrupulous to batten on the credulous, and inaugurate a new era of human existence which shall revolutionise the world.

\section{Section 9. The Evolution of Vegetal Intelligence:}

In a general survey of plants we seem to observe a gradation of intelligence from, say, the unicellular snow-plant or fungus to the orchid and sun-dew. This intelligence corresponds more or less with the complexity of the plant's mechanism, and especially with the complexity of its nervous tissues. Thus, Huxley averred that the nerve fibres of animals and the nervous tissues of plants were alike but "linear tracts of protoplasm which served as media of communication between two points," thus levelling the life and intelligence of plants and animals to the same plane.

From our demonstration that every plant is a living magnet deriving its energy from a natural magnetic battery, all the mechanism connected therewith must be more or less arranged on, and controlled by, what we may term electric telegraph principles. The tracts of protoplasm are but the telegraph wires along which the messages are sent and returned; while the complexity of the message and its answer 
depends almost solely on the complexity of the telegraph system.

The most complete vegetal mechanism is, however, simple compared to the simplest animal mechanism, hence, a plant's intelligence is limited in comparison to that of an animal.

All vegetal as well as all mineral intelligence is also unconscious or unintentional, the result solely of stimuli or reflex action; for although there seems an apparent intention in a half-formed snow-shrub or frost-fern to construct a leaf, in a plant with tendrils to climb and clasp some support, in the mistletoe to suck juices out of the elm, in the orchid to duck bees in its bath, in the sun-dew and fly-trap to kill insects and eat them, yet, at bottom, all act automatically, for all can be hoaxed. Plants truly discriminate, but only to a certain extent, and then only because certain conditions automatically required by them are fulfilled. Beyond these limits they are unconscious.

We thus see that in its genesis or incipient stage there is no more miraculous agency employed or required in the production of vegetal intelligence than of vegetal life, hence plants are but automata, mere playthings of their environments, positions, and conditions; and this intelligence is interesting to us because foreshadowing or forerunning human intelligence, of which we boast so much and with so little cause. 
Section Io. The Aim and Purpose of Vegetal Evolution:

If plants are unconscious automata, we cannot accord them ambitions, aspirations, aims, ends, and intentions, although a semblance of all these feelings may be traced in the vegetal kingdom. Assuming that the ideal vegetal is a tree of great height, of proportionate width, with graceful trunk, tapering branches, lovely foliage, brilliant flowers, and luscious fruit-the most beautiful, most useful, and most prolific object in nature-do any plants, either intentionally or automatically, evolve on these lines? The only answer is a negative. The finest apples often grow on the most gnarled of trunks, the choicest roses on the most scruffy of stems, while the loveliest outlines appear on the most barren of plants; hence, no known law correlates the size, worth, and beauty of a tree to the excellence of its fruit, flowers, and form. Seemingly, then, a vegetal cherishes no object in existence beyond mere existence. As a mere ambition or aspiration it has no intentional desire to propagate better flowers or fruit than other trees; hence, if this end be attained it is solely by accident. The tree can claim no merit, for it is all a game of chance.

Again, trees harbour no intentional rivalry, yet for the purposes of fertilisation they vie with each other in enlisting birds and insects into their service. Further, although not murderously inclined and entertaining no premeditated design to kill and root out one 
another, yet the effect of the superabundance of vegetals, especially in the Tropics, is to convert them into vegetal criminals, and cause that terrible "struggle for existence" which is ever one of the curses of human life.

The purpose or object of vegetal existence fundamentally thus consists in a struggle solely to live. The motto of plants is not excelsior, or a united effort upwards and onwards to ever-increasing vegetal perfection; but a selfish and inglorious scramble by each plant to exist at all, in any form, with any functions and in any locality, provided only that it perish not. Whether a tree be beautiful or ugly, fruitful or sterile, useful or baneful to other things, is of no moment to the plant individually, so long as its form, functions, and fruitions are useful and advantageous to itself. It may become a beautiful and serviceable tree or an ugly and useless one, but either alternative is equally accidental; for while, as a tree, it truly grows by inviolable law, its details, eccentricities, and modifications of growth accord it, through the automatic influences of its automatic environments in its ceaseless automatic developments, unlimited licence for producing either foods or poisons, beauties or monstrosities.

Vegetal evolution thus chiefly consists in developing infinite modifications of parental types, modifications introduced automatically and accidentally, and continued by natural selection, because they are useful to the plant itself in its life-struggle; but so far as man 
is concerned, quite independent of all epicurean, æsthetic, or commercial considerations whatsoever. In a plant's higher efforts these modifications resolve themselves into apparent endeavours in the different species of plants to diverge as much as possible from one another, because in this divergence (although we cannot credit them with a knowledge of it) they achieve, through the creation of different needs and modes of living, new organs of endurance and perpetuation. 


\section{CHAP'TER XIII.}

The Evolution of Animals.

As with minerals and vegetals, we shall now endeavour to prove that the evolution of animals is equally spontaneous, haphazard and automatic; that their energy is equally magnetic and electric, their origin an accident, their life a peradventure, and their purpose a mockery. Each and all, but especially men, are automatic puppets evolved by natural laws and manipulated by natural agencies; so that they strut about for a brief space on a provincial stage, are cursed with a more or less painful death, and then disappear for other puppets to arise in turn incessantly and endlessly.

Our special purpose in this chapter shall be to show that animals like plants are living magnets, but through an ingenious mechanical device, already referred to, they are rendered complete and self-contained organisms, so that they enjoy perfect freedom of action, and are not tethered like the plants to the soil, or confined to a circumscribed area of existence. 
To follow our arguments intelligently, illustrations are almost essential, for words fail to convey an adequate idea of the beauty, the ugliness, or the intricacy of the lowest forms of life especially. A study of such an article as that of Professor Ray Lancaster on the Protozoa in the Ency. Brit. would be of immense service in understanding our exposition, as well as be a revelation to the general reader. For it is undoubtedly largely due to ignorance of the lower forms of life and the intelligence which they exhibit, that men in the mass have such a vain, conceited, and preposterously exalted notion of themselves.

Assuming, therefore, that our readers shall verify our descriptions by a reference to the illustrated literature of the subject, we shall in our rapid survey of the animal kingdom, confine ourselves to examples of striking forms, striking functions, and such other characteristics of the animal kingdom generally as shall seem best suited to illustrate our argument.

Commencing with unicellular animals, we find that the simplest protozoa are but lumps of protoplasm which exhibit no more apparent structure than a speck of mucilage, yet the least of them manifest complex life processes.

Thus the protomonas is extremely voracious, and is often seen stuffed with infusoria captured by its pseudopodia. Instead of reproducing itself by fission, it retracts its pseudopodia and becomes a perfect sphere. The envelope then thickens and forms a membranous cyst, while the internal protoplasm undergoes seg- 
mentation into quite a number of small globular masses. The cyst then ruptures and the masses escape as pyriform objects with the smaller end prolonged into a delicate filament, by which the young spore propels itself in the water. Soon, however, pseudopodia project from the entire surface of the young spore, and the filament becomes confounded with them. The cycle of life is completed by a number of these modified spores assembling together again, becoming completely fused (undoubtedly a sexual process) and reconstituting a protomonas.

The mycetozoon is a curious crawling fungoid animal of naked protoplasm, spreading like a net-work of egg yolk over old bark, tan, moss, leaves, etc. It has affinities to both plants and animals, and is thus, as many new forms constantly being discovered are, a living cross between the two great organic kingdoms. It forms plasmodia which (in fuligo) encyst, and yield millions of spores about $\frac{1}{1500}$ inch in diameter. Two hundred species of mycetozoa have been described.

Although the ameba resembles in its general characteristics the lowest protozoa such as protamœba and protogenes, it manifests a distinctly higher organisation and predominates over them in permanence, size attained, and physiological importance. It possesses a clearly defined nucleus-usually a dark granular concretion-and sometimes also a nucleolus, or nucleus within the nucleus. The amoeba, in common with nearly all protozoa, has a pulsating cavity called a 
contractile vacuole (some algae also possess the same), which appears and disappears every few seconds. Probably it is an incipient heart, lung, stomach, and excretory apparatus all in one; for, in rudimentary organisms, one organ performs many different functions afterwards specialised. Thus, as Darwin observed, the alimentary canal respires, digests, and excretes in the larva of the dragon-fly, and in the fish cobites; while in the hydra, if the animal be turned inside out, what was the exterior surface digests and the stomach respires.

The amoba feeds, like other pseudopodial creatures, by engulfing infusoria and other minute life in its protoplasm which its shoots over its victims in streams.

Summing up its life-processes, an amœba is capable of finding, seizing, devouring, digesting, and assimilating food; it has a special provision for collecting fluid and pumping it out of its body; it respires by its whole surface; it moves about apparently where it wills; it exhibits a sensibility to tactile impressions, and reacts in all probability to smell, if not to sound and light. In short, it is capable of performing rudimentarily almost every function which animals vastly higher in the scale of organisation exhibit.* The amcba is, however, lower in its reproductive processes than the protomonas, for it divides by fission like the protomøba, each half retaining half also of the nucleus.

The eggs or ovules of many low animals are virtu* "Article Histology," Ency. Brit. 
ally amœbre. They are all lumps of amorphous protoplasm with a nucleus and nucleolus. They project pseudopodia and wander about from place to place. Haeckel has even seen the eggs of sponges crawling about among the parent canals and cavities. Reichenbach also observed the embryonic cells of the cray-fish throw out pseudopodia and engulf the yolk spheres provided them for nutriment.

The microscope has revealed many strange phenomena but few more astounding than this, that man's body is filled with innumerable independent living beings called the white corpuscles of the blood. To all intents and purposes these organisms are separate individuals, veritable amœbæ, amorphous masses of protoplasm, projecting and withdrawing pseudopodia, creeping about from place to place, absorbing solid food, and even bloodthirstily devouring their more diminutive companions the red blood corpuscles. When we are also told that no less than one hundred and twenty species of animals are parasitic to humanity, we begin to realise that man is not so much an individual as a colony, or "cell-monarchy" as Haeckel says, a veritable microscopic menagerie, the interests of whose inhabitants are not always that of the host, and whose triumph is his death.

The Heliozoa class contains the sun-animalcula, actinophrys, etc. The latter is a spheroid amoba, but instead of moving about it remains stationary, spreads out numerous stiff isolated filamentous pseudopodia like a spider's web, paralyses small organisms 
which touch its ephemeral tentacles, buries them in its body, and slowly digests them. The likeness of this animal to the vegetal sun-dew is striking, the only essential difference being that the sun-dew possesses roots and a stem. Some allowance for lesser activity must also be conceded to the sun-dew, as an organism trammelled by cellulose membranes and tissues rather than fitted with albuminous envelopes.

The heliozoa reproduce by fission and encystment.

Sporozoa.-The sporozoon is a minute animal, parasitic in all classes and orders of animals. It differs from the preceding protozoa in possessing a firm outer layer. It reproduces by conjugation and encystment.

Flagellata.-These animals are nucleated cell-bodies, provided with one or more large processes of vibratile protoplasm. Some have a mouth, but in others imbibition as in plants takes place, chlorophyll being present. Many flagellata construct collar-like outgrowths or stalk-like processes, others gelatinous shells or cups arranged in aborescent colonies.

Reproduction in more simple forms is effected by conjugation and fission, but, in the volvocina, sexuality reaches a high degree of modification in the copulation of the male spores (microgonida) with the female cells (macrogonidium). Some colonies, moreover, only produce male spores, others only female egg-cells.

Some flagellata have one or two pigment cells called "eye spots," but whether they subserve the function of sight has not yet been determined. 
Dinoflagellata.-These animals are phosphorescent and possess a mouth, hence would seem to be highly developed; but as their cell-walls are composed of cellulose, and their medulary protoplasm contains chlorophyll, diatomin, and starch, they are closely related to vegetals.

The Ciliata have cilia or hair-like processes protruding over the whole body. The cilia act as oars or locomotor organs, or serve for introducing food particles into the mouth. Some species contain isolated individuals, while others constitute colonies. One highly modified form (Thuricola valvata) represents a tube fitted with a valve, like the door of the "trap-door" spider's nest. In the most developed species the cilia are modified and enlarged into muscular appendages (setae) by which the animal ambulates.

The Reticularia constitute a connecting link between amorphous and symmetrical protozoa. Although the reticularia are themselves shapeless, structureless, and unorganised masses of protoplasm in their normal manifestation, they project like an actinophrys outspreading rays of ephemeral pseudopodia, and secrete skeletons of carbonate of lime, innumerable in pattern and exceedingly elegant in design. They do not resemble molluscs, for their shell is not external but semi-external and internal; sufficient to enclose the animal when retracted, it is yet perforated by numberless minute orifices through which the protoplasmic rays project. 
In explanation of these phenomena, it is supposed that during the processes of reproduction the pseudopodia retract, and the animal resolves itself into a solid jelly round its nucleus. It then remains stationary for a time, acting as a sort of mould, while it secretes lime on its back, which then hardens. As the organism grows, chamber is added to chamber until the structure is of the most complex description. The reticularia are thus assumed to be compound animals, each chamber housing a complete individual; but this is mere conjecture at present as their mode of reproduction is only imperfectly known.

The most astonishing circumstance concerning them is their number. Though so small, they are so plentiful that it is computed an ounce of the sand at the port of Gaeta contains no less than a million and a half of their skeletons; while, along with the kindred radiolaria, whole islands-Barbadoes, for example, are composed of them.

Molluscs.-The crystalline enclosures of the molluscs are formed in a somewhat similar way to the reticularia; the carbonate of lime or silica being merely secreted by their external cells.

Corals.-The most conspicuous of the animals which are largely crystalline in structure are the corals. The typical coral, as we see it in museums, is a beautiful lime formation branching like a tree. In its living state, the coral is a compound animal containing a hard internal core or skeleton composed of calcareous secretions. This core is enveloped by a fleshy cover- 
ing which bristles with mouths. It is in fact a colony of animals-a "living co-operative store" as Huxley aptly called it. Each polyp possesses a mouth, but only a stomach in common. These mouths are adorned with tentacles somewhat resembling the flower-like orifices of the sea-anemone. After continually budding and growing and secreting crystal to crystal of carbonate of lime, the mouths gradually develop into coral branches and form submarine forests of vast extent. Thus the great reef-builders-the Millipores and the Madrepores-construct coral barriers, hundreds of miles long and many fathoms deep. Yet these coral polyps do not intentionally build reefs any more than man intentionally constructs his skeleton.

The acting law is the same as that which forms a frost fern, builds a lead tree, or grows a snow shrub. The polyps truly secrete the lime, but as the colony is a magnet with branches all issuing from the same pole, the law of like-polar-repulsion steps in and causes every branch to repel every other as if it were an actual tree.

Plant-like Animals.-Thesimplest plant-likeanimals are the microscopic flagellate infusoria. These are cells with funnels acting as mouths, out of which project one or two flagella or vibratile lashes. In their simplest forms they are independent locomotor organisms. Some (astasice) may be reckoned complete unicellular plants, for they are green, and are enveloped for a time in a membrane of cellulose. The peculiar arborescent character of these infusoria is most con- 
spicuous when they are united in colonies and incorporated into stalks of membranous tissue.

The simplest form (dinobrya) represents an upright tier of cups which fit closely into one another. Each cell or cup is a complete and independent organism, with its own flagella projecting over the lip. When small creatures are captured by these flagella, they are drawn into the body of the cup and there digested. Reproduction or perpetuation occurs when the topmost cell reaches maturity with its nucleus and flagella complete. It then becomes detached and floats away to found a new colony elsewhere, while the next in order succeeds to the top.

Some species (codosigoe) appear as bouquets on the summit of a long peduncle or stalk. Others resemble dahlias bunched together on more or less ramified and flexuous stems. Sometimes these stalks, tubes, or membranes attain vast proportions compared to the animals inhabiting them. Thus, a boy cracking a whip on the top of the Monument (London) might fitly represent the comparative size of some infusoria to their stalks or houses.

Thus far the animals constituting arboriform colonies are distinct individuals, each one fishing out of his own cup solely for himself, the union with others merely mechanical. They must, however, secrete in common their supportive membrane, yet the growth of the membrane is inevitably as automatic as is the skeleton of the coral, the acting laws being probably the same like-material-attraction and 
polarity. A more complex phase of arborescent animal life is manifested by the polyzoa, zoophytes, and sponges. Of these the most remarkable, if not the most enigmatical of all living things, is the polyzoon christabella. This is a sea-mat, somewhat like a square-shaped snail, on whose back the clustered polypides project their horse-shoe shaped crown of tentacles; while the base is a muscular foot by whose aid the whole colony crawls along. It is difficult to conceive how, without calling in the aid of automatism, volition could be communicated to its foot by an animal possessing such a multitudinous head.

The horny zoophyte, nextly, buds like the infusoria and fresh-water hydras, but instead of breaking off and starting an independent existence on attaining maturity it remains attached; hence a huge plantanimal eventually grows, each bud duly provided with a separate mouth, but only enjoying the privilege of a stomach in common.

Sponges also form colonies and secrete a horny supportive net-work, while their collective action is strikingly mechanical: consisting in sucking water through innumerable small holes in the external surface, and after extracting all floating nutriment, pumping it out again through larger orifices.

In seeking a cause for arboriform growth among animals, we find that the carbonate of lime in the animal skeleton is not entirely acting on its own account. In many instances, if not in all, the action is but the hardening of the creature's internal tissues 
or external cells, hence, the shape of the living albuminoid animal practically determines the form of its crystalline core or covering. The shape again is largely, if not wholly, a matter of chance. Thus, in the coral, the particular spot at which a bud appears is not intentionally determined upon by any single polyp, or by the whole colony in anxious deliberation, but occurs solely through the automatic energy of the substance itself detecting a suitable breathing space; this energy in all substance being polarity.

Hence the tree-like, or plant-like forms of animals are undoubtedly produced by the same energy which forms the frost ferns and snow shrubs, and even the buds and branches on plants. Each animal absorbs automatically the right kind of substance by the substance's own automatic law of like-material-attraction; and, as a magnet, its form is determined by the equally automatic and all-powerful law of all growing substance-like-polar-repulsion.

Electric Animals. - From our view of the vast influence wielded by magnetism in natural operations, fishes are, in a sense, the most important of all animals, for they illustrate in a practical way the magnetic nature of their mechanism, and corroborate our theory that all organisms, from the amoeba to man, are natural electric machines.

About fifty species of fishes with electrical properties are known, but only a few have been minutely investigated. The most familiar are the Torpedo, the Gymnotus, and the Thunderer-fish of the Arabs. 
Without entering into minute detail, for full information may be obtained in numerous volumes dealing with the subject, it is only necessary to say that these fishes have powerful electric organs, the whole apparatus consisting of three parts: (I) "Electric centres in the brain or spinal cord, (2) electric nerves passing to the electric organ, and (3) the electric organ itself."*

The electrical organs are extraordinary structures. That of the torpedo consists of about a million electric plates, each supplied with a distinct nerve fibre, the whole resembling an old-fashioned voltaic pile battery. The torpedo discharges as many as two hundred shocks in the second. The electric currents have all the usual characteristics; they render the needle magnetic, decompose chemical compounds, and emit the spark.

A curious fact is that the electric eel knows the nature of its energy, for, like an experienced electrician, it curves its body towards its victim and discharges the shock to the greatest advantage by touching it with both the nose and tail.

While the normal electric fishes thus wonderfully corroborate our theory of the magnetic and electric character of all life, they fall far short in electric power of their relatives of the deep sea, discovered recently by the United States Fish Commission.

Bassalia-the name given to the dark deep seas-

* "Electric Fishes." Dr M'Kendrick. Fortnightly Review, October IS93. 
is more or less illuminated, and light-producing organs are common to all the Bassalian fauna.

The primitive form of the animal lamp, as seen in these fishes, is a simple gland secreting mucus largely charged with phosphorus; but in the highly specialised fishes the light is undoubtedly electric. Thus, the Linophryne Lucifer carries a light on its forehead, like the miner's hat-lamp; while he trails a luminous bulb beneath as a bait. The Echiostoma Barbatum also trails an illuminated tassel, and has a row of jets along its sides, like the gleaming port-holes of an ocean steamer at night. The Chouliodus has a halllamp hanging in its huge mouth; while others have a luminous spot on the side of their heads, which, like a passing ship in the dark, shows either a red or green light.

It is rather marvellous to reflect that while men are only now perfecting means of lighting up their towns and houses with electricity, nature, through a lower set of organisms, has lit up the deep seas for probably untold ages. Man conceitedly thinks he is without a rival in the universe in intelligence, and truly his electric discoveries are wonderful, considering his opportunities, but he has not yet rivalled the fish in developing a reading lamp on his forehead to be switched on or off at pleasure.

With these proofs before us of numerous animals existing as living electric machines, and considering that all animals are more or less constructed in a similar way, with similar material and mechanisms, 
there should be little doubt that all are governed by a similar electric energy, though it may be exhibited in infinitely diverse ways. But of this more anon.

Animals as .Machines.-One of the most important points in connection with animal evolution is, that each animal, much more than a vegetal, is a machine. This mechanism, comparatively simple in a protozoon, becomes more and more complex as we ascend the scale of life, until it reaches its ultimatum, so far as we know, in man himself.

It may be profitable briefly to trace this increasing complexity, so as to show that all animal forms have not been created according to foreordained designs, but have evolved in a haphazard and even a bungling fashion, sufficient to discredit any omniscient Creator.

In order to grasp the changes in motor complexity between the protozoa and the metazoa, we begin with the amœba. In this typical example of the protozoon, the mechanism is rudimentary, almost structureless. It maintains no permanent form, indicates no definite organisation, and creates inconstant arms and legs ad libitum. When we remember, however, that it moves from place to place, that it catches and eats its own food, possesses a contractile vacuole, and contains millions of atoms if not millions of molecules in its body, it would be unwise to characterise it as either structureless or devoid of a mechanism. Yet, comparing its normal mechanical manifestations with its characteristic mode of reproducing itself by fission, 
we anticipate that no great complexity of mechanism could be attained, even by natural selection, on those suicidal lines alone.

Mollusca.-In the mollusca we have two distinct types of shell-fish-the bivalve and the univalve-but in both the mechanism is crude. For purposes of locomotion, the bivalve's machinery, as in the oyster, is practically useless, motion consisting almost solely in opening and closing the shell. Its life mechanism, on the other hand, is complex, comprising a stomach, gills both for receiving food and respiring, and quite a number of coloured eye spots set round the borders of its mantle, each organ necessarily fitted with proper muscular and nervous machinery. Razor-shells can dig, mussels anchor themselves to the rocks with their slender muscular organs called fect, while cockles jump by means of the same. We can conceive, however, of no very complex motor developing from the plan of imprisoning an animal in a bivalve shell. Lastly, although seemingly capitally constructed for defence, bivalves are not invulnerable, for they are at the mercy of such an enemy as the whelk, who, with his rasp, bores a hole through their armour and lunches at his leisure. Univalve shell-fish display more locomotion ; still, a snail is not a synonym for activity. The necessity of carrying their heritable property on their back is rather a handicap in the race of life and the survival of the fittest. Progress, moreover, is accomplished by a lengthening and shortening of one's self; a mode of motion necessarily 
awkward, tiresome, and slow, not capable of much improvement.

Crustacerns. - Although the mechanism of crustaceans is wonderfully complete in its way, and skilfully adapted to the peculiar mode of life manifested by them, yet the sidelong motion of crabs cannot be characterised a brilliant invention; while the plan of encasing animals in tight-fitting shells, which growing obesity dooms them to desert, thus endangering their lives each moult, can only be styled a clumsy expedient, the tentative contrivance of a blundering, mechanical apprentice. The connection between the vegetal and animal kingdoms is illustrated by crustaceans in that curious but useful habit, unfortunately not extended to men, of reproducing lost limbs. Thus crabs and lobsters may often be seen disporting with ill-assorted old and new claws.

Star-fishes, sand-stars, and brittlc-stars are all endowed with the same convenient faculty of mending themselves. Amputation, consequently, must be comparatively painless among the lower organisms, for brittle-stars especially are, exceedingly reckless with their appendages, sometimes snapping themselves into bits at the slightest provocation.

Locomotion becomes more highly developed in the lecch. Here a shell is discarded, although some seaworms live in horny tubes. No external locomotive organs are observable, and yet by merely lengthening and shortening themselves, leeches move comparatively 
quickly in the water. The motive machinery is contained in the innumerable muscles which form the ring-walls of its body, each worked by a system of nerves, connected with knots or nerve-centres down its back, and directed from a chief-centre in the head as a brain. It is also provided with suckers at either end for fastening itself. Intelligence, it will be observed, increases with the increase of sense organs, and, consequently, more complex machinery to work both senses and muscles.

The earthworm also progresses like the leech, but, in addition, it possesses incipient legs, in the shape of four pairs of bristles on each ring of its body. These are not used for walking, but for gripping the sides of its tunnel when boring with its head. Though blind and deaf, its sense of touch is highly developed, the slightest vibration on the ground sending it instantly to cover. It also grows a new tail when the old one has supplied the early bird with its breakfast. The mend is sometimes performed very clumsily too; but this may depend upon the nature of the amputation. Some marine worms use their bristles for walking. Others develop complicated machinery for other life-purposes-gills for breathing, aerating the blood, etc.

Caterpillars. - A curious development of locomotion characterises the "inch" caterpillar, which progresses by measuring its length at every stride. Other caterpillars and centipedes develop feet on each ring of their bodies. But, while this mode of pedestrianism 
betokens an advance on what we may call the "concertina" principle of locomotion, no great increase of speed is attainable on this model either. Increase of rings and legs only means more rings and legs to move. A new departure was inevitable. Nature must bestir herself and evolve something new. The desiderata were concentration of motors, increase of limb-length, better machinery for aerating the blood and a central nervous bureau for instantaneous direction and control. In other words, nature must construct a more complete electric and telegraphic mechanism.

These improvements were effected in two ways and among two sets of jointed animals-one set aquatic or pelagic, the crustaceans already mentioned; the other set terrestrial and aerial, spiders and insects. They occur in a strange fashion in the caterpillar itself. Thus after gorging for months and casting skin after skin like the crabs, as it increases in fatness, it at length on a final moult reappears as a mummy or chrysalis. After hibernating in this natural sarcophagus for months, resurrection ensues, and it bursts into its final stage as a beautiful butterfly.

Insects.-All insects metamorphose from the worm or grub condition, hence we might assume that the insect machinery is an evolution from the worm mechanism; but the two are quite distinct, the final organic machine bearing little resemblance to the sketch model. The insect body is divided into three parts-the middle compartment being the engine 
or dynamo room which contains those powerful muscles that move the legs and wings.

The great object in a body adapted for quick locomotion is strength combined with lightness. This is attained in the insect by the blood bathing the internal organs and muscles directly, without the aid of vessels; the blood aerating in a wholesale manner, not by gills or lungs, but by air-holes (spiracles) down their sides, which communicate with air reservoirs inside. These again divide and sub-divide into countless tubes with thousands of ramifications. A dragon-fly thus outstrips the swallow; while few animals can out-jump a flea, comparatively to its size. These extraordinary motor phenomena are seldom dwelt on, and fail to excite the wonder they deserve through their familiarity.

It must not, however, be imagined that the mechanism of all insects is perfect. Indeed, of all animals, insects present the most extraordinary and fantastic of organic combinations, ranging from the most dextrous, wonderful, beautiful, gorgeous, dazzling, amusing, artistic, and intelligent of living things, to the most clumsy, formidable, eccentric, repulsive, exasperating, disgusting, and.shocking. Thus, even in the matter of weapons and tools they furnish an appalling arsenal of armour, pincers, augers, pikes, hooks, horns, rasps, rollers, saws, stings, screws, sickles, lancets, mandibles, dentilated teeth, and cupping-glasses; while, as a whole, the insect world constitutes a complete "pharmacy, chemistry, and 
perfumery." Some eject poisons, caustic secretions and fulminating powders; some contain drugs, ethers, and dyes; while others emit odours, noxious or agreeable.

Out of such a medley of anomalous creations it is difficult to select typical examples of the accidental and automatic character of insect mechanism and life, but a few striking forms at once suggest themselves. For instance, the "walking leaf" (Phylliida), whose wings and legs are foliaceous; the beetle whose shrivelled-up wings are contained within soldered-up wing-cases; the moths and butterflies, whose excessive size of pinion entails an early death; the fire-flies of America which, Diogenes-like, carry a lamp with them; and the "bombardier" beetle which, on being disturbed, discharges a cloud of vapour that spreads and enables it to escape under cover. $\dagger$ But perhaps the most extraordinary and disgusting of all living things is the termite queen, an animal with unchanged head, but body so enormously swollen (sometimes two thousand times its normal size) that it is out of all proportion, while its fecundity is terrible, for it pours out an uninterrupted torrent of eggs at the rate of eighty thousand per day. Finally, when we remember that no less than 200,000 species of insects are known, while probably thousands more actually exist, imagination fails to convey to us any idea of the multitude of mechanical oddities in Insecta alone.

* "The Insect." Michelet, p. 195.

† These phenomena are undoubtedly the result of electric action. 
Birds.-In the mechanism of a fast-flying bird, its shape is skilfully adapted to cleaving the air. Its bones are, for lightness, hollow cylinders, and so constructed for strength that weight for weight they are six times as strong as cast iron. The hollow spaces connect with the lungs, and can be filled with air or emptied as occasion requires. As in the insect, abundant means also exist for purifying and aerating the blood. An engine burns fuel according to the amount of work done; so does an organism. Some birds (the swallow and sparrow) are model highpressure engines, consuming as much as their own weight of food per day. There is a vast difference, however, between the natural and artificial machine in the quantity of fuel expended and the resultant energy obtained. Thus the human body utilises every fraction of its heat, while the locomotive wastes 90 per cent. of its fuel.

All the motions of animals are effected by the shortening or contraction of their muscles. The great muscle which moves the wing of an albatross contracts at each stroke with a force of about $30 \mathrm{lbs}$. The rapidity of the wing-strokes of birds is also amazing. Thus the lazy-flying heron executes I 50 strokes per minute; the wild duck 540; and the sparrow, 780. Again, the hawk for long distances attains a speed of 150 miles an hour. The energy which accomplishes all this activity is said to result from electricity evolved by chemical action; every nerve and muscle in their movements receiving and 
discharging a current of electricity. This statement is interesting in view of our magnetic and electric hypotheses, unthought of as they are by the world of science at present.

The wings of birds are also perfectly adapted to their purpose. The feathers are both strong and light, yielding at the upstroke but rigid in the down. Organic conditions have, however, accorded to the bird less efficient pinions than the insect, for the broad end of the wing in birds is nearest the body instead of outermost as in insects. But more powerful muscles are required to work the latter; consequently when great size of pinion is attained, as in butterflies and moths, without efficient working machinery, weakness and sluggishness supervene. On the other hand, when wing, weight, and working power are accurately balanced, as in the dragon-fly, no bird can outstrip it.

Finally, despite the excellence of the bird machinery generally, few are perfect flying machines. As in insects, infinite grades of motor mechanism abound, showing infinite varieties of sketch models, from the eagle to the dodo, while monstrosities are not uncommon. The ostrich's wings, for instance, only assist it in running; and the penguin's for paddling in the water or scudding over its surface. Barn fowls are not particularly aerial, while the arctic auk, the garfou, and the puffin are mere caricatures of birds. Indeed, when we consider that no less than 5000 species of birds are known, each with its own special 
mechanism, aves must be admitted to contain quite as heterogeneous a collection of models as insecta, and such as might be expected to evolve spontaneously from the natural automatic working of automatic matter-in-motion, once the archetypal bird organism had in the course of time and circumstance developed itself. Taken altogether, birds furnish no more evidence of intelligent design by an Intelligent Designer than other organisms lower in the scale of life.

Of motor mechanisms either higher or lower than those mentioned, it is unnecessary for the purposes of the New Materialism to detail; for their forms are just as fantastic and numerous, and their spontaneous evolution no more difficult than the natural creation of a sponge. The complexity and wondrousness of the motions evolved neither vitiates our theory of their common material origin, nor alters our conception of their fundamental and haphazard generation. The substance, energy, and functions of the highest animals are, in essentials, not one whit higher or less material than those of the lowest. Each and all are composed of the same matter, their life all arises from the same fundamental energy, and their functions all develop from the same reactions of stimuli.

Man, for instance, is a complex mechanism built up of a number of infinitely complex sub-mechanisms. These sub-mechanisms are common to almost all animals, though they may work in infinitely different 
ways. Hence, although animal mechanism is said by man, naïvely enough, to reach its ultimate development in himself, the life-motion fundamentally is alike in all organisms.

For instance, man's eye comprises millions of fibres, connected with millions of cells and fibres in the body and brain to work it. Whenever, therefore, we observe an eye in a bird, a fish, an insect, or only a pigment spot in a protozoon, we immediately infer, and rightly so, that this eye subserves the same purpose of sight to the animal as it does to the man; that it is equally a mechanism, connected either with a brain or a nerve-centre acting as an equivalent; and that if not composed of millions of cells and fibres, it has at least thousands, which, equally with those in man, automatically know their work and automatically do it. Similarly with all the senses or tell-tale organs, each and all are intricate mechanisms, comprising millions of fibres connected with the brain and motor muscles of the body, and all acting automatically. Thus, if a man's eyes are open he cannot help seeing; if his ears are unclosed he cannot help hearing; if his tongue touches substances he tastes; while he smells and responds to the normal sense of touch, all automatically.

Although, moreover, all these senses may be taught, developed, and improved, this organic adaptiveness does not vitiate the fundamental character of organic automatism; it only increases our wonder at its complexity. Further, if food be injected into a man's 
stomach, he automatically digests it. He respires, shivers, sneezes, and coughs, all automatically, every action responding reflexly as question and answer to some stimulus from without. Motion within in every action is but the complement to motion without; hence also life within is but the complement to life without. This sweeping deduction, however, involves such momentous issues that it requires more detailed proof. This is given in a later chapter.

In conclusion, respecting the mechanism of animals from an amceba to a man, the essential differences between them arise solely from size, pattern, and complexity. The motor energy or life of all organisms emerges, as already indicated, and as we shall further detail, from the same source, the inherent motion of the atoms, and is complicated in infinite ways by the infinite modes in which magnetism and electricity may be made to work. 


\section{CHAPTER XIV.}

\section{Causes of Animal Evolution.}

(I) Animal Substance.-Although animal substance differs from vegetal and mineral substance, yet this difference is more structural than constitutional; for the same elements which form animals form also vegetals and minerals.

The elements which form organic substance are sixteen in number, eight being non-metallics and eight metallics, as follows:-oxygen, nitrogen, carbon, silicon, sulphur, phosphorus, chlorine, iodine; along with hydrogen, potassium, sodium, calcium, magnesium, aluminium, iron, and manganese. Animal substance is thus a dual or sexual compound.

(2) Cells and Unicellular Animals.-The evolution of an animal cell or a unicellular animal from elementary matter is no more difficult to natural laws than the evolution of a vegetal cell or a unicellular vegetal from the same or similar substance. The component atoms may differ, but only slightly, while the processes of evolution must be governed by the same 
primary laws. The atoms are never at rest. All the laws which control their motion are ever operating. A combination of atoms as substance can thus never remain unformed, but must assume one structural condition after another eternally. No thing or body in nature, crystal, plant, or animal is the same for two consecutive seconds: hence there is a certain amount of absurdity in man claiming an individuality and an individual immortality. If in such apparently stable crystals as diamonds, present science assures us that the atoms "dash against each other millions of times in a second," what must they not be doing in such unstable compounds as animal cells, or in unformed substance. The evolution of cells therefore from a chance aggregation of suitable material is just as likely to happen as any other formation. It is only nature sprouting.

Huxley says:- "The process of development of the egg, like that of the seed, is neither more nor less mysterious than that in virtue of which the molecules of water, when it is cooled down to the freezing point, build themselves up into regular crystals."*

But he might have gone a stage further, and asserted that the spontaneous or automatic formation of animal and vegetal cells also indicates nothing more mysterious in their processes of development from the sexual atoms and molecules. Even as on a frosty night the surface of the ground is whitened with crystals of rime, so in many a river and ocean 
bed the water must often coagulate with millions of vegetal and animal cells.

It will be unnecessary for us to describe the probable mode of the automatic evolution of animal cells, for the process must be similar to that already described for vegetal cells. We thus pass on to the evolution of the unicellular animal.

The simplest unicellular protozoon, though apparently a homogeneous mass of jelly, is a complex chemical compound. The first endeavour of the aggregated cell molecules (automatic, of course, and resulting from the fact that these cell constituents are themselves magnets) is to form a magnetic battery in which chemical action may have free scope. But in these low forms the body is all stomach or all battery, a living magnetic battery which absorbs all over its surface, and digests all through its substance. These living batteries grow by absorbing or feeding upon (practically attracting) like material to themselves, either organic or inorganic, probably both, likematerial-attraction assisting. The food then dissolves by chemical action in the battery, and the disengaged material is distributed through the organism. The energy resulting from this chemical action further thrills all through the animal's body, as magnetism or electricity, endows it with what we call its life, and automatically directs all its life actions.

In seizing and devouring other animals near it, the action is probably caused by irritation of its sense of touch, felt on its surface and induced through the 
motions of the prey, the act of seizure being but the automatic or reflex action resulting from the nature of the stimulus.

Dr Allman gave an interesting address before the British Association (1879) "On irritability as a property of every living cell." But if, as we have proved, all substance is magnetic, the irritability which one minute cell exerts on another cell cannot fundamentally differ from the irritation of a magnetic needle by a magnet. Even as iron knows of the proximity of iron, so organic matter must in a similar way know of the proximity of organic matter; an animal is thus only a thinking magnet. In their conjugation and fusion, these simple protozoa blend their substances like wines. This fusion does not differ materially from the amalgamation of several globules of quicksilver into one large drop. The result however differs, for it is a sexual process. Germination and the reproduction of spores ensue; too much mixture of like matter in an active centre resulting in "like-central-repulsion," and the ejection of seed.

The whole life-history of the lowest protozoon, as revealed by Professor Ray Lankester and others, inerely resolves itself into the automatic operation of the primary laws which gorern inorganic matter. All organisms are dual in material, metallic and nonmetallic. They grow by absorbing or feeding upon like material according to the law of likc-matcrial attraction. The food dissolves by chemical action in the vacuoles as in a magnetic battery, while the dis- 
engaged material and electric energy disperse through the animal by like-polar repulsion, or like-central-repulsion. Reproduction is automatic, mechanical, and chemical; for material combination only happens when the compound contains the dual elementsmetallic and non-metallic. Again, even as combination in simple chemical compounds only occurs in definite proportions, or according to the combining weights of the elements, so the nature of the combined animal constituents, as well as the result of reproduction, is determined, as in plants, solely by the combining formula of the type-cell. Hence when this combination or cyst ruptures, the duality of the compound manifests itself in the duality of the segments; for males and females in all low forms are virtually complete animals broken in two, and only needing to be re-united or their sexual substances again blended in order to complete the cycle, or normal life-processes of the animal's existence.

Over twenty thousand different species of protozoa are known, but they probably number hundreds of thousands. As the earth contains infinite room for such minute organisms, as the automatic motions of matter are illimitable in variation and complexity, as the lowest protozoic life is a mere chemical existence, and as generation must automatically ensue whenever conditions are favourable, we may warrantably assume that there is a daily entrance and exit of millions of ultra-microscopic protozoa into the world, even as millions of crystals spontaneously sprout on a frosty 
night, and as spontaneously dissolve with the morning dew.

(3) Animal Structure.-As we have seen, all animals originate from a living cell or germ. Biologists now believe that when two or more cells unite and form a multicellular animal each cell still remains distinct and lives an individual as well as a collective life. Hence every animal is but a colony of individuals, a veritable "cell-monarchy" as Haeckel says (even as a plant is a "cell-republic") bound together temporarily for a common purpose. This startling hypothesis we can understand in the corals, sponges, and zoophytes, but when applied to man our credulity is tasked. Yet so far as can be judged, facts are on the side of the biologists. For all animals are but an agglomeration of identical cells, specialised however to perform different functions according to their position in the body. These cells moreover increase or renew themselves by interminably dividing and re-dividing themselves, so that likeness of parts is permanently retained. Thus the squint eye always remains squint and the snub nose snub.

While the structure or what we might call the grain of animals, is thus merely an agglomeration of cells; yet in the development of the animal mechanism from the simple into the infinitely complex, the evidence shows that the improvements have been accidental and haphazard. For as all motion and all action in nature is automatic, nature has no plan, specification, or architect. What is formed or produced in structure, 
as in everything else, just comes without any foresight whatever. Everything is undoubtedly produced by inviolable law, but no law working towards a premeditated end. There is thus a delightful sense of expectancy, wonder, newness, and anticipation in universal operations. Everything is possible, but only the actual happens.

The sequence of structural differentiation proceeds somewhat on the following lines in all animals.

All animal cells are alike in appearance, and consist of a cell-wall enclosing protoplasmic elements in solution. After impregnation a cell attracts and aggregates protoplasmic components similar to itself from its environments. This action constitutes growth. After attaining maturity it divides similarly to the vegetal cell.

Continued fission or cell-division results in an aggregate of cells or cell-aggregate; then follows the formation of an external layer of small polyhedral cells round the cell-aggregate, called the blastoderm, the interior cavity being filled with fluid. Such an organism is called a plamula. Next, invagination occurs, or the pushing in of one side of the spheroid planula, until from a cup it grows into a double-walled sac with an opening; in other words, a mouth and stomach are formed. This constitutes a gastmula, the simplest ancestral form of the metazoa, that is, all animals above protozoa.

The outer layer or epidermis of this gastrula is called the epiblast, and the inner the hypoblast. But 
during the process of invagination, a central layer of cells has been growing between the outer and inner layers, called the mesoblast. The significant organic facts in connection with these layers are that from the epiblast are developed the permanent epidermis and the outgrowths, the nervous system, and the organs of sense; from the hypoblast-the alimentary canal, liver, pancreas, etc.; and from the mesoblast-the bones, muscles, heart, blood-vessels, lymphatics, etc.

From the gastrula stage a marked differentiation begins, and the hidden constitutional features of each organism become more and more developed until such unlike creatures as fishes, birds, and beasts diverge into their several classes, orders, and genera.

(4) Animal Mechanism.-The animal mechanism is dual. The one section works the body in all its life processes, such as digestion, the circulation of the blood, the action of the liver, kidneys, spleen, etc., and does so unconsciously. The other connects the animal with its externals through its sense organs, and does so more or less consciously. But although dual, the two mechanisms are so inter-related or inter-woven that the growth or development of both from the lowest animal to the highest proceeds contemporaneously.

A protozoon's mechanism does not seem to be dual, for it is apparently without sense organs, but in its epidermis or whole external envelope it possesses an organ practically comprising all the fire senses.

As a living magnetic machine, the chief mechanism 
of every animal is the stomach or central battery. This is the first definite organ, and all the others follow in most haphazard fashion. What all animal mechanisms are and how they have been evolved is no part of our business. This may be obtained in any encyclopredia. It is only necessary for us to say that from eridence no mechanism from the highest to the lowest is beyond the power or reach of the primary laws working automatically and harmoniously, for many animals are faulty in the extreme; even cripples among men are not infrequent. In fact, summarising the whole field of animal mechanism, there is among the lower animals especially a crudity, clumsiness, and eccentricity which can only be attributed to accident. No omnipotent and intelligent Creator could father them and claim any credit for their construction. Witness the oddity of producing a prehensile organ out of the nose of an elephant and the tail of a monkey; the absurdity of furnishing beetles with wings in soldered-up cases; the farce of providing a bee with a sting used only to compass its own death; the murderous instincts of the queen bee towards her daughters; the untoward fate of a bee prince consort; the risk man runs of choking at every meal ; and the whole business of external metamorphosis generally, with the danger attendant to moult in birds, crustaceans, and snakes.

Further, tracing up the development of a single organ or limb from the lowest animal to the highest, we obtain overwhelming evidence that Nature at her 
average is but a blundering apprentice, and only rarely becomes a journeyman. Thus the leg passes through thousands of transformations, very few of which could be pronounced perfect, although they all answer their purpose more or less well. Starting from the simple pseudopodia of the amœba, and passing on to the sting ray of the actinophrys, the flagellum of the flagellata, the cilia of the ciliata, the stiff striated flagellum of the noctiluca, the muscular ambulatory setre of the higher ciliata, and the suctorial tentacles of the acinetaria, we leave the protozoa and follow the same limb through the bristles on earthworms and the myriad kinds of locomotors on centipedes, spiders, crabs, lobsters, frogs, lizards, birds, seals, bats, horses, dogs, and monkeys, until we come to what we consider the well-proportioned leg of man himself; and yet who can say it is the most useful that could be constructed. In fact, we practically say it is not, for we use stilts to give us increased height, and bicycles to give us increased speed.

After examining all nature's handiwork, we find that she has no ideals, no set type, and no perfect mould; she is merely ever trying by practical experiment and temporary model to invent the mechanism best fitted to the needs of each animal in its everchanging conditions of existence in water, air, or on land; but the result is not always a triumph, nor even to her credit. Indeed, far from this being the case, she even displays a want of judgment in not adhering to a good type when found, for not only 
have we a record of her progress, her successes, and failures in almost every department of animal mechanics, but in embryology and metamorphosis we have demonstrative evidence also of her regress, of higher forms incontinently discarded for lower. This is conspicuous in the evolution of the barnacle, as observed by Darwin, for the mature cirrepedia is lower in the scale of organisation than its larva. The larva in the first stage have three pairs of legs, a very simple single eye, and a probosciformed mouth with which they feed largely. In the second stage, answering to the chrysalis stages of butterflies, they have six pairs of beautifully constructed natatory legs, a pair of magnificent compound eyes and extremely complex antenna, but a closed and imperfect mouth which prevents them feeding. In the third and last stage their legs are converted into prehensile organs, and they again obtain a well-constructed mouth, but they have no antennæ, and their two eyes are now reconverted into a minute and very simple eye-spot.* On no other hypothesis save that of accidental evolution could we account for such arbitrary, not to say stupid, transformations.

Again, when anatomists, botanists, and biologists respectively assure us that the mammal skull is formed of 'metamorphosed vertebre; that the crab's jaws are metamorphosed legs; that the sepals, petals, stamens, and pistils of a flower are metamorphosed leaves arranged in a spire; and that all the different 
sense-organs of an animal are originally only specialised parts of the sensitive external integument, we then comprehend in some small degree the mode by which many, if not all, mechanical eccentricities in animal forms have been accidentally developed by automatic laws. We can also understand how organisms are independent of supernatural agents, while it is further obvious that the whole scheme of universal existence shows no intentional struggle after those higher ideals hitherto postulated by inspired sciolists as nature's "chief end."

Lastly, among the legions of mechanical models indigenous to earth, it is but natural that some should be admirably adapted to their life conditions. Thus, few organisms are more perfect than the salmon for swimming, the swallow for flying, the greyhound for coursing, and man for handiwork. Yet no animal, not even man, is perfect, for nothing living adequately fulfils our ideal of a form best fitted for mundane, not to say universal, existence. Nature through her ordinary agencies has obviously attempted (accidentally) to combine an xerial, a terrestrial, and an aquatic existence, but the products, such as the penguin and garfou, are ludicrous.

The perfect animal, according to current opinion, would be an angel, at home everywhere; but angels are only poets' dream-stuff.

Assuming then that animals in their structure and mechanism are haphazard and cliance, the sport of spontancous creation and accidental development, the 
earth should contain shoals of mechanical models in every sub-kingdom, ranging from the most clumsy and awkward of contrivances to the most skilful, ingenious, and perfectly equipped. This we find, for a more heterogeneous museum of motor anomalies could not be swarmed in nightmare than abounds on our congested planet, from a suctorial acinetarian to a termite queen, or from an ornithorynchus to a Siamese-twin.

(5) Animal Reproduction.-According to a French writer, the beautiful is simply an excess of the useful, and reproduction simply an excess of nourishment. So long as nourishment in low organisms conduces to growth, then growth only is the result, but when surfeit occurs, reproduction takes place and the organism divides into two.

Keeping in view our magnetic theory, this hypothesis of reproduction could be illustrated in a simple manner. Thus, if we take a bar magnet, and holding it up load one end with iron filings, a time would come when the magnet would not be able to sustain the weight of added filings. The superabundant mass would then drop, and through being magnetised by the magnet would retain its magnetism and thus form another magnet; a virtual child-magnet produced by over-feeding the parent.

Coupling this theory with what has been now advanced regarding the evolution of animal cells, structure, and animal mechanism, it will be obvious that production and reproduction are simple chemical 
and mechanical processes, alike in man and the lower animals as well as in vegetals and minerals. The generation of a human ovule in a human ovary resembles fundamentally in all essential particulars the isolation or fission of an amœba, the budding of a coral, the fructification of a fungus, or the petrifaction of a crystal. In all cases organic generation merely consists of the isolation of a cell, or concrete fragment of matter, embodying the fundamental character, constitution, and essence of the organism; a process simple enough in natural operations when we remember that minerals are only infinite aggregations of mineral molecules, vegetals infinite aggregations of vegetal cells, and animals infinite aggregations of animal cells.

Further, while the conversion of mineral molecules into crystals is due merely to their aggregation in a suitable solution under suitable conditions, the conversion of vegetal and animal cells into ovules or eggs only happens from their more specialised aggregation in that interesting chamber of the organism, the ovary; a modification of growth as natural as the metamorphosis of leaves into flowers and fruit. The mechanical nature of the operation, too, is strikingly evinced in the immense number of ovules and eggs generated by various animals. Witness the daily issue of $\$ 0,000$ from that organic egg-manufactory, the termite queen, swollen out of all proportion with over-feeding; the million and a half laid by the queen-bee, and the quintillion de- 
posited by the aphis or plant-louse. Again, the herring produces 25,000 ova ; the lump-fish, 155,000 ; the halibut, 3,500,000; the sturgeon, 7,635,000; and the codfish and oyster no less than from nine to ten millions.

(6) Animal Form. - The normal animal form differs from the normal mineral or vegetal form in a striking degree. The reason why it is so is obvious, for, like all else in nature, animals are in their form subservient to the universal law of design-Polarity. In them the design, following the lines of force, is from the centre or stomach-battery outwards. But, as the animal is not stationary like the plant, the polarity is less marked; yet, even in man, if he stands navel deep in water, with outstretched limbs, the evidence of polaric design is conspicuous in his bifurcation, his legs and toes forming one pole, corresponding to the roots of the plant, his arms and fingers another, corresponding to the branches. Even, therefore, as we see innumerable forms produced in the mineral and vegetal kingdoms by the action of the polaric law, so there is no limit to the operation of the same law in the animal kingdom. No design drawn by man is so beautiful that it is not excelled by innumerable animals, and none so hideous but that living monsters rival it.

(7) Animal Energy and Life.-The British Association is a scientific thermometer which registers yearly the maximum point of the world's scientific knowledge. Thus, at Oxford 1894, Lord Salisbury, as 
President, said :- "Life is the action of an unknown force on ordinary matter." "What is the mysterious impulse which is able to strike across the ordinary laws of matter and twist them for a moment from their path?" This view, we may assume, is the current notion of life, and perhaps it is the only one consistent with received data. But our readers should now be so familiar with the effects of the automatic laws and the bases of the New Materialism that they ought to see no mystcry in it.

In the first place, as already explained, life is not an "unknown force," for no force is more familiar than magnetism; and, secondly, it is no "impulse" different from the "ordinary laws of matter," but one of the most ordinary laws known.

We here associate animal energy with animal life, for both, as in the lower kingdoms, are virtually alike. In animals, however, as well as in vegetals, the energy or life is dual, and results from the separate conditions of the component substance.

Thus, the constituents of an animal viewed simply as elementary constituents, are, as repeatedly said, magnets, hence an animal as a mere mass of conjoined magnets would, like a. bar of iron, be a combined magnet with an individual polarity. It has thus the energy or magnetism resulting from mass, and manifests gravity, attraction, and repulsion. But, as also a machine containing a virtual magnetic battery in its stomach, as already described, it has a special energy as a magnetic machine. 
To make the point clear, it can be demonstrated that the causes which generate mechanical motion in a locomotive produce almost identical dual energies in an animal.

Thus, a locomotive on leaving the workshop is apparently, but not actually, motionless. According to Mr Herbert Spencer's definition of life ("the continuous adjustment of internal relations to external relations") it is, even alive; for, by contracting and expanding according to the temperature, like a thermometer, it is constantly adjusting its internal relations to its external relations. Nextly, it is ever pressing with all its weight (gravity) against the ground. And lastly, it is a huge magnet, for, if tested with a compass, all its upper surfaces attract the north pole of the needle, and its lower surfaces the south pole. (This is the case with all iron structures, even the Forth Bridge, as already said). These motions, generally unobserved or ignored by scientists, the locomotive possesses in virtue of its material constitution, and it exerts them as regularly and constantly as the ocean in its ebb and flow, or as the earth in its ceaseless rotation. In addition to this natural material motion (which maty be called its "energy"), the locomotive is fitted up for a special mode of motion (which may be called its "life") as a locomotive. This life, however, is only ephemeral, characteristic of it only so long as certain inviolable conditions are complied with. In other words, it must be fed, or supplied with water and fuel. But 
the essence of feeding in effecting motion in any organism or mechanism is simply to produce a stimulus. In effect, one kind of motion (chemical action) only evokes another kind of motion (locomotion); for energy cannot vanish, it only changes from one mode of motion into another eternally.

Further, the digestion of food or the combustion of fuel involves consumption of food and fuel and the expenditure of energy; hence, in order to sustain the "life" exhausted by the locomotive in moving itself -practically the opposite of Spencer's definition of life, the continuous adjustment of external to internal relations-the machine requires constant feeding with suitable fuel. In other words, a going locomotive requires coal, water, and air, in motion, which yield as the residuum of their spent energy, steam, smoke, ashes, and motion. But in those changed conditions the fuel is no longer fuel but cinders, material unfit for locomotive use; consequently, the real fuel supply must be continuous, or else the engine's locomotive life, so to speak, stops.

We now ask, Has the animal a similar dual energy and life? One, its cnergy, associated with its material; and the other, its life, associated with its mechanism? The answer is clearly affirmative. An animal is composed of similar elementary matter to a locomotive, but, in addition to iron-of which it possesses little - it contains numerous other more unstable elements-oxygen, hydrogen, carbon, nitrogen, etc. These elements equally with iron exert motion as 
gravity, and in the case even of a corpse, exert energy, for the body in decomposition is continuously "adjusting its internal relations to its external relations," the rapidity of decomposition corresponding to the temperature and state of purity of the atmosphere.

The animal life, on the other hand, comprises those more ephemeral motions, associated with the temporary locomotion and mechanism of the animal as an individual body, and is caused by and originates solely in its magnetic animal battery in the stomach.

The conditions of mechanical life in the animal organism are thus in essentials, precisely similar to the conditions of mechanical life in the locomotive. In the animal stomach (furnace, boiler, and voltaic battery in one) the fuel or food is burnt, digested, or oxidised, thereby generating energy which tingles all through the body as heat, electricity, vitality, or life. The food on oxidation is converted into blood, which bathes the internal machinery by means of the veins and arteries, and executes all needed repairs in bone, muscle, and nerve. The refuse from the stomach is excreted, but the waste from the muscles is either exuded by the pores of the skin, or thrown as carbonic acid and water into the blood, where it is ultimately purified at the lungs.

The whole of this mechanical motion called animal life is thus as entirely automatic as the burning of fuel, the generation of steam, and the development 
of energy in the locomotive, and requires no effort even of consciousness; for when we are asleep our food is digested, oxidised, converted into blood, and passed automatically through all the other stages of its usefulness, so long as it is associated with us.

Life, notwithstanding its importance to us, is thus by the evidence a mere adventitious existence, a sort of haphazard or chance manifestation of eternally living or moving matter in magnetic bodies such as our own, which accident or chance conditions set agoing on earth, which changed environments have rendered more and more complex, and which natural selection through automatic law maintains so long as conditions are favourable.

The evolution of life is thus neither more nor less mysterious than the evolution of any other form of material energy, but it requires a particular kind of mechanism to exhibit it. The nature and complexity of this organic mechanism, from its simplest to its highest electric form, thus constitutes the sole difference between one form of life and another. That human life should be deemed higher than any other kind of life is a harmless infatuation, soothing to weak minds and a sop to man's incurable vanity.

(8) The Inter-relation of Life and Death.-In connection with animal life, we may here mention that a startling and strikingly suggestive problem, significant of the times, recently stirred biological circles to thei: utmost depths, respecting the relation of life to death in organisms. As pointed out by Professors Ray 
Lankester* and August Weismann, $†$ the protozoon, which increases by fission, practically never dies. In the amoba, for instance, the one half of it is as much the amoeba's self as the other half; consequently, when the sub-division of amœbre continues indefinitely, the relationship of the millionth amoba about to segment to the common progenitor of the suicidal million, is virtually the same. An amœba thus never dies, for even supposing that millions of them are swallowed, digested, assimilated, or destroyed, the primordial amœba still lives-as an infinitesimal fraction of being - in its continuous self-splitting posterity.

Similarly in the vegetal kingdom, the sole endeavour of a plant is to live in the best way it can. Reproduction constitutes a part of this endeavour, and consists in a virtual continuance of a vegetal's existence; for the seed of a plant is only a fragment of its living self detached; hence, when this seed lives, the plant lives. In other words, vegetal reproduction is only a modified function of automatic growth (flowers and fruit being merely modified leaves and cells); hence, to a fruitful tree death comes not, it survives in its progeny for ever; every tree of a forest of the same species being not only brothers but

* "Article Protozoa," Ency. Brit.

+ Prof. Weismann advocates the immortality of unicellular organisms and the reproductive cells of the metazoa. The somatic cells of the metazoa, which undertake the providing of sustenance for the organism, he does not consider immortal. Contemporary Revieu', October, 1893 . 
actually members of the same individual. It matters not, therefore, whether one of these related trees or a thousand of them be uprooted, the parent tree's immortality is ensured by its living representatives.

But if this be the kinship in plants and low animal organisms, it does not crucially differ in the higher animals; for growth and reproduction by cell-formation and cell-aggregation are alike in all organisms. Hence (adopting the theory of the spontaneous evolution of primordial cells) the ancestral germ of a man or any other animal, even though evolved millions of years ago, still lives; for it grew and increased similarly to an amoba, by halving and interminably halving itself. Whether, therefore, these halves aggregated into special forms or became detached and then aggregated into other forms, involves no essential difference to the immortal cell; for the relationship of every halved cell, and consequently the relationship of every aggregate of those halved cells is alike, so far at least as its life is concerned. Finally, whether millions of men have dissipated into dust or not is immaterial as regards the life of the original human cell, for the remaining men and their aggregated cells still constitute the primordial human cell in perpetual suicide.

Death, therefore, in a sense, no more assails animals and plants than crystals. Individually, the child through its cellular aggregation is as much a growth of the parent as the parent's own fingers or toes; hence, a man, in his children, may be enjoying a 
dozen different lives at once; he himself but extending in a diluted form the lives of his great grandfathers and grandmothers. In a restricted sense, therefore, only the sterile and unfruitful perish as human beings, for so long as a man leaves direct descendants on earth, he lives. True, this fact may afford small satisfaction to a dying man, but we have no other choice in the matter. We have come without asking and we shall go without leave.

Another kindred speculation is suggested here. If, as all observation assures us, the atomic constituents of our bodies are constantly attaching themselves to us and leaving us again with every breath that we draw, no man can even claim his own body, wherein dwells his individuality, as a permanent possession, or, more curiously, that he is even limself for two consecutive days.* Composed as he is of unstable elements soiely on loan, which change day by day and hour to hour, his ephemeral constituents are as the wind which passeth over him. That which is himself to-day is compost to-morrow; and that which he shall be to-morrow is roast beef and plum pudding to-day. A man may thus be called a cannibal and a phoenix, because, through eating the manured products of agriculture around him, he

* Though this conception of existence was taught over two thousand years ago, it was probably as little considered then as now. Thus Heraclitus says :- "We are and are not the same for two consecutive seconds; the fire in us is perpetually becoming water, and the water earth, but as the nppnsite process goes on simultaneously we appear to remain the same," 
is constantly renewing his being from the embers of his own and others' decay. He is but the flame of a candle, alive only so long as he is alight.

(9) Animal Intelligence.-As the heritage of past ignorance and the treasure trove of theological superstition, man, until recently, claimed possession of an intelligence distinct from that of the lower animals. But the researches of Darwin, Romanes, Buechner, Lubbock, and others have shown that the objections to extending a mind, or its equivalent, to animals, are as frivolous as man's arrogant attempts to retain a monopoly of it have been both whimsical and pitiful.

In the first place, What is Animal Intelligence?

Fundamentally, it is solely discriminate motion or the power or faculty of accurate selection; the purpose of which selection primarily is to enable animals to supply themselves with like materials to themselves, as food; to protect themselves from enemies; and, generally, to help them to live to the best advantage for themselves and their kind. Problems, of course, which the lowest organisms only perceive and solve automatically.

A preliminary query thus is, What is the mechanism and motive power of animal intelligence?

As animals are of infinite kinds, ranging from the simplest unicellular organism with no more apparent structure than a speck of mucilage, to insects, birds, and apes, with infinitely complex mechanisms, it follows that intelligence must more or less mark time 
with the complexity of the animal's mechanism, and especially with the complexity of its nervous and sensory systems.

We have seen that the sense organs and mental machinery of the higher animals have been evolved by their gastrula ancestors out of their epiblast, or external integument or skin cells. It thus follows that the epidermis of a low protozoon is a comp:ehensive sense-organ, combining in a primitive fashion all the sense organs of the higher animals. This leads us to ask, Is there a fundamental sense, a sense comprising all the senses, and of which all the more specialised senses of the higher animals are but offshoots?

The sense of touch may be so regarded. It is perceived by us as well as the protozoon all over our body, internally and externally. But higher animals have, in addition to the gross sense of touch, subtler organs of touch which we call sight, hearing, smelling, and tasting. Yet when we analyse these senses, their organs and their mechanism, we find that, fundamentally, the action of all the senses may be resolved into tonch and its re-action. The touches or vibrations on the eye or ear are indeed surpassingly subtle, but they are none the less touches. We are thus bound to deduce that not only may the lowest or most incipient form of animal intelligence be resolved into touch and its re-actions, but we are bound to assume also that any animal, even the highest, possessed as all are of only tactile senses, can hav' no higher form 
of intelligence and no higher form of mind than can be. constructed out of touch. That whatever is perceived and that whatever is done by any animal is merely the action and re-action of touches. Finally, therefore, we reach the startling conclusion that even conscionsness is touch and its re-action, and that any animal is conscious of anything and everything, through any one sense or through all its senses, simply because it has been touched; the re-action, whatever form of intelligence it may take, being but a continuation of this consciousness in the manner which each animal through its environments has taught itself. How touch and re-touch are the whole of consciousness in the animal is the great physiological and metaphysical puzzle; a problem we deal fully with in Human Intelligence.

Nextly, What does the mechanism of touch consist of?

In low organisms as it is the epidermis only which is touched, a nervous mechanism springing from it grows and pervades the whole body.

In higher animals this nervous mechanism forms knots, nerve-centres or ganglia, the incipient animal brains. Thus, in the leech, the nervous system consists of fibres ramifying from all parts of its body to a series of nerve-centres down its back, each centre being an automatic switch both for receiving and transmitting external and internal touches or vibrations. As we ascend the animal scale the sense organs begin to develop. Thus, where the eye eventually appears, there is simply a pigment spot. This, 
however, becomes more and more complex, until the perfect eye of the bird or mammal is at last evolved with its millions of fibres and cells. Similarly with the other sense organs. Still, whatever form the senses may eventually assume, inasmuch as they all originated from touch, so also in their most complex forms they are still adapted to receive, and can only be played upon by means of touch, however subtle these touches may be.

With the evolution and growth of the sense organs and their connections there is also a corresponding centralisation of the nervous system. The animal telegraphic system demands an office. Thus while the nervous centres in different parts of the higher animals are still retained for automatically working various sections of the animal machinery; there also evolves a chief nerve-centre, sensorium, or brain, for co-operating with all the senses, as well as guiding and controlling the nervous and muscular systems of the body as a whole. The brain, however, in all animals is still an organ of touch, and acts as but an automatic switch in simply receiving and transmitting touches. Hence, we reach the reduction, startling in its rank materialism, that all intelligence is but matter signalling to matter throughout the length and breadth and infuity of the universe.

Assuming then, as proved, that all animal intelligence is but touch and re-touch, we require to account for the subtlety of these mental touches, and the accuracy with which they act. 
As in mineral and vegetal intelligence, the chief agent of animal intelligence is again magnetism or electricity.

A living organic cell or low form of protozoon is, like everything else, composed of magnetic atoms and is a magnet. But as shown, it is more,-it is a living magnet, worked by a natural magnetic battery. But a magnetic battery composed of organic elements in solution must exhibit a different energy from a galvanic battery. Even as an iron magnet shows by its action that it knows of the presence of another iron magnet by attracting or repelling the stranger, so the animal magnet and battery have a similar knowledge of the presence of organisms, composed of like or unlike material to it, which approach it. Thus is it enabled to feed by absorbing like organisms, and save itself by repelling or fleeing from unlike organisms. The whole of low animal intelligence is thus animal magnetism, or animal attraction and repulsion.

When cells aggregate and form larger and more complex animals, the battery, as well as the muscular and nervous machinery connected with it, becomes also more complex. We have thus seen that the nervous machinery forms first into ganglia, then larger nerve-centres, and lastly brains, connected with sense-organs and infinite sub-offices and organs. But the stomach or battery remains practically the same in all, an organ which dissolves food or material by chemical action, and so produces an energy identical 
with magnetism or electricity in as much as it pervades the nerves as a virtual electric circulation.

While the intelligence of the lowest animal is thus allied to magnetic manifestations, that of the highest is akin to electrical action.

That this electricity works the animal machinery somewhat differently, and by different agents from an artificial electric machine is what might be expected, but that the points of resemblance are numerous, have long been obvious to all physiologists and biologists and enrich every book now written on the subject of mind or intelligence. Remembering that our knowledge of electricity is still in its infancy, even an Edison might learn much valuable information from the electric mechanisms of animals if properly investigated.

It is no part of our purpose to detail the mental mechanisms of animals, or to describe the various mental systems in serial development from the lowest to the highest. Such already exist in numerous physiological and biological works and are matter of common knowledge to scientists. But the interpretation we place on the mode of motion in these organisms is different from current authority and has yet to be exhaustively tested. We shall content ourselves in a succeeding chapter with a fuller description of that which chiefly concerns ourselves, the mental mechanism of man, the evolution of human intelligence, and the physical processes of human consciousness. 


\section{CHAPTER XV.}

\section{The Evolution of Man.}

HOWEVER interesting all speculations on origins may be to thinking minds, they shrink in importance to our theories of man's own origin; for the nature of his origin virtually settles the nature of his existence, reveals the purpose of his life, and answers the everfateful inquiry of his destiny.

Preliminary to a detailed statement of man's natural evolution from matter, according to our Materialistic system, we shall clear up a few preliminary points.

I. Man's Substance.-Men, like other animals and vegetals, consist of proteids-albumin, glutin, fibrin, sintonin, etc.-substances not met with in mineral bodies. Decomposed, these proteids resolve themselves into carbon, hydrogen, oxygen, nitrogen, etc. - primary chemical elements equally common to minerals, vegetals, and animals. Though man, therefore, in his substance differs secondarily, he does not differ primarily, from either organic or inorganic products. He is allied to sticks, stones, and rubbish, 
the air he breathes, the water he drinks, the food he eats, and the soil he is ultimately resolved into. Further, although every animal organism is a combination of unstable elements which ceaselessly add themselves to the body and leave it again, yet that same kaleidoscopic substance is indestructible, and reasserts itself in endless other forms throughout the cycles of eternity. Man, therefore, in his matter though not in his manner, in being though not in form, is coeval with his cause, whatever it may be.

2. The Date of Man's Origin.-The quaint conception of man's divine creation some six thousand years ago in the Garden of Eden has long been discredited by criticism, disproved by geology, and discarded by all intelligent men; while recent discoveries of pre-historic human remains practically establish the existence of man in the miocene epoch of the Tertiary age. This implies an antiquity of hundreds of thousands, if not millions, of years. Further, if those pre-Adamites evolved from apes or some ape progenitor, as Darwinians allege, then that transformation at the same ratio of progress must be anti-dated by other millions of years. But, although Darwin propounded man's descent from some common progenitor of the catarrhine (narrow-nosed) or old-world apes, he added:- "We must not fall into the error of supposing that the early progenitor of the whole simian stock, including man, was identical with or even closely resembled any existing ape or monkey." According to Huxley; 
this ancient ancestor and common progenitor of both man and ape was in all probability descended from some amphibian; not a present form of amphibian, but some extinct type. This extinct amphibian's progenitor, in turn, was probably descended from some extinct type of fish; this fish from some arthopod; this arthopod from some mollusc; this mollusc from some cœlenterate; this colenterate from some protozoon; and lastly, this protozoon from some lump of protoplasm. Hence, this lump of protoplasm was the celebrated "primordial form," the ancestor of all the ages, and necessarily of an age almost unthinkable.

3. The Human Ovule.-The human germ in appearance and development is no different from any other animal cell. It is nucleated and consists of a cellwall enclosing protoplasmic elements in solution. After impregnation it attracts and absorbs like protoplasmic components from its environments, and on attaining maturity it divides similarly to all animal and vegetal cells.

Continued fission results in a cell-aggregate, and, after following on the lines of the normal animal embryological evolution in many particulars (described further on), it ultimately results in that complete cell-aggregate, a babe.

4. Subjection of Organisms to their Environments.Mr Herbert Spencer, in what might be termed a new theory of "Embryological Selection," * drew special 
attention to the connection subsisting between an animal and its environments, especially in the lower organisms, as he found therein a cause of the differentiation of similar species and development of new species entirely dissociated from Darwin's doctrine of "natural selection." Perceiving, for instance, how the homogeneous protoplasm of a ruptured vaucheria escaping into water envelops itself, simply through the chemical action of its environments, with a firm peripheral covering (a covering out of which, as we have seen, higher animals than gastrula primarily evolve all the organs of sense and the nervous system), he suggests that the inevitable contact of a lowly organism's epiblast and hypoblast with its surroundings, whether touched or tasted, virtually originates those rudimentary formations which gradually develop into the immense variety of animal motors and sense-organs. Hence, by a difference in the nature, temperature, transparency, motion, etc., of its environments, a gastrula, or even a young foetus in the womb may develop new organic variations which virtually entitle it, when fully developed, to be called a new species of its own genus.

Not only so, but what is doubly important from the mental side of the problem, the nature of an animal's intelligence, dependent as this intelligence wholly is on an animal's sense-organs and nervous system, must also be largely influenced in its evolution from a lower grade of intelligence by the kind of 
reciprocity which is developed between the primal epiblast and its environments.

5. Metrmorphosis.-An important factor in organic evolution, hitherto minimised, is that common phenomenon metamorphosis, characteristic of nearly all organisms in the sub-kingdoms of vegetalia and animalia. In the lowest fungi and algæ, a spore passes by "alternation of generation " through several moults before reproducing the parent type. In the protozoa, hydrozoa, actinozoa, and polyzoa, metamorphosis is general; the difference in appearance, organisation, and function in all the stages being equally as marked as in man's embryonic transformations. In insects, metamorphosis is universal. Among the crustaceans, the barnacle, acorn-shell, crab, and lobster, evince strange metamorphoses. The tadpole stage of frogs is familiar to all; while the marsupials among the mammals (kangaroo, opossum, etc.) produce their young imperfectly formed, and nurse them in pouches until fully developed.

The significant fact for human evolution in connection with these metamorphoses is, that reproduction does not occur in any of the intermediate stages, but only in the mature animal. For instance, the butterfly does not reproduce either in the caterpillar or chrysalis state, but only when fully developed as a butterfly. Similarly, in the series of metamorphoses through which all primordial organisms transmuted while developing from the ovule to the mature phase, 
we assume that no organism reproduced itself except the last.

Reproduction, consequently, is the phenomenon which marks the completion of a generic organism, the end of its series of susceptible transformations, beyond which (except in slight modifications of form and colour, whereby it is arbitrarily classed into different species or varieties) it cannot pass. Thus the amœba by undergoing fission, and the volvox by copulating, never surmount the protozoic subkingdom; while the caterpillar and the tad-pole by not reproducing, metamorphose higher.

Reproduction is thus the supreme aim and end of all cxistence, the goal of nature, the purpose of creative activity, the prize of life, which, being won, nature is bankrupt, nothing more can be attained and nothing gained. It is the apex of universal being, after which comes the coffin.

That primordial man, as well as the original ancestors of all the leading genera of animals, was also evolved by a series of moults or metamorphoses, ${ }^{*}$ assisted and modified more or less by the agencies graphically described in current theories of selection - i.e., "natural" (Darwin), "physiological" (G. J. Romanes), "colour” (A. R. Wallace), and "embryological" (Herbert Spencer), - is thus not without circumstantial evidence. The time which each organism required to develop in this way from its automatically created ovule is, however, a subject for

* Virtually Metamorphological Selection. 
speculation. At present the human ovule grows into a babe in only nine months, but the embryo under present conditions of generation is developed in the best of circumstances, in a regular man-making machine, which works automatically, with only one thing to do, everything to hand, and the risk of modification by untoward environments reduced to

a minimum.

Primordial man-evolution by metamorphosis, on the other hand, was bound to occupy immense time, for we could hardly expect a human ovule spontaneously developed in a pond of water, to metamorphose month by month through amcba, gastrula, fish, frog, mammal, and monkey phases, and eventually appear as a man-child in the ninth month, because the conditions were not suitable. Instead of being fed automatically, as a child is in the womb, the metamorphosing ovule would require to feed itself at every stage, but a new-born child is helpless, and unfit even for years afterwards to provide for itself under the best of circumstances; hence, we must infer that human evolution by metamorphosis was a slow process, that ages were consumed in development, and that a comparatively adult age was reached before the final moult scaled off, and man in his finished form and complete reproductive functions recognised his superiority to his brother, the ape.

6. Genital Centres and Causes of I'ariation.-On the hypothesis of animals originating in and dispersing from one genital centre, a seeming difficulty (in higher 
animal evolution) arose from the fact that similar highly complex plants and animals were proved to tenant continents widely separated by deep seas. But Darwin ably met this objection by showing how eggs and seeds could be transmitted long distances by the agencies of birds, floating trees, winds, currents, etc. Geology also indicated that the pre-historic continents and seas of earth differed vastly from those of our era, hence, that continents now widely separated were formerly joined.

On the hypothesis of spontancous or automatic generation, the difficulty is still further lessened; for the time which ensued between the birth of the ovule and the appcarance of the fully-developed reproducing animal, would be sufficient to enable similar organisms to migrate in their natal seas, thousands of miles from one another. Further, the fact of animals being subject to different climatic influences and material conditions during the various stages of their growth, is sufficient to account for them evolving into different species of the same genus. IVe can thus understand how men are not all white, but red, yellow, and even black.**

7. Man's Embrgological Development.-From embryology we learn that man's evolution in the womb up to the gastrula stage is practically similar to that of all animals. Then after living as a sort of jelly-fish

* Haeckel divides men into ten species, as follows:- "Papuan, Hottentot, Caffre, Negro, Australian, Malay, Mongol, Polar man, American, and Caucasian:" The Pedigree of Man, p. 86. 
and acquiring a skeleton or backbone, he develops gill-like slits on each side of his neck up to which the arteries run in arching branches as in a fish; while his heart is a simple pulsating chamber like that of the lowest fishes. Nextly, he is a tadpole with branchiæ. At a later period he is a mammal with a movable tail considerably longer than the legs, while the great toe projects from the foot like the toes of adult apes. During the sixth month the whole body is thickly covered with fine wool-hair, extending even over the face and ears, everywhere indeed, save on the lower sides of the hands and feet-which are also bare in the adult form of the monkey. Only at a still later period does the embryo show signs of becoming a man instead of remaining a gorilla.

Man's embryological development thus indicates a rising scale of being evolved in the womb, paralleled by existing animal life as evolved by natural laws on the earth's surface; hence, biologists naturally infer, and the evidence seems overwhelming, that the embryonic stages of man's development but illustrate what actually occurred in prehistoric ages during man's gradual development, during countless centuries, from his spontaneously produced ovule.

The orthodox, however, pertinently ask, If man evolved spontaneously by natural laws thousands of years ago, why is he not evolved spontaneously now ; and why cannot we trace him in some of his lower transitions-his ape-like, frog-like, fish-like, oysterlike, and amoba-like phases? The answer is obvious. 
If man evolved from a particular chance combination of atoms at some particular juncture of conditions xons ago, the recurrence of this particular juncture is tremendously improbable, especially when untold millions of possible organic combinations are equally open to inorganic matter. Besides, nature, like an original artist, prefers to create a new form rather than copy an old one in her vast atelier. But even supposing some human progenitors were passing a period of painful pre-human probation among the protozoa, the colenterata, the mollusca, the annulosa, or the lower vertebrata now, how could we possibly recognise them as our brethren?

8. General Summary of Man's Materialistic Evolution.-Gathering all the threads of evidence together, we now propose to indicate the probable mode of man's natural automatic evolution on earth, by correlating all his elementary, amœba, jelly-fish, tadpole, amphibian, and ape phases, until he finished his probation as a lower animal and, rising above them, transformed into the master-mind of earth.

In the birth or evolution of the earth from elementary substance (no matter what its sidereal parentage may have been) the acting energies were the same as now, though perhaps differently manifested. The conditions of substance were then only favourable for producing crystals, for the high temperature of those natal ages precluded organic existence. But as igneous activity subsided to solid quiescence, and water, soil, light, and heat interacted, 
the protoplasmic elements-oxygen, hydrogen, carbon, nitrogen, etc.- would meet in suitable proportions and combinations, and permeated as they were by the allpervading selective, formative and magnetic laws, the spontaneous production of simple organisms-protophyta, protozoa, and the lowest kinds of fungi and algæ-would ensue as a matter of course; while the evolution of higher vegetal and animal germs would naturally follow through the consequent increase of complexity in combination. All sorts of organisms would thus sprout contemporaneously, including not only protozoa, but the cells of future colenterata, mollusca, annulosa, vertebrata, fishes, amphibians, reptiles, birds, mammals, and even man. In other words, instead of assuming the creation of only one or a few "primordial germs," at any imaginary beginning, we assume the incessant evolution of thousands of germs, many of which probably never progressed, but gradually became extinct, even as more advanced organisms die out in our own day.

In this original invasion of life into the planet, the germs of the higher vegetal and animal genera would not be likely to evolve contemporaneously in different localities; a view confirmed by the endemic nature of much of the world's flora and fauna. Hence, the evolution of the germ of each genus of animal probably occurred in circumscribed areas of earth and nowhere else. Further, it is unlikely that monogenisn prevailed - that is, the evolution of solitary primordial germs of each animal genus; but polygenism, involving 
the evolution of many primordial genetic germs, which all sprang spontaneously from the same primal protoplasm, and afterwards differentiated by metamorphological or other modes of selection into the numberless present species and varieties of animals.

Man's first progenitors thus probably appeared on the earth as spontaneously produced protoplasmic cells or ovules, hundreds or thousands in number, developed by sexual and magnetic affinities from a flux of the chemical elements in some ambrosial inlet of water. These cells, or those which survived, were propelled probably by flagella or cilia, and grew firstly into protozoa. Conditions being altered, and their elementary constitution affected and changed by their food, their increase in size and the nature and action of their environments, they were nextly converted into gastrulæ, then into jelly-fishes, and later into vertebrates. In this latter state they probably migrated immense distances from one another along the shores of their natal sea, feeding on minute infusoria, etc., and subjecting themselves to different conditions and environments so that different organic functions developed. On entering new inlets and rivers, and still growing larger, they then metamorphosed into amphibia, and browsed on herbs as well as alga. Forsaking their natural element-the water-in some stress of circumstances, and adopting a life on land, they would then change into small mammals, develop a coat of hair, legs, and a tail, and subsist on grass and herbs. Still another meta- 
morphosis converted them probably into the ape-form, in which state trees would be their home, and fruits and roots their diet. Lastly, on a final moult they would discard their coat of hair, drop their tail, emerge as fully-developed men and women with perfect sexual organs, and capable for the first time during their long series of metamorphoses of sexual union and reproduction of their kind.* That is, hitherto they would only eat and grow, now they would also reproduce.

Henceforth during pre-historic and historic ages, the fiat of increasing, multiplying, and replenishing the earth would be in force, changes innumerable would occur, improved varieties of the race would develop, and farourable conditions of food and climate so enable man to cultivate and polish his faculties, that the highly differentiated European eventually strutted upon the scene, the perfected product up-todate of all this blind bye-play of the great godsubstance-Matter.

Material and chance as man's origin and being have thus inevitably been, and insignificant as he necessarily is in the universe to a degree, the most civilised peoples had no sooner discovered their superiority and

* Haeckel divides man's ancestral chain into twenty-two stages, eight of which are invertebrate and fourteen vertebrate. The invertebrates are :-Monera, Amœbæe, Synamœbæ or Colonies of Amcebæ, Ciliata, Gastrœada, Turbellaria, Scolecida, Himatega or Sack Worms. The vertebrates are :--Acrania, Monorrhini, Selachii, Dypnoi, Sozobranchii, Urodela, Protamnia, Promammalia, Marsupialia, Prosimiæe, Tailed-apes, Man-apes (gorilla) Ape-men (Papuans, Hottentots, and Australians), and lastly, Men.--The Pedigree of Man, p. 75. 
developed an intelligence above the brutes than they crowned themselves lords of all they surveyed; fancied that the earth yielded of its substance and increase merely to sustain them; that fish, flesh, and fowl were appointed to minister to their service; that the sun, moon, and stars made obeisance to them, and that all the hosts of heaven only existed to worship their pompous little selves, adorn their planetary dwellingplace, apportion their seasons, measure the length of their days, and circle over them as a vast diademed clock to tell them the time of day in the infinite. 


\section{CHAPTER XVI.}

\section{The Evolution of Mind.}

In the light of previous observations on mineral, vegetal, and animal intelligence, it should now be obvious that the vanity of philosophers in the past has led them to study mental phenomena on wrong lines, to formulate interpretations based on foregone conclusions, and to assume that they, the philosoplrers themselves, were the divinely-inspired interpreters of the human intellect.

The plan adopted and still thoughtlessly pursued is that of asking mind to explain itself, without either learning what mind is, or ascertaining whether it could explain itself. In asking their mind through itself to explain itself, philosophers virtually ask their eye to see itself, their nose to smell itself, and their mouth to swallow itself, without being aware of their foolishness. That any kind of mind could explain itself independently of other things or other minds, is a nonsensicality, and the endless jargon of metaphysics in 
attempting this fool's-feat during the past two thousand years is ample proof of it.*

The origin, purpose, and limitations of an organism cannot be learnt by the organism itself from itself, any more than a church organ can tell its maker or clescribe its action; hence, an intelligent organism can only learn its own nature by studying the life-history of other organisms.

All knowledge moreover is external, not internal; that is, all knowledge comes to us from the exterior through the only gateways of our knowledge, the senses. Hence when a philosopher pretends to read in his mind the verbiage so amply served up in all metaphysical works, it is only because he himself has first stowed up the rubbish there. In pretending to read his mind he resembles the gipsy reading fortunes in another's hand. They are both frauds, but while the gipsy only imposes on the ignorant, the metaphysician as successfully imposes on the intelligent.

We thus assert that a man can only learn what mind is, what it contains, how it originated, and how it works, not by tatooing on his own mental organ, but by examining other men's minds or, better still, by studying the mental mechanisms of lower animals; ascertaining their constituents, construction, and action, and thus perceiving through the lower forms how the

* Metaphysics in fact is but a species of morbid introspection, which is as deadly to a man intellectually as it is physically. Their mind, it may be said, is an over-wound screw, that turns till doomsday but never gets home. 
higher man's mind has been gradually developed from its lowliest phase.

Consistently, therefore, with the rest of our materialistic system, we shall reduce the human mind to its physical elements, see what it is in skeleton form, strip it of the magic virtues which ages of ignorance have wrapped around it, drive out the fetich which has hitherto dwelt in it, expose the mountebanks who have hitherto traded on it, and show its purely mechanical nature, origin, being, and working.

Section I. What is the Human Mind?

The mind is usually defined as man's thinking faculty, and its seat is supposed to be in the brain. The brain is thus called the organ of mind. What then is the brain, and what is the nature of the action by which it produces mental phenomena?

Avoiding technical terms, the brain is the sensorium, or centre of the nervous or sensory system. It is an infinitely complex mechanism situated in the head of all the higher animals. It contains, or is composed of millions of nerve cells, from which millions of nerve fibres pass outwards to all parts of the body. At the end of the nerve fibres are terminal organs capable of receiving and transmitting to the sensorium certain impressions.

The sensorium does not act as a whole, but is differentiated so that special areas are devoted to special senses. Each area generally speaking is dual and has a location in each hemisphere of the brain. 
The special terminal organs are those for sight, hearing, smell, taste, and touch. The brain is thus not a self-contained organ, for it cannot exist or act of itself. If it be detached from man it is no longer a brain but a putrescence.

The brain only works when in perfect accord with the rest of the human mechanism. Thus if some of the nerve fibres to a sense-organ be cut, it does not respond to that sense; hence it is from thenceforward an imperfect machine, with the further consequence that the man has not only an imperfect body but an imperfect mind.

As regards mental phenomena, so much do they pervade the whole nervous area that the whole mechanism of man must, more or less, be included in his mental system. Consequently, while the brain is said to be the organ of man's mind, it is really only the centre, not the sum of it.

Further, as the five sense organs constitute our only media of intelligence, all our knowledge, as said, comes from the outside, not the inside; hence, affiliated constituents of man's mental system are the external environments of the senses-in effect, the whole outside world.

Man's intellectual horizon thus has through his senses a circumference as vast as space; his mind the central jet of intelligence shedding rays of light into the infinite, and so illuminating the universe that Nature through him sees, reads, and understands herself. 
The brain, the central organ of man's mind, is thus a machine located in man's larger machine, his body; a body subordinate in turn to the much larger machine, the world. Hence, as a machine, the brain, and consequently the mind, but registers the motions communicated to it by the other mechanisms of existence, externally and internally associated with it. Outside of these mechanisms and motions the brain cannot act and the mind cannot know.

Section 2. The Evolution of Human Conscionsness:

The great physiological problem is consciousness, and the utmost efforts of sane philosophers since philosophy began has been to describe in physical terms the conscious state, so as to say, in such and such acts is consciousness done. The modus opcrandi, or reflex action of consciousness, is as follows:-A stimulus automatically vibrates a sensory surface; this vibration in turn automatically ripples as a wave of molecular movement along the sensory nerves to a nerve centre; this again automatically transmits a wave of molecular movement down a motor nerve to a group of muscles over which it presides; they automatically contract, and this contraction produces one or other of the thousands or millions of actions known as human consciousness. Or to state the process differently:-A stimulus from outside applied to a terminal nerve, in, say, the eye, causes molecular changes which result in the transmission of an impulse to the brain. In the brain, molecular changes again 
occur resulting in the transmission of an impulse, say, to the hand. As the receiver of one sensation and the transmitter of another is the brain, the centre of the state of consciousness is either the molecular changes in the brain cells, or it is something bridging the receptive and transmissive brain cells.

But as physiologists cannot detect a condition in the physical chain of motion, or brain-bridge of cells, which in their opinion would represent consciousness, they postulate consciousness to be an "immaterial agent"* or ghost outside of the physical chain. This is a lamentable break-down on the part of scientists, a contemptible confession of weakness, if not incapacity, for it unscientifically shuts the door on further investigation, and at the same time explains nothing.

Captious critics also say that "a statement of all the processes of consciousness even in physiological terms does not explain consciousness." This, however, depends upon the investigator, and the kind of explanation he looks for. A preliminary point would be to define the kind of explanation that is required, for the defect in comprehension may be more in the obtuseness of the critic than in the obscurity of the physiologist. To understand requires perspicacity in the inquirer as well as perspicuity in the teacher. We, as men, can only know that which man can know, and we can only understand that which can be understood. Hence, if we refuse to accept an explanation

* Physiology of the Senses. Professors M'Kendrick and Snodgrass, p. 297. 
from ascertained facts, because we assume it is not subtle or mysterious enough, we are traitors to our own intelligence. Educated as men have been in our universities to attach a transcendental definition to the term mind or consciousness, it is heresy to accept a physical definition. But if we admit the necessity of progress in philosophy, as in other things, man cannot be bound either with the thongs of ignorance or chicanery. Intellectual perception must mark time with the progress of science and intelligence. Accepting, therefore, the fullest explanations of physiologists regarding the processes of consciousness in the human organism, down to where they apparently lose the scent and wander into the region of mental mares' nests, we must believe, until it is disproved, that the motions in our brain and body are the whole of human consciousness. The proof being that we can trace (as we practically have already done), the origin of consciousness from its physical basis-the atom and its energy, to its most complex condition as animal intelligence. And this has been done by but continuing the method adopted by scientists and physiologists in evolving the present accurate knowledge of all natural phenomena, mental or otherwise-namely, observation, experience, and scientific verification.

Thus instead of attempting, like philosophers, the impossible feat of dissecting our own brain and nervous connections, we follow those scientists who have dissected other men's and other animals' brains 
and nervous systems, until they laid bare the whole mental machinery.

The deduction at this stage consequently is, that as a church organ, in pieces, can furnish no music, so a man's mind, in pieces, can furnish no intelligence. As it is the motion in the complete organ which constitutes the music, so it is the motion in the complete brain and body which constitutes the intelligence.

Some simple-minded person might, however, here say that as the organ cannot play itself, and requires the aid of an external agent, the organist, to produce the music, so man's brain needs an external "immaterial agent" to produce its consciousness. True enough ; but that agent is not a ghost but our unconscious cnvironments, which are incessantly yet unintentionally and automatically playing upon our terminal sense organs. Any other agent or cause is consequently superfuous.

From men and the higher animals, physiologists and biologists have traced down the mental mechanism to the almost structureless protozoon, the microscopic unicellular infusorium. Haeckel goes further and accords a special delicate "soul" to the minutest plant. Below this no biologist descends. Yet if we have no fixed definition of "consciousness," and if our only reason for ascribing consciousness to low animals or plants, is in observing them perform what are apparently to us "conscious actions," it follows that our actual though unwritten definition of consciousness is, the performance of apparcntly conscious actions. 
But consciousness, as so defined, is withdrawn from the immaterial world and classed as a mere physical performance, hence we cannot draw the line of consciousness at the plants; for a compass needle in recognising the presence and polarity of a magnet is equally entitled to be called conscious. We have already assumed this in previous chapters, and carried out the deduction to its logical conclusion by retracing consciousness and intelligence from the animals and vegetals, down through the minerals until we unearth its genesis in the intelligent attractions and repulsions of the atoms, of which the universe and all it contains are composed. Below this we cannot go.

Mind thus does not originate mind; nor does a divine mind necessarily precede a human mind any more than a universal time-piece precedes our watches. Stephenson did not require a locomotive to be in existence before he invented one ; all he needed was the hundred and one odds and ends of machinery which by skilful and original adjustment, fitted and refitted in hundreds of different ways, eventually grew to be a new thing, a locomotive.

Similarly, the universe is not a mind, nor does it require a presiding mind to direct it, or to evolve animal minds. The only necessaries are, for the universe as a whole, the presence of all-comprehensive laws; and for animal minds, the thousand and one intellectual constituents of organisms, in the shape of atoms, cells, pseudopodia, fibres, nerves, etc. These by infinite adjustment and re-adjustment, almost 
always by haphazard and through the chance working of their inherent affinities and antipathies, eventually evolve what we call a mind; of which there are hundreds of thousands of forms or designs, ranging from the simple mind of the protozoon to that of a President of the British Association. The highest mind therefore invented by nature is but the clash of millions of minute intelligences-the intelligent atoms; and what the highest mind even on earth may eventually be no present prophet can foresee.

As the whole chain of sensation and action in the human organism is necessary to complete consciousness, the final definition of human consciousness is, the intelligent physical motions performed by millions of agents in our body, no one of which can be said to be our consciousness to the absolute exchision of the others. The chief office, concentrator, or exchange of these motions is, however, the brain.

Section 3. The Will or Reflex Action:

Our definition of consciousness may be said to be disproved by the alleged fact of our having another immaterial factor or agent called a Will. The definition of this "will" or intellectual "will o' wisp" is, that which causes the initiative in all our actions.

The solution to this problem is, however, virtually determined by the extent to which we can reduce the human machine to a mere automaton. If all our actions are reflex, the result of stimuli, then we have 
no will. That which we imagine our will is only unnoticed stimuli which are the real initiatives in all our actions. If there be a hiatus anywhere which cannot be attributed to stimuli, then we would be justified in assuming some unknown agent as our "will," but there is none. What are the facts?

In adult animals, the spinal cord and lower part of the brain consist of nerve centres of reflex action. The entire working of our body, our digestion, breathing and the circulation of the blood, etc., is automatic, and is supposed to be controlled more or less by nervous connections with the cerebellum or little brain. We see, hear, taste, touch and smell all automatically. So much too are our bodies like automatic artificial machines that by stimulating the grey matter of the cerebral hemisphere of an unconscious man with electricity, we may even throw definite groups of muscles into action. Thus man's mechanism can be hoaxed.

In sleep our bodies are entirely automatic in action. According to Wundt, nearly all dream representations originate from impressions on the nerves; so that by clever manipulation we can divert a sleeper's dreams into numberless channels.

Mental automatism is further demonstrated by the generally fantastic and utterly nonsensical nature of most of our dreams. Even when awake, the most diverse notions and images obtrude themselves at the most inopportune moments, still further proving the irresponsible and uncontrolled character of the motion 
and the mechanism which is supposed to constitute our " mind."

It has been calculated that from sixty to seventy distinct thoughts pass through our brain in a minute; thoughts not called up by our will, but often against our will, forcing themselves upon our notice, and distracting our attention when we wish it riveted on something else. Far, therefore, from cur will regulating our thoughts, our thought mechanism is virtually as little under our control as that of digestion. Further, the persistence with which our brain works night and day, and our utter helplessness in stopping it, shows that far from having an all-powerful will, we are but a spinning-top at the mercy of a remorseless whipper, a mental locomotive driven full steam by reckless and irresponsible drivers swayed by everconflicting emotions. And the drivers are in myriads, knocking incessantly at all the gates of the senses.

This incessant action of our bodily machine and the consequent incessant flow of our consciousness are thus free from the dominion of any supposed will, and result solely from the automatic constitution of our machinery. We only require to shovel in food, the machine itself does all the rest. Even in starving ourselves, our will, or some stimulus which causes us to refuse food, cannot long maintain itself against hunger.

Finally, when our body is momently affected by thousands if not millions of stimuli through all our senses, internally and externally, all sending a 
message to the brain, and all expecting an answer in return ; every initiative or will action must have countless numbers of stimuli, all acting unconsciously. For though we are unaware of their action, the stimulus in a snuff-box, which causes us to sneeze, is not more real than these imperceptible and unnoticed environing stimuli.

However distasteful the statement may thus be to the vanity of philosophers, we see no absolute freedom of action in man. We have no absolute will. Possessing a certain deliberation in our movements through the cultivation of our senses, and our experience or knowledge gained through them, we yet are at bottom living marionettes completely at the mercy of our environments.

Section 4. The Mind as a Five-Scnse Organ:

Recent discoveries in vermes and fishes of senseorgans and, consequently, of senses different from the normal five senses possessed by all the higher animals in this planet, throw a new light on mental problems which is bound to revolutionise philosophy. For while we are five-sense animals only, with a five-sense mind, there may be beings in other spheres endowed with six, seven, or more senses, the purposes and uses of which we cannot even imagine, and covering a range of intelligence impossible for us to realise. As the limits of human knowledge are the limits of the operations of our five senses, it is thus as impossible for us to attain the "absolute knowledge" of a 
universal mind, so glibly spoken of by philosophers, as to fly to the moon. We would require an infinity of senses to evolve such omniscience.

Still more absurd is it that hair-splitting philosophers should pretend to revel in an Empyrean of "Pure Intelligence," colonised by themselves. Indeed, metaphysics and Alice's Adventures in Wonderland are much alike in philosophical value. For if we grant that "Alice" can go through the "lookingglass," then Wonderland is possible. Similarly, if we concede that philosophers can glide through their mind into a region of "Pure Intelligence" closed to common men, we must also grant them the privilege of distilling unlimited bathos as the highest human wisdom : a privilege amply taken advantage of.

Lastly, as there cannot be a sense without a senseorgan, we perceive how excessively silly it is for men to claim possession of a sixth sense, called a psychic sense, which is devoid of any known organ. We do not wonder that its possessors are enabled to correspond with Mahatmas, hold converse with "Spooks," turn tables with "spirit-rappers," and flirt with phantasmal "Julias."

Section 5. Mind and Mechanism:

Through the knowledge of mind mechanism furnished us by physiologists, we learn another of the barriers of mind which fence it within the material fold.

When any man undertakes to lecture or hector the 
human race on a special subject, our first inquiry should be-not is he sincere-this may be taken for granted, but, in the slang phrase, "Is his head level?" or "Has he a slate loose?" In other words, have we an assurance that he has an unimpaired mental mechanism. For only those gifted with such a mind, accurately trained and richly endowed with the latest knowledge, can be leaders of thought, teachers and preachers to mankind.

A man's opinion or verdict on any subject is thus not dependent on his knowledge alone, but on the entirety of his mental mechanism. For example, some of the greatest intellects have suddenly, through the collapse of fibres or cells in their brain, become drivelling idiots. Nor are they conscious of the change, for they continue to air their opinions with the same lofty disdain of the common man. The numerous cases of blindness, deafness, and dumbness, of colour-blindness, of the lack of an ear for music, of perverted taste and smell-all indicate that defective mental machinery is far from uncommon. Obtuseness, want of perspicacity, and downright stupidity, also indicate the imperfection of the mental mechanism, and the consequent limitations of the mind. These wants thus practically prove that men gifted with accurately working and perfectly balanced bodily mechanisms and minds, are scarce in the extreme.

Section 6. Electric Action in Mental Phonomena: When it is stated as matter of common knowledge 
in our "Monthly Reviews" * that "the investigations of physicists make it highly probable that all movements of matter, even those of a molecular character, are linked with electrical phenomena;" that "all molecular chemical changes in inanimate nature are associated with changes in the electrical state;" that "all our methods of producing electricity and our electrical machines are but imitations of processes and mechanisms familiar in nature;" that "experiments have elicited electric currents in our skin, muscles, and nerves;" that "nerve fibres are not subject to much wear and tear, and act like metallic conductors conveying currents of electricity;" that "observers with the galvanometer have explored the spinal cord and brain and, in a sense, tapped the wires of the living telegraphic system;" that "when the brain is in full action currents probably flash in thousands of directions, and pursue paths, the intricacies of which are many times greater than if all the telegraphic and telephonic wires of London were concentrated in one vast exchange;" that "it is only a matter of detail to demonstrate the existence of both animal and human electricity." Finally, when we remember that the electric fishes have been known sincc the time of Aristotle; that the shocks of the torpedo were demonstrated to be electric in 1773 ; and that Galvani, over a hundred years ago, surmiscd

* "Human Electricity," Prof. M'Kendrick, Fortnightly Revierw, May I892; also in Physiolosy of the Senses, by Profs. M'Kendrick and Snodgrass, 1897 . 
that "magnetism was life," the wonder to us is that man and all animals have not before our day been demonstrated to be natural magnetic and electrical machines, in which life was really magnetism and thought electricity.

With our fuller data to work on, these conclusions are inevitable. That the animal body is such a magnetic and clectrical machine there is now no doubt, but it is an hypothesis only in embryo. Organisms have never been dissected and experimented upon with this object in view, hence, much data is still required for complete confirmation. The facts wanted are those relating to the stomach and intestines as a "battery," and the manner in which the "wires" or nerves are connected with it and charged with magnetism.

Scction 7. Man's Automatic Mental Apparatus:

As a probable hypothesis or sketch outline of our mind mechanism and action, we venture the following as something for physiologists, and others better acquainted with the human mechanism than we are, to work upon and fill in.

We have shown that the cells and all organisms composed of cells, including man, are living magnets with acting magnetic batteries of a special organic kind. In man's battery (the stomach and intestines) the dissolving of food is as much a chemical and electrical action as the dissolving of metals in a voltaic cell. 
This chemical action generates energy which charges all the muscular and nervous machinery of the body with what is virtually life. Then, assuming that the nervous system is the special electrical system of the body, the nerves are at the same time charged with natural or human electricity, just as a voltaic cell charges all the telegraph wires in connection with it.

Further, as man (after years of strenuous endeavour and numberless failures) forms a number of magnetic cells into a telegraph system and conveys all the connecting wires into an office, where, by a break in the circuit and so forming poles, he can read the messages sent along the wires; so incessant selection and development has, through centuries of failures, automatically arranged the human brain into such an electric stop-office for the use of the body, so that news from the outside world is automatically conveyed to us. Nerves from all the organs of the body are concentrated dually in special parts on each side of the brain. The brain is divided into two cerebral hemispheres which are the poles of the electrical system, the necessary break in the circuit being formed by the separation of the two hemispheres themselves. Each cerebral hemisphere contains millions of cells, each probably with its counter or reciprocating cell or pole in the opposed hemisphere. Hence, if the nerves are continuously charged with energy or electricity from the chemical action in our stomach, there must be a continuous discharge of electricity in the brain, and a consequent continuous 
action or reciprocation between the cerebral hemispheres as the two main poles, or between the thousands or millions of minute nerves or poles there meeting.

Not only so, but, as all the senses and other organs of the body are connected with the brain, every message received, say, by the eye, is transmitted to the brain and there read or interpreted and acted upon by the reciprocating sight-poles in the sensorium. If we thus say that the reciprocating motions between the nerves or cells in the two cerebral hemispheres are thoughts, we virtually imply that man is but a telegraphic machine, different only from those which he himself constructs in that he is conscious of, and able to read, the messages from within and without which pass through him,* the messages or motions being themselves consciousness.

But how can this reciprocal intercourse in the brain be consciousness or thought?

Like everything else in the universe, the evolution of thought as well as the explanation of thought is progressive, hence, we may have to revolutionise our conceptions of thought. The child cannot think like the man, because its brain is neither so large, so complex, nor so well exercised as a man's. It is only by laborious effort on the part of others as well as the

* Even the telegraphic machine acts accordingly as the messages pass through it, and may thus in a sense be said to be conscious of them by so acting. The action and the consciousness truly are automatic, but is our consciousness or our conscious actions in any way different, save in their greater complexity and subtlety? We think not. 
child, and with the stimuli to the sense organs repeated times without number, that the child can even read or understand the messages sent by the nerves to the brain. In fact, it can only understand the products of its five senses properly, when the sense organs, sensorium, and body, are automatic in action. Why should our thoughts, then, not be automatically thought?

As an explanation of the processes of thought, we may assume as a tentative hypothesis, that in every message sent to the brain, certain cells in the one cerebral hemisphere which receive the message reciprocate with corresponding cells in the opposed hemisphere. When a particular message is sent numberless times, these particular cells always receive the same message from the same sensory nerve until they become automatic in their reception of these particular sensations: whether we are aslcep or awake, or whether they have been naturally produced, or artificially excited in the surgery with the aid of electricity.

When naturally produced, the sensation is accurate; but when artificially produced the sensation is inaccurate. Showing that the mind or mind mechanism is an automatic machine which, as we have said, can be hoaxed, thus reducing it to the level of the plant's intelligent mechanism, and degrading it from its present high position as a "divine intuition."

Human thought or consciousness may thus be classed with the consciousness of the mincrals and the vegetals, viz., as automatic action or motion. Every 
state or act of consciousness is a motion and an automatic action whether we are aware of it or not. When we experiment with this object in view, we find it to be so in innumerable instances. Where it seems to elude us and to pass into an immaterial region, the complexity and subtlety of our mechanism are accountable for the intellectual gloaming. For, when we are working with millions of cells, thousands of which are in action every second, it would be an impossibility to locate, follow, or dissect every act of consciousness. We would be perfectly justified therefore in drawing a conclusion from what we do know as to the materiality of our consciousness, more particularly when it is corroborated in thousands of other ways in lower organisms, as shown in previous chapters, than to profess belief in mystical hypotheses, originated in ignorant times, which are neither intelligently explained nor comprehensively understood, but are yet worked for all they are worth by dry-asdust philosophers in all our universities.

\section{Section 8. Summary:}

In summing up the materialistic explanation of the origin, nature, and development of human intelligence, we have practically demonstrated that the origin of all intelligence, mineral, vegetal, and animal is in the automatic motion of the atoms of which all intelligences are composed; that the fundamental nature of this motion is magnetic and electric; and that the development of this motion into intelligence, from the 
lowest mineral, vegetal, and animal forms to the assumed highest in man himself, consists simply in the ever-increasing likeness attained by the mechanisms to a telegraph machine, the ever-increasing complexity and subtlety of the organisms' sensory mechanism, and the consequently ever-increasing complexity and subtlety of all their physical and mental motions.

In other words, that there is no greater mystery in the automatic evolution of human intelligence from a basis of physical atomic motions, endless in action, and capable of infinite complexity, than in the evoluticn of a metaphysical or other philosophy from an alphabet of letters capable of infinite combinations. To reply that the difference is explained by an intelligent man shuffling the letters in the latter case, while brute, inanimate, or unintelligent action is the agent in the former instance, is to insolently place man above nature. To any sane mind, man is but an insignificant unit among the million mechanisms which together constitute the great Being, Nature; and as he is himself, so ought his science, religion, and philosophy to be.

Human mind, consciousness and intelligence thus only mean the sum of the reflex or complex motions of atoms and senses incessantly throbbing in man's brain and body; even as the order, design, instinct, and acting laws of all nature consist of what are virtually identical, the reflex motions of matter in the intelligent things of existence. 
All intelligence whether organic or inorganic thus resolves itself into the universal reciprocal motions or touches of matter constantly occurring between all sorts of material. These range from the simple attractions and repulsions of a single element, as iron in an iron magnet, to the thousands of instantaneous vibrations transmitted to man through his sensory organs. These vibrations in turn are instantaneously and automatically reacted upon through his cerebral switch by his nerrous and muscular systems, according to the perfection of his bodily machine and as his mental and motor mechanisms have been educated. Instead of intelligence thus being a wonder, cither in origin or operation, it is a mere commonplace in the evolutions of matter; and yet until the clectric telegraph was discovered it was bound to remain a mystery, and all philosophy but vanity. In other words, a philosophy suitable for to-day was only possible to-day, through the knowledge of to-day.

Finally, despite man's lowly origin, we have the satisfaction of knowing that intelligence in its highest form, as in the intellect of the most cultured man, is a torch of light which relieves the dull materiality of being, illuminates that which would otherwise be gross darkness, and opens up to the ken of nature through her self-made eyes in her own chosen sons, the source of life, the secret of being, and the mystery of the Universe.

To concede somewhat to man's present ideals of intelligence and of a Deity, the loftiest conception of 
the Universe, from to-day knowledge, may perhaps be to look upon it as a gigantic organism, constructed like all other organisms in the universe as a colony of units: a Universal Being of which all solar systems, suns, and planets are but members, each with its own work to do, yet all working in unison: a Being eternal in existence, of kaleidoscopic form, kaleidoscopic functions, and kaleidoscopic purposes; the same and yet different yesterday, to-day, and forever. But while we may thus admire and wonder at such a Being, it would be folly to worship it. As well may we expect a blood corpuscle to worship a man, or a coral polyp to adore a coral reef. 


\section{CHAPTER XVII.}

\section{The Evolution of WORLdS.}

A STUDY of those theories which advocate the volcanic origin of comets and meteors* induces us to hazard the following hypothesis regarding the evolution, or origin, development, and cyclic life-history of all suns and solar systems. This hypothesis may fitly enough for to-day form the keystone to our whole scheme of automatic evolution and devolution, and round the cycle of universal existence.

The evolution of worlds and the evolution of the inhabitants of worlds, are problems which differ more in detail than in cause. If the one is self-made, so is the other. Both the world and its progeny are phenomena. Both are ephemeral, not permanent. Both bask in the sun's rays for a time, live a longer or shorter interval, then meet their doom, disperse into fragments, and start another existence in another form. Disaster, death, or dissolution is the destiny

* "Whence come the Comets?" R. A. I'roctor. Ninctecntis Century, May 1886. 
of everything with form. To have form is to live; to lose it is death. The question thus is, How in the great chemical laboratory of the universe do worlds arise? Out of what are they made? By what processes have they being? To what laws are they the slaves and upshot?

As already argued, the inclestructibility and uncreatability of matter involve the absence of both a beginning and an end to the fundamental constituents of the universe. The universe in its general details is ever the same-an eternal Now--beginning and ending momently in respect to its form and phenomena, but persisting eternally in the substance of these phenomena. Consequently, what the universe was in the past is virtually what it is in the present, a sea of worlds in incessant motion; hence a knowledge of the infinite vista of the past is practically revealed in the ever-rolling panorama of to-day.

Meteors and comets have been described as disporting in space like fish in the sea, but the analogy may cover the denizens of the whole universe. For space, or the void, is virtually a sea in which disport all material bodies, suns, plañets, moons, asteroids, comets, meteors, nebula, etc. These bodies assume many varied forms. Thus suns may either be childless or they may govern families infinitely more numerous than the satellites in our own solar system. They may be in all degrees of incandescence, of all sizes compared to our sun, and may live in groups, or revolve round each other like the twin stars. Like 
fish in the ocean, too, the heavenly bodies are ever moving, though perhaps less arbitrarily; and, like fish, if we concede them polarity, they can also to a certain extent avoid one another.

Fish, however, are not immortal, neither are asters ; the "grim reaper" comes indiscriminately to both; thus fish, big and small, die from internal disintegrating causes, decompose into their original elements - as carbon, oxygen, nitrogen, etc., or air, water, and soiland complete their cycle of universal existence by assimilating with various food products, which in turn probably help in the upbuilding of other fishes.

Small fish, in crossing the track of larger fish, and unable to escape, are swallowed, digested, and assimilated, eventually repeating of necessity the preceding disintegrating phases, for in all organisms the cycle of material existence is invariable-from clements to clements.

So far as is known, similar transitoriness characterises the heavenly bodies. Biela's comet showed how an aster could become internally disintegrated and as utterly dissipated as a human organism; while the passage of meteors in regular orbits probably indicates a planetary cemetery towards which all travel sooner or later.

Grouping all the facts together, along with the hypothesis of the volcanic origin of comets and meteors, we obtain data for sketching a plausible theory of our own solar and planetary evolution, as well as that of other suns and solar systems. 
An absolute beginning to sun-making being as impossible as unthinkable without introducing conditions and causes whose sun-making powers and properties would be equally inexplicable, we start with the only possible beginning, a universe of worlds in motion. For it is wiser to commence our assumptions with the existence of something we know of (universal phenomena) rather than with the imagined existence of a postulate we know nothing of and which is equally inexplicable-a Creator of universal phenomena.

We thus assume that, infinite ages ago, two huge suns with satellites, probably peopled with intelligent beings like ourselves, crossed each other's orbits while careering through space. Then through the polarities of both being attractive instead of repulsive they collided with immense force, dragged their satellites and all intervening comets, meteors, and asteroids to them as into a net, each falling body adding to the heat, until the whole company ultimately fused into one huge luminary, torn and distracted by uncontrollable eruptive energies.

In those throes and dying agonies of former worlds, our sun, the product of the whole fusion, was born; a sun immeasurably larger, brighter, and mightier than now-an orphan amidst the other starried hosts. Soon, however, it generated its own company. The collision and fusion was practically, on a large scale, the simple sexual process of "encystment" observable amongst various families of the protozoa. The fused mass was not barren, but fruitful. It was, in fact, an ovary in 
which germinated not only comets and meteors, but the vital nuclei of planets. In due time, therefore, the sun travailed, and by like-central-repulsion and the aid of vo!canic forces vastly greater than now, she was delivered at intervals of the giant planetsNeptune, Uranus, Jupiter, and Saturn; followed by the smaller Mars, Earth, Venus, Mercury, etc., until, through the incessant waste of material and energy entailed by her maternity, she became so gradually reduced in size and enervated in function as to beget only comets and meteors. This delivery of bodies, she may still perform intermittently, hence a.time may come when, by shrinking to less in mass than her planets, she may lose her magnetic hold on them, and they unchecked and unguided shall become scattered and lost to each other in the wastes of the void; while she herself dark, cold, and barren, may drift away in space, either to become swallowed up in another catastrophe, or from mistress of a system of worlds to perform servile lunar functions to an insignificant planet like our own.

The planets, in turn in their active youth, probably ejected their own moons, comets, and metcors, until having cooled down to the temperature of the earth, the same material energies entered on the more important automatic creation of minerals, vegetals, animals, and man.

Few of the planets, however, seem to be as habitable as our globe, yet this is probably due to our ignorance, and perhaps long before all have quitted their sun-like 
states, developed fauna and flora, and evolved other querulous races of intelligent beings, a separation or another collision may occur and another cycle commence. Until that crisis happens, our fellow-planets as members of one family, generated in the same central ovary, born under the same germinating polarities, and guided in their orbits by the same infallible natural laws, shall shed upon each other the benign brotherly influence of their rays in their common objectless pilgrimage through eternity. 


\section{CHAPTER XVIII.}

Man's Place in Nature.

TIIE value of anything depends upon its use. Nothing in the universe has any intrinsic worth, for environments alone fix the prices of things. Bread is worthless to a drowning man, it is priceless to a starving one. As with food, so with organisms. Even Deities would be impotent were there no dupes.

Man has hitherto declared himself to be lord of the universe; but as this is his own valuation it is of necessity discounted by his ignorance. Unknown outside of his own puny planet, we should require an astral, not a planetary estimate of man's universal value. As this is an impossibility, self-glorification is inevitable. All things considered, moreover, man would be a fool to depreciate himself when it is virtually his prerogative to fix his own price, settle his own worth, stablish his own origin, record his own pedigree, and award himself at pleasure either mortality with the brutes or immortality with the gods. The aim of the philosopher hitherto has thus rightly 
been to exalt his species. "Man, know thyself." "On earth there is nothing great but man," etc. Such exordiums, dinned into men's cars from the earliest civilisation, naturally puffed up the species with pride and discouraged undue humility. When we couple these pretentious notions with primitive man's crass ignorance of the conditions of his existence, particularly his relation to other things in the universe; his ignorance, even in conception, of other inhabited worlds, and his preposterous views of the size, shape, and motion of the earth, we need not wonder that our ancestors formulated the most heroic notions of the race, that they ranked themselves as demi-gods, and bowed the knee to divinities or idols which were, even in the most exalted types, only more or less gilded and glorified images of man himself.

Man's valuation of himself, again, differs according to his degree of civilisation. Thus, the lowest tribes, with the instincts only of the brute, think of their fellow-man, when an enemy, as simply a choice roast for a feast; a higher civilisation truck!es in him as a slave, and buys and sells him with other chattels; while among the most enlightened and cultivated nations now living, priests use him as a dupe, play upon his fears, threaten him with hells, and rob and bleed the simpleton to save his terrified soul from imaginary damnation.

In the Scottish Review, I888, in an article on "Charles Darwin," we find the following curious and apposite paragraph :-- 
"The creation and perfecting of man is the goal towards which nature's work has all along from the beginning been tending, the chief object of that creative activity which the physical universe everywhere reveals."

That this is not a joke, or an exceptionally puerile idea by some fatuous dreamer, is evidenced by a Gifford Lecturer* in Glasgow using last year (I897) words almost identical as follows:-- "Man is not merely one of the infinite number of effects produced by Divine causality, but he is the effect which explains all the rest; the end in view of the Creator in all his creative work." That such bathos should be addressed seriously to an intelligent audience in this enlightened age speaks volumes for the ignorance of a Glasgow audience. To the lecturer and his listeners, the world is still the centre of the universe, and the sun, moon, and stars still make obeisance to this Benjamin of a planet.

It was natural enough at the cradle of the race that man in his vanity and ignorance should imagine the universe to be a theatre solely for the evolutions of our planet, and the earth a stage solely for the comedy and tragedy of human life. But the advance of science disposed of these flattering notions by revealing that amidst the myriad stars of space there were few planets more insignificant than ours; while our

* These valuable Lectureships are rapidly degenerating into a travesty on their founder's intentions, for they are already virtual sinecures for superannuated parsons and senile metaphysical professors. 
own existence on this pigmy sphere is proof positive that larger worlds also contain inhabitants who are, at least, equally as intelligent as ourselves. Hence, if the purpose of the universe be merely to serve as a theatre for the evolution of myriads of worlds of all degrees of insignificance, then our earth and all other worlds serve, in like manner, only as theatres for the evolution of their own equally insignificant parasites. Consequently, man, as one of these parasites, can have no special use, meaning, or purpose outside of his own planet. He exists but for a time, in common with all nature $\mathrm{He}$ buds and blossoms as earth's noblest flower, and that is all.*

To take a lower standpoint in our survey, and appraise man from man's own level, we see that his existence reveals two aspects, a degrading and an ennobling. And herein we may find ground for appreciating ourselves, and perhaps even discovering an apology for our existence. Looked at in his lowest aspect, it must be admitted that, compared to the phenomena of the universe and the creatures of his own planet, man, as a completed natural product, is of unquestionably modern "origin; that he differs not in substance from the earth on which he lives; that his pedigree is as base as that of the lowest of the brutes; that his mental faculties are only a stage higher than the so-called instincts of the animals; that he is tied irrevocably to the earth; that he is

* His dreams of universal pre-eminence are, therefore, excessively silly, and his religions the height of absurdity. 
the sport of nature and her laws; and that he has no control over his birth, and as little, through natural causes, over his death. What else, then, can we rank him but as a parasite of the earth, a growth from the soil, the spawn of sun and rain and material energy; a maggot of planetary cheese, begotten of earthly substances, nourished on earthly products, and dissipating into earthly elements. What man is to-day was but earth, and air, and sky yesterday; and what he shall be to-morrow, earth, and air, and sky shall again proclaim, for "dust unto dust" is the eternal refrain. The world to-day is fragrant with life, but it is born of the corruption of a former existence. We live, yet every step is on another's grave, for we dwell amidst the ruins of a universal and unending holocaust. Thus, each man born is but a living wave of matter curving over the ocean of being, to sink again into the unseen trough of the next, while the calm of obscurity settles over all in this Universe of Oblivion.

To turn to man's nobler aspect, we must acknowledge that the more cultured human beings undoubtedly tower above all known created things. True it is we are only material, but so is every phenomenon. True; also, we are evolved by causes beyond human control, yet within certain limits we can bend these to our will, and make them minister to our service. Our power physically and individually is little, but by our collective power valleys are 
raised, mountains are lowered, and continents are chained together.

Herbert Spencer eloquently apostrophises man as "a product of to-day," but the constituents of our body are as old as the universe, and our energy coeval with eternity. Though mortal, we have also an immortality, for even when dead our atoms shall in other forms live for ever. Some of our past immortality is now smiling at us in the flowers, some now laughing at us in the air, some now fascinating us in a bewitching face; while our present mortality is but that "Bridge of Sighs" which spans the silent River of Death, and joins one form of immortality with another. Immortal we thus are, ever have been, and ever shall be. Existing from the beginning, we shall last to the end. Coeval with the Deity, we shall outlast the Judgment. But the present mortality is the hey-day of being. We not only live and exist now as men, but existence itself is conscious and luminous in us. We have truly lived before, but darkly. Now we are active volcanoes of being, the flames and torches of creation leaping above the dead uniformity of denseness, and forming one grand illumination of intelligence; nature at a white-heat of evolution, burning and betraying itself to itself in its flame, lighting up the outer darkness of hitherto impenetrable mystery, and in its own consumption rising again from its embers with ever-renewed youth, vigour, and prescience to re-run the race of being. Tongues of flame, therefore, we are, which shine as 
the lamps of an ever-intelligent existence, the spokesman of a potential universal mind which nature reveals in us and honours as her mouthpiece.

Man, consequently, as a living being, is responsible to no one. His own God and the model of all past and present deities, his worship is due only to that which is greatest in himself. Heaven is his own illusion, and hell his own damnation. The shuttlecock of natural laws and environments, he is primarily chance made, though secondarily self-makeable. Nonexisting before birth, he retains no individuality after death. The soul which he inherits from the elements, whatever it may be, he also returns to them: his personal immortality consisting solely in great thoughts, words, and deeds, and the depth of their impression on the shifting sands of men's memories.

Despite all sickly moralising to the contrary, our life in its perfect form is long and complete, and yields untold harvests of happiness to those willing to reap, so that when old age beclions with withered fingers, and the snow of life's winter wraps around us its hoary vestment, we shall, without regret, glide again into the bosom of that great Mother from whom we sprung, conscious that as immortals we shall speak again through other tongues, live again through other lives, and clie again through other deaths, eternally. 


\section{CHAPTER XIX.}

\section{Tile Purpose of tile Universe.}

The Purpose of the Unizerse, viewed from the standpoint of the New Materialism, necessarily differs from the orthodox ideal. Hitherto, even from the highest religious platform, Protestantism, the universe has been pictured as the realisation of an ideal, begotten in the mind of an omniscient and omnipotent Intelligence; a world-show designed in the all-knowing intellect, and constructed in time, with phenomenal gearing, as a temporary mundane diorama for purely omniscient purposes and its divine Author's own honour and glory. Every phenomenon thus had its foreordained sequence ; every product its special purpose and use; every organism its appointed place, work, and duration; and every man his pre-destined damnation ; while all things, even the diorama itself, had their inevitable dissolution in the practical oblivion of eternity. In effect, the beginning and end of all things was the Showman himself.

On the other hand, the beginning which materialists 
enunciate is that the universe perennially exists, with each phenomenon revolving upon its own axis and solely for its own day, the whole universe being but the sum of the parts, and each part a product at once ceaselessly new in its form and everlastingly old in its constituents, so that a different panorama is presented. For though phenomena but cycle from automata to automata ceaselessly, they include in their wondrous metamorphoses combinations of materials endowed with infinite complexity. Unending evolution and devolution, creation and resurrection, are therefore inevitable. The unconscious atoms, small builders though they be, evolve not only a universe in its general outlines but an existence peopled with infinite forms and endowed with limitless capacities. Man pictures himself as nature idealised, but while earth knows of none higher, it is folly to install him as the most exalted or ultimate product in the universe; for of the contents of other worlds we know not, while the womb of the eternal possesses endless fertility.

The universe thus unrolls before our cyes as a magnificently coloured and gaily caparisoned pageant of things great and small, transient and durable, yet beginningless and encless; for into the eternal past it rolls never more to be seen, and out of the eternal present it unwinds, full-blown and complete, the same yesterday, to-day, and for ever. Nature to the seer thus seems a vast semi-conscious leviathan, feeling with countless fingers along unending lengths its fitful shapes, which shrink at every touch and shirk the reading 
of their riddle; or peering with countless eyes the dim vistas of the eternal, through which its outstretched limbs and fading lights extend in a vain attempt to see and understand itself; or listening with countless ears to the hushed voices of the void, whispering to each other in broken chords and unknown tongues that which they think and feel they really are. Existence has thus ever been from eternity but a struggle to see itself; and its intelligence-through matter as well as man-solely an endeavour to realise in itself and through itself what itself really is.

THE ENI。 
e 


AA $000183687^{3}$

UC SOUTHERN REGIONAL LIBRARY FACILITY
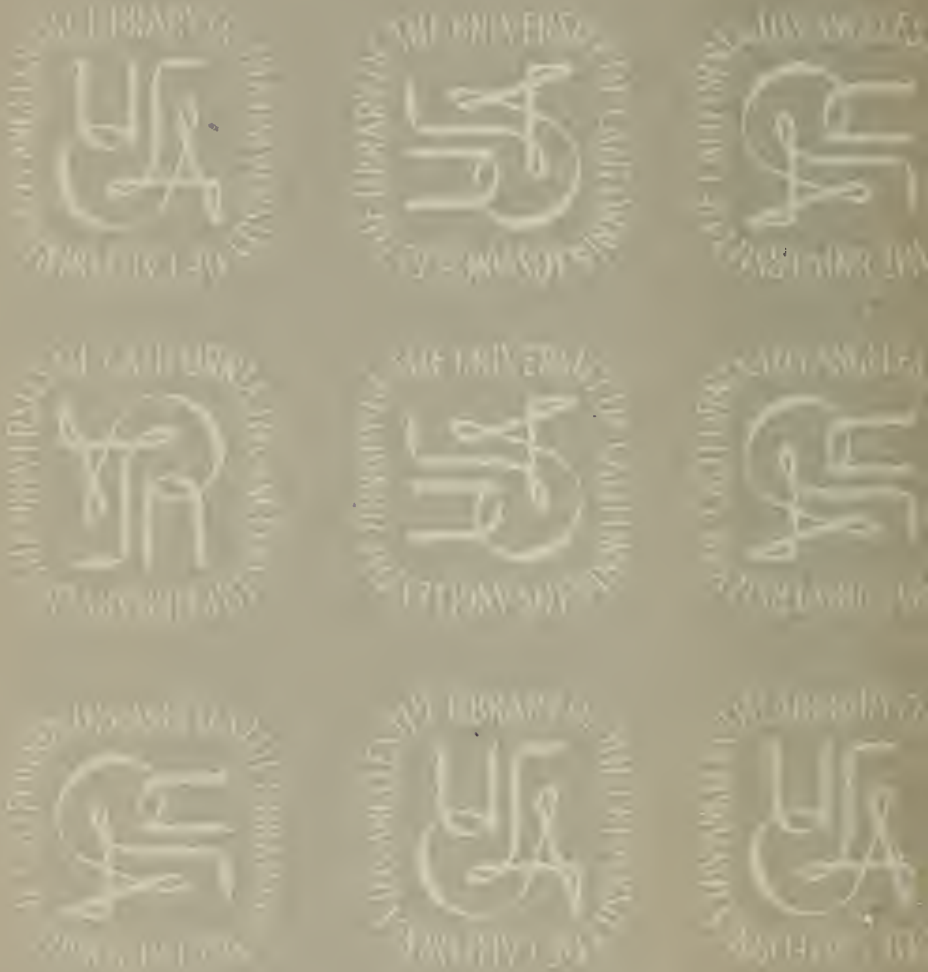


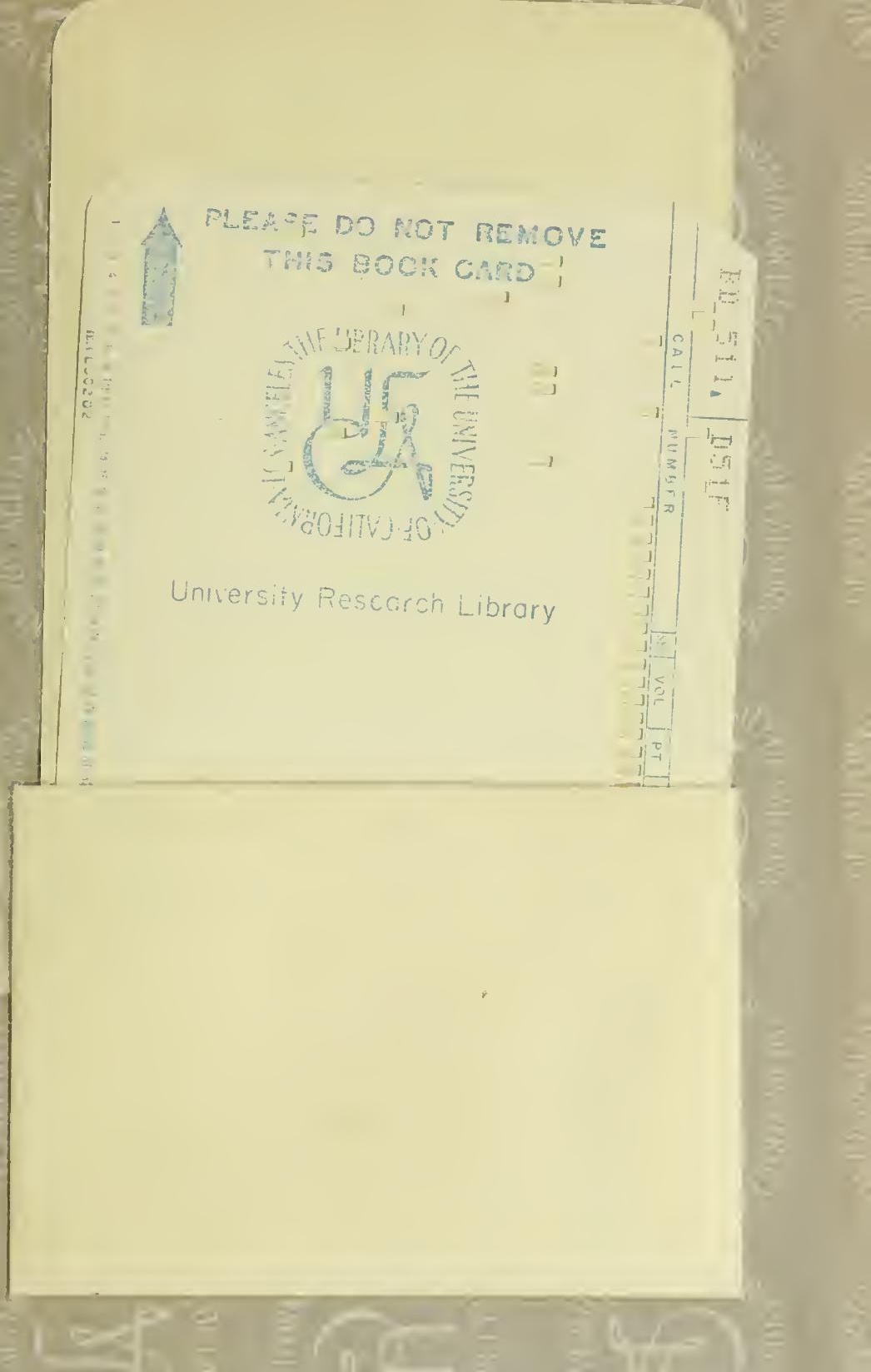


$\prod_{0,0}|10|$

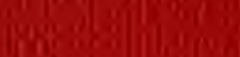

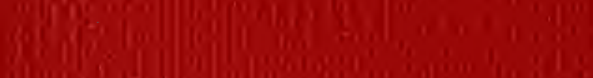

|

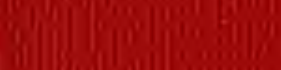

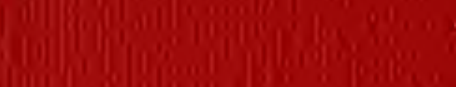

|

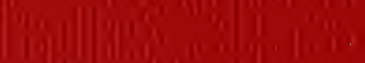

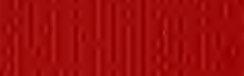

(19)

I:

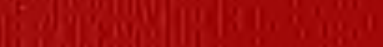

III

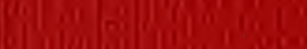

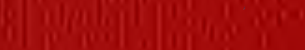

")

6)

10

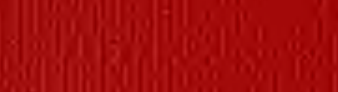

(1)

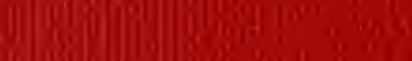

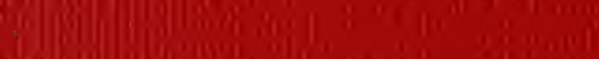

A6)

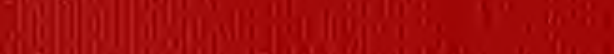

(6i:

1

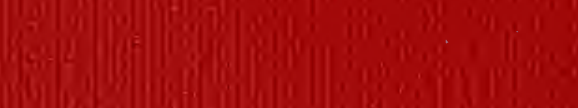

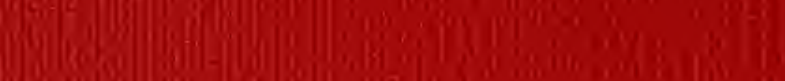

WWMol|

(2)

fes

(1)

a.

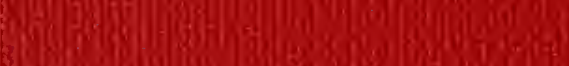

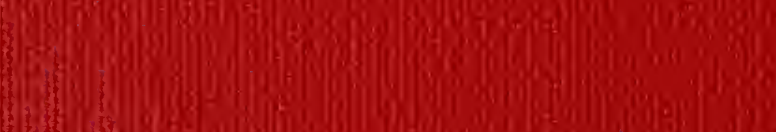

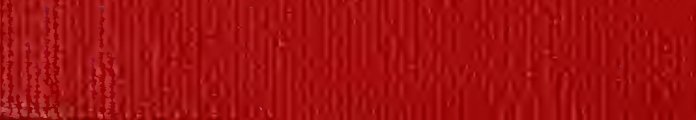

